\title{
Reallocation Effects of Monetary Policy
}

\section{CAMA Working Paper 59/2020 June 2020}

\section{Daisuke Miyakawa}

Hitotsubashi University

\section{Koki Oikawa}

Waseda University

\section{Kozo Ueda}

Waseda University

Centre for Applied Macroeconomic Analysis, ANU

\begin{abstract}
Responding to the increased attention on the distributional aspects of monetary policy, we investigate the reallocation among heterogeneous firms triggered by nominal growth. Japanese firm-level data show that large firms invest more in R\&D and grow faster than small firms under higher inflation. We then construct a model that introduces nominal rigidity into R\&D-driven endogenous growth with heterogeneous firms. The model shows that high nominal growth leads to an increase in the market share of innovative firms because menu-cost burdens are relatively heavier for less innovative firms. This reallocation effect yields a positive effect of monetary expansion on both real growth and welfare. The optimal nominal growth can be strictly positive even under nominal rigidity. Moreover, the presence of menu costs can improve welfare.
\end{abstract}




\title{
Keywords
}

Reallocation, firm dynamics, creative destruction, menu cost, optimal inflation rate

\author{
JEL Classification
}

E5, O3, O4

Address for correspondence:

(E) cama.admin@anu.edu.au

ISSN 2206-0332

The Centre for Applied Macroeconomic Analysis in the Crawford School of Public Policy has been established to build strong links between professional macroeconomists. It provides a forum for quality macroeconomic research and discussion of policy issues between academia, government and the private sector.

The Crawford School of Public Policy is the Australian National University's public policy school, serving and influencing Australia, Asia and the Pacific through advanced policy research, graduate and executive education, and policy impact. 


\title{
Reallocation Effects of Monetary Policy*
}

\author{
Daisuke Miyakawa $^{\dagger} \quad$ Koki Oikawa $^{\ddagger} \quad$ Kozo Ueda ${ }^{\S}$
}

June 3, 2020

\begin{abstract}
Responding to the increased attention on the distributional aspects of monetary policy, we investigate the reallocation among heterogeneous firms triggered by nominal growth. Japanese firm-level data show that large firms invest more in R\&D and grow faster than small firms under higher inflation. We then construct a model that introduces nominal rigidity into R\&D-driven endogenous growth with heterogeneous firms. The model shows that high nominal growth leads to an increase in the market share of innovative firms because menu-cost burdens are relatively heavier for less innovative firms. This reallocation effect yields a positive effect of monetary expansion on both real growth and welfare. The optimal nominal growth can be strictly positive even under nominal rigidity. Moreover, the presence of menu costs can improve welfare.
\end{abstract}

Keywords: reallocation; firm dynamics; creative destruction; menu cost; optimal inflation rate

JEL classification: E5, O3, O4

${ }^{*}$ We are grateful to Editor, three anonymous referees, Paul Beaudry, Guido Cozzi, Chris Edmond, Yuichi Furukawa, Kyoji Fukao, Giovanni Gallipoli, Hiro Kasahara, Rasmus Lentz, Makoto Yano, and seminar and conference participants at the CIGS, EEA-ESEM, Research Institute of Economy, Trade and Industry (RIETI), SED, Singapore Economic Review Conference, the Macro Conference (Tokyo), University of British Columbia, University of Connecticut, University of Milan, University of Washington, and Waseda University. This study was conducted as a part of the project "Microeconometric Analysis of Firm and Industry Growth" undertaken at the RIETI. Oikawa is grateful for financial support from the JSPS Grant-in-Aid (17K03635) and Inamori Foundation. Ueda is grateful for financial support from the JSPS Grant-in-Aid (16KK0065). All errors are our own.

${ }^{\dagger}$ Hitotsubashi University (Email: dmiyakawa@hub.hit-u.ac.jp)

¥Waseda University (Email: oikawa.koki@gmail.com)

${ }^{\S}$ Waseda University and Centre for Applied Macroeconomic Analysis (CAMA) (Email: kozo.ueda@waseda.jp) 


\section{Introduction}

The literature on firm dynamics has emphasized that sizable heterogeneity exists among firms, plants, and establishments even within narrowly defined industries, and that the reallocation among heterogeneous firms has a significant implication for macroeconomic performance. ${ }^{1}$ However, they do not pay attention to the nominal side of the economy, although the consideration of how monetary policy influences firm dynamics is important in deriving the optimal monetary policy or the optimal inflation target. Indeed, Yellen (2016), former chair of the Federal Reserve, states that economists should place greater emphasis on the heterogeneity among firms and households, as ignoring it could overlook important transmission channels for monetary policies. Kuroda (2017), the governor of the Bank of Japan, states that central banks should pay more attention to the distributional effects of monetary policy.

In this study, we investigate the reallocation effects of monetary policy in a model that introduces nominal rigidity to a model of R\&D-driven endogenous growth with heterogeneous firms. In the model, nominal rigidity brings about changes in the firm dynamics in response to inflation. Such a relation between inflation and firm dynamics has empirical relevance. We use Japanese data and find that the size distribution and growth of firms are associated with, and also likely to be influenced by, inflation rates. Specifically, in the regression of firm-level growth measured by real sales and employment, the cross-term of inflation and the lagged size is positive and significant, indicating the negative effect of inflation on growth is partly offset when a firm is large. Moreover, the regression of firm-level $R \& D$ shows that large firms tend to invest more in $R \& D$ than small firms under higher inflation. These results are consistent with our model prediction.

The model has three features: Schumpeterian creative destruction, multi-product firms, and menu costs. The Schumpeterian creative-destruction model, developed by Grossman and Helpman (1991) and Aghion and Howitt (1992), enables the analysis of firms' entry and exit as well as endogenous growth. However, the basic model assumes that each firm produces only one product. For all firms, the amount of sales is the

\footnotetext{
${ }^{1}$ For example, Baily et al. (1992), Bartelsman and Doms (2000), and Bartelsman et al. (2004) show sizable dispersion among firms. The macroeconomic implications of firm dynamics are examined by Caballero and Hammour (1994), Hsieh and Klenow (2009, 2018), Restuccia and Rogerson (2013), and so on.
} 
same, and thus, the firm-size distribution is degenerate. The second feature, multiproduct firms, enables the analysis of firm dynamics. Klette and Kortum (2004) build a model in which incumbent firms can produce more than one product by continuing R\&D investment and taking markets from other firms. These multiple products lead to ex post heterogeneity in their size. Lentz and Mortensen $(2005,2008)$ introduce ex ante heterogeneity in the innovativeness of firms to investigate the effect of resource reallocation from inferior to superior firms.

The third feature, menu costs, is our theoretical innovation. We shed new light on the reallocation that stems from the nominal side of the economy, namely, monetary policy, by extending the Lentz and Mortensen (2005) model to introduce menu costs as nominal rigidity (e.g., Sheshinski and Weiss (1977); Golosov and Lucas (2007); Midrigan (2011)). One of the contributions of this study is that it provides a tractable framework to consider the reallocation effects of monetary policy.

The main results from our model are as follows. First, nominal growth can enhance real growth. Second, the optimal nominal growth (and inflation) rate can be positive. These results are in a sharp contrast to the results of standard New Keynesian models in which the economy is the most efficient without nominal growth. ${ }^{2}$ Although nominal rigidity incurs a cost for all firms, the burden is relatively larger for lower quality firms, and thus, higher quality firms increase their market shares as well as relative $R \& D$ expenditures. As a result, the average quality of firms increases under positive nominal growth, leading to a higher rate of aggregate real growth and greater welfare. If this reallocation effect dominates the inefficiency that stems from nominal rigidity, then the optimal nominal growth (and inflation) rate can be positive.

A model calibrated to Japan demonstrates that the optimal nominal growth is indeed positive. Under higher nominal growth, the ratio of large firms' sales to those of small firms increases, which is consistent with our empirical finding.

Some studies argue that nominal factors, such as inflation and nominal interest rates, affect both real growth and welfare in endogenous growth models (e.g., Bilbiie et al. (2014); Chu and Cozzi (2014); Chu et al. (2017); Arawatari et al. (2018); Oikawa and Ueda (2018)). Chu and Cozzi (2014) show that the optimal nominal interest rate is strictly positive if $\mathrm{R} \& \mathrm{D}$ is overinvested in a Schumpeterian model

\footnotetext{
${ }^{2}$ The optimal inflation target is often zero if the real growth rate is zero and unless other frictions, such as the zero lower bound of a nominal interest rate and downward wage rigidity, are present. See Goodfriend and King (1997), Khan et al. (2003), Burstein and Hellwig (2008), Schmitt-Grohé and Uribe (2010), and Coibion et al. (2012).
} 
with cash-in-advance in R\&D. Recently, Adam and Weber (2019) derive a positive optimal inflation rate in a New Keynesian model with growth and firm heterogeneity, but both productivity growth and entry in their model are exogenous, and thus, monetary policy does not have distributional effects. Compared with these studies, ours is the first work to combine a New Keynesian model with an endogenous growth model that embeds reallocation and firm dynamics.

Acemoglu et al. (2018) is related to our study, although they do not consider the nominal aspect, as they analyze several industry policies (e.g., R\&D subsidy) by extending the model of Lentz and Mortensen (2008). One of the main results of their study is that a government should impose taxes only on inferior incumbent firms to achieve the social optimum. However, as the authors mention, governments rarely conduct such a selective policy in reality. By contrast, our model shows that monetary policy that is not selective has different effects across firms: inferior firms incur a greater burden of menu cost payments under high nominal growth than superior firms do. In other words, a policy of monetary easing automatically works as an entry barrier only for low quality firms.

To study the reallocation effects of monetary policy, other types of models are useful as well (e.g., Hopenhayn (1992); Bernard et al. (2003); Melitz (2003); Luttmer (2007); Restuccia and Rogerson (2013); Lucas and Moll (2014)). Compared with these models, our model explicitly incorporates the R\&D investment decisions of both entering and incumbent firms. In particular, we consider incumbents' R\&D as important for growth and reallocation. As shown by Malerba and Orsenigo (1999), incumbents hold the majority of the newly granted patents. Argente et al. (2018) report that firms grow by continuously adding products and that incumbents are the main agents of product reallocation. In our model, R\&D by incumbents plays a key role in their own growth as well as aggregate growth.

Our study complements the growing literature on the effects of monetary policy on heterogeneous agents. For example, Iacoviello (2005), Gornemann et al. (2016), and Bhandari et al. (2018) investigate how monetary policy influences different types of households. A notable difference from these studies is that the focus of our study is not on household heterogeneity but on firm heterogeneity.

The rest of the paper is organized as follows. After Section 2 provides the empirical findings, Section 3 presents the theoretical model. In Section 4, we define stationary equilibrium and investigate the reallocation effects of nominal growth in Section 5 . 
Section 6 gives the results of numerical simulations. Section 7 concludes.

\section{Relation between Inflation and Firm-size Distri- butions: Empirics}

In this section, we provide some empirical evidence on the relation between inflation and firm-size distributions. We first briefly review the literature and then present observations based on Japanese firm-level data.

\subsection{Inflation and Firm Size Distribution in the Literature}

Although empirical studies using firm- or plant-level data have been growing rapidly, studies on the relation between the nominal side of the economy and firm-size distributions are scarce, as there is almost no theoretical analysis of this issue. However, some indirect evidence indicates the existence of a relation between firm distribution and inflation. For example, Alfaro et al. (2009) report that less developed countries, notably India, are more likely to have a greater mean establishment size than advanced countries are. Similar findings are reported by Bartelsman et al. (2004) and Poschke (2018). Considering that less developed countries tend to have relatively high inflation rates, this fact suggests that there is some association between inflation and the growth of large firms relative to small ones in a cross-country dimension. ${ }^{3}$

\footnotetext{
${ }^{3}$ There are considerable measurement errors for firm or plant distributions because of the large cost of collecting data and the presence of informal small establishments. The latter problem is particularly serious in less developed countries, where there are a large mass of informal small establishments. Thus, the more informal small establishments we include as firms, the lower the share of big firms is, which may lead to the opposite result: that less developed countries have smaller mean firm sizes than advanced countries. This issue is related to the so-called "missing middle." Tybout (2014) calculates the deviation of employment share from the estimated Pareto distribution by country and the category of plant size and finds that for India and Indonesia, the smallest and largest size categories have a relatively more density than predicted by the Pareto distribution, while for the United States, the largest size category has a smaller density. In fact, the issue of the missing middle is consistent with our study. In our model, a firm is an agent that makes an R\&D investment to invent new ideas and employs people for both production and R\&D. This type of firm is not like an informal small establishment. For this reason, we exclude informal small establishments and pay attention to the large and medium-sized categories in Tybout (2014). "Missing middle" suggests that in less developed countries, which are typically more inflationary countries, large firms are relatively more common than medium-sized firms, which is consistent with our model's prediction. Another important issue is that cross-country differences in firm distributions are caused by many other factors as well as differences in the nominal side of the economy. Clearly, policies and institutions
} 


\subsection{Japanese Firm-level Data}

There is considerable cause for concern about how to accurately measure firm distributions or what drives different ones. For example, policies and institutions are very different across countries. To alleviate this concern, we analyze the relation between inflation and firm-size distributions using Japanese firm-level data. Policies and institutions are considered less heterogeneous within a country than between countries. We control for industry differences and time-series changes in policies, institutions, and measurement errors by using firm (industry) and year dummies. Furthermore, by using instrumental variables, we aim to study if there is any causality from inflation to firm-size distributions.

As firm-level data, we use "the Basic Survey of Japanese Business Structure and Activities" that is an annual governmental compulsory survey conducted by the Ministry of Economy, Trade and Industry in Japan. The survey covers all firms with no less than 50 employees and no less than 30 million Japanese yen in stated capital in the majority of industries in Japan for 1991 and 1994-2015. For inflation rates, we use the industry-level input price indexes from the Producer Price Index (PPI) reported by the Bank of Japan. We consider the average input inflation during the past three years as the main explanatory variable for consistency with the theoretical model in the next section. We focus on manufacturing firms because of the availability of industry-level input price indexes. Appendix A.1 shows the basic statistics of the data.

\section{Firm Size Dispersion}

First, we calculate percentile points of nominal sales within each major division of industries to observe changes in firm-size distribution. ${ }^{4}$ Table 1(a) shows the industrylevel panel estimation results on the relation between the lagged trend input inflation in industry $i$, say $\bar{\pi}_{i t-1}^{\text {input }}$, that is the average input inflation during the past three years (i.e., over the year $t-3, t-2$, and $t-1$ ), and sales dispersions that are measured by the ratios of the 90th percentile to the median (Top/Middle) and the 90th percentile

differ by country.

${ }^{4}$ We follow the industry classification used in the producer price index. Because the Statistics Bureau of Japan revised the classification a few times during the sample periods, we use the 2005 industry classification to obtain consistent price index sequences. The list of the 14 industries we use is summarized in Appendix A.1. 
to the 10th percentile (Top/Bottom). We estimate the following equation:

$$
\text { Dispersion measure }_{i t}=\beta_{0}+\beta_{1} \bar{\pi}_{i t-1}^{\text {input }}+\boldsymbol{Z}_{i t}^{\prime} \boldsymbol{\beta}+\zeta_{i}+\zeta_{t}+\epsilon_{i t},
$$

with industry and year fixed effects, $\zeta_{i}$ and $\zeta_{t}$, respectively. As the basic OLS estimate shows, in columns (1) and (4) in Table 1(a), the coefficients for inflation are positive and significant. Sales dispersions increase under higher input inflation. For robustness, we add control variables, $\boldsymbol{Z}_{i t}$ : the industry-level financing position index, the Diffusion Index from Tankan (DI), and log of industry-level real sales (industry $\mathrm{RS}$ ) as shown in columns (2) and (5). Real sales are calculated by dividing nominal sales by the industry-level output price index from the PPI. The financing position DI is a proxy for the degree of financial constraint (the higher the DI is, the looser the constraint is). ${ }^{5}$ We control for the degree of financial constraint, because unanticipated inflation allocates resources from lenders to borrowers and vice versa, and this effect of inflation may differ depending on firm size. In the table, "Financing DI" is the industry-level index, and "DI gap" represents the gaps in the financing position DI between large and medium-sized firms (top/middle; T/M) or between large and small firms (top/bottom; T/B). We include the industry-level real sales to control for the aggregate real factors. The table shows that the coefficients for inflation remain positive.

These effects on the firm-size distribution from inflation may be subject to an endogeneity problem, because high demand for inputs from large growing firms could drive up input prices in an industry. In columns (3) and (6) of Table 1(a), we perform a two-stage least squares (2SLS) method using the information on international primary commodity prices as the instrumental variable, which is reported by the IMF (converted to Japanese yen by the average nominal exchange rate in each year). The first-stage regression is

$$
\bar{\pi}_{i t-1}^{\mathrm{input}}=\alpha_{0}+\alpha_{1 i} \bar{\pi}_{t-1}^{\mathrm{ipc}}+\boldsymbol{Z}_{i t}^{\prime} \boldsymbol{\alpha}+\theta_{i}+\theta_{t}+u_{i t},
$$

where $\bar{\pi}_{t}^{\text {ipc }}$ is the average inflation rate in the international primary commodity in the same three-year window to measure the trend input inflation. The coefficient

\footnotetext{
${ }^{5}$ The financing position index is one of the DIs that the Bank of Japan surveys. It indicates the difference in the shares of firms that answer whether their financial positions are "easy" or "tight." Data at the industry and firm-size levels (large, medium, or small; defined by the number of employees and the size of stated-capital) are available.
} 
$\alpha_{1 i}$ is distinct across industries to allow for different dependencies on the primary commodities that enables us to obtain the instrumented variable $\hat{\pi}_{i t-1}^{\text {input }}$. The association between inflation and sales dispersion is significantly positive again. We also observe that the financing position DI is negatively correlated with the sales dispersions, indicating that a looser financial constraint shrinks the size gap among firms. The coefficients in the 2SLSs indicate that a $1 \%$ increase in inflation leads to about a 1.1-unit increase in the $\mathrm{T} / \mathrm{M}$ ratio and about a 4.5 -unit increase in the $\mathrm{T} / \mathrm{B}$ ratio.

Table 1(b) shows the estimation result when we measure the firm-size dispersion using total employment. The coefficients for inflation are positive but insignificant in the OLS. However, they are significantly positive when we use the 2SLS, which is similar to the result with sales dispersion.

\section{Firm Growth}

To understand the source of the rise in these observed dispersions, we examine the relation between firm growth and inflation by using the firm-level panel data. The regression equations are

$$
\begin{aligned}
& \operatorname{Firm~growth~}_{i j t}=\beta_{0}+\beta_{1} \hat{\pi}_{i t-1}^{\text {input }}+\beta_{2} \log (\text { Sales })_{i j t-3} \\
& \quad+\beta_{3} \log (\text { Sales })_{i j t-3} \times \hat{\pi}_{i t-1}^{\text {input }}+\boldsymbol{Z}_{i j t}^{\prime} \boldsymbol{\beta}+\zeta_{j}+\zeta_{t}+\epsilon_{i j t}, \\
& \begin{aligned}
\bar{\pi}_{i t-1}^{\text {input }}=\alpha_{0}+\alpha_{1 i} \bar{\pi}_{t-1}^{\text {ipc }}+\alpha_{2} \log (\text { Sales })_{i j t-3}+\boldsymbol{Z}_{i j t}^{\prime} \boldsymbol{\alpha}+\theta_{j}+\theta_{t}+u_{i j t}
\end{aligned}
\end{aligned}
$$

where the dependent variable is the average growth rate of real sales or employment for firm $j$ in industry $i$ during the past three years, and $\hat{\pi}_{i t-1}^{\text {input }}$ represents the instrumented variable for lagged input inflation. ${ }^{6}$ We introduce the lagged sales, defined as the log of real sales three years ago to capture firm size and its interaction with inflation as explanatory variables. The control $\boldsymbol{Z}_{i j t}$ contains the average financing position DI with which firm $j$ is confronted, the $\log$ of total real sales in industry $i$, and the log of the three-year-lagged leverage of firm $j$ that is defined as the ratio of liability to net worth. Variables $\zeta_{j}$ and $\zeta_{t}$ are firm and year fixed effects, respectively $\left(\theta_{j}\right.$ and $\theta_{t}$ are those for the first stage). We introduce the lagged leverage to control the firm-level financial condition while the financing position DI is an industry-level variable.

\footnotetext{
${ }^{6}$ In Appendix A.2, we check the robustness with an alternative specification of the first-stage regression because the present first-stage regression uses firm-level variables to estimate the industrylevel inflation.
} 
Table 2 reports the estimates when we use the OLS for which we use $\bar{\pi}_{i t-1}^{\text {input }}$, and the second-stage of the 2SLS for which we use $\hat{\pi}_{i t-1}^{\text {input }}$. The first and second rows of the table show that input inflation has a negative effect on growth and that a larger firm leads to lower growth, respectively. ${ }^{7}$ A more important result is observed in the third row of the table for the cross-term of inflation and lagged sales. The coefficients for the cross-term are all positive at the $1 \%$ level of significance, indicating that the negative effect of input inflation on growth is partly offset as firms are larger. The financing position DI is positively associated with sales growth, indicating that firms grow faster in a less financially constrained environment. The coefficient for the leverage is positive, indicating that firms with more borrowing grow faster.

Table 2 also presents the estimates when we measure firm growth by employment with the same explanatory variables. We confirm that the estimation results are robust to the choice of measurement for firm growth.

\section{R\&D}

Now we turn our attention to an engine of firm growth. As surveyed in Hall et al. (2010), the literature shows that R\&D investment is one of the significant factors that determine productivity and output growth. ${ }^{8}$ Because $R \& D$ investment plays a key role in endogenous growth and firm heterogeneity in our model, it is extremely important to empirically study whether R\&D investment reacts to inflation differently depending on firm size.

We consider several R\&D investment measures: (i) log of real R\&D investment, (ii) the ratio of $\mathrm{R} \& \mathrm{D}$ expenditure to sales, (iii) $\log$ of $\mathrm{R} \& \mathrm{D}$ expenditure over firmlevel average wages, and (iv) log of R\&D expenditure over total salary. The first two are standard measures of R\&D investment that represent the level and intensity, respectively. We use the third measure because it corresponds with the number of R\&D workers in our model below. The fourth is another measure for the R\&D intensity expressed in employment units. We take logs for the last two measures because there are large dispersions in their unlogged values across firms. ${ }^{9}$

\footnotetext{
${ }^{7}$ There is a vast literature on Gibrat's law on firm growth, which states that the growth rate is independent of the firm's size. Empirically, many papers indicate that size has a negative effect on growth at the firm level. See Santarelli et al. (2006) for an empirical literature survey.

${ }^{8}$ Fukao and Kwon (2006) report a positive association between R\&D and TFP growth using Japanese firm-level data.

${ }^{9}$ There are records of negative R\&D expenditure in our dataset. We drop observations with
} 
We regress equation (3) by using the firm-level panel data, but replace the dependent variable with the aforementioned R\&D investment measures. Table 3 shows the OLS and 2SLS results. The coefficients for the input inflation are significantly negative for all R\&D measures, and those on lagged sales and the interaction term are significantly positive in most cases. The negative effect of input inflation on R\&D investment is partly offset when a firm is large. These results imply two things. First, inflation affects R\&D activity that influences firm and aggregate growth and thus generates a long-term effect. Second, the effect of inflation is heterogeneous across firms, which triggers the reallocation of resources among firms. These implications are consistent with our theoretical model developed in the following sections.

\section{Exit}

Inflation also influences a firm's exit. We set an exit flag if a firm disappears from the dataset before the end of sample period. The equation regressed is the same as equation (3), but now we use the exit flag as the dependent variable. We use a linear probability model including firm-level fixed effects. ${ }^{10}$ Columns (5) and (10) in Table 3 show that exit is more likely to occur under higher inflation, but is conditional on the lagged size: the coefficient of the cross-term is significantly negative that indicates the possibility of occurrence is smaller for larger firms.

It should be noted that firms disappear from the sample when employment drops below the cut-off of 50 employees. Owing to this cut-off, it is hard to exactly identify entry and exit from our data. We discuss this problem and check the robustness of the present result on exit in Appendix A.2. We also discuss entry in this appendix.

\section{Robustness Checks}

We conduct additional regressions for robustness checks of our results. We present quick view over those results here, leaving the details in Appendix A.2. First, we examine if our main results depend on firm age distribution. In the above analysis and the theoretical model in the following sections, we consider that firm growth

negative or missing $\mathrm{R} \& \mathrm{D}$ expenditure. When we take the log, we add one. The unit of $\mathrm{R} \& \mathrm{D}$ expenditure is one million JPY that is almost equivalent to 10,000 USD.

${ }^{10} \mathrm{We}$ use the linear probability model because our model specification comprises the cross-terms between inflation and firm size. For the benefits of using linear models for the estimation of an equation that includes cross-terms, see Ai and Norton (2003) and Wooldridge (2010). 
performance is correlated with firm size. However, potential growing powers of young and old firms with similar sizes may be different. To control the age factor, we split firms according to firm ages and rerun the regressions for each age group. The relation of inflation and firm growth is the same as that reported in the above.

Second, we investigate the impact of leverage further. Tightly financially-constrained firms may respond to inflation differently from weakly constrained firms. To see this, instead of including leverage ratios in explanatory variables as in the above regressions and implementing the regression for all the firms, we split firms according to leverage ratios and regressed the same equation separately. The result is again similar to the main result.

Third, we check the robustness of our results to the choice of year windows in measuring past inflation. The impact of inflation discussed above works similarly when we use the 5-year average of inflation rate, while it is relatively weak when we use one year lagged inflation. This suggests the importance of looking at trend inflation rather than short-run inflation movements when we analyze firm dynamics.

Fourth, we confirm that the same relation is observed when we replace the input price inflation with wage inflation that is calculated as the change in the average wage in each industry $\times$ size groups. Note that our theoretical model considers labor as only input to produce final goods.

Last but not least important, we document a similar relation between inflation and firm growth for the non-manufacturing sector. It is important to see the relation in the non-manufacturing sector to consider macroeconomic policy implications because the manufacturing sector does not account for the majority of the total value-added and it is declining over time in many countries.

\section{Model}

The model is based on Lentz and Mortensen (2005) and Oikawa and Ueda (2018). A representative household consumes and supplies a fixed amount of labor. Firms, both potential entrants and incumbents, make R\&D investments to develop new products with superior quality and take over the markets of other firms. Firms must pay menu costs when they revise their output price as well as when they enter the market and set an initial price. Because of menu costs, some firms decide not to enter the market even if they develop a new product when their product quality is not sufficiently high. 
Firms are ex post heterogeneous in their product quality and, in turn, their size.

We focus on a balanced growth path. We assume for simplicity that a central bank exogenously sets the growth rate of nominal aggregate output, $E_{t}$, at $n .{ }^{11}$ Denoting the quality-adjusted aggregate price index and its change (inflation rate) by $P_{t}$ and $\pi$, respectively, we can write the real growth rate, $g$, as $g=n-\pi$. For convenience, we denote the initial values in period $t=0$ without time subscripts, for example, $E_{0}=E$. In the following analysis, we consider the case with $n \geq 0$, because trend nominal growth rates are usually positive. Even in the lost decades in Japan with long-term stagnation periods, the average per capita nominal GDP growth rate was above zero.

\subsection{Household}

A representative household has the following preferences over all versions of $a \in$ $\left\{0,1, \cdots, A_{t}(j)\right\}$ of each product line $j \in[0,1]$ :

$$
\begin{gathered}
U_{t}=\int_{t}^{\infty} e^{-\rho\left(t^{\prime}-t\right)} \log C_{t^{\prime}} d t^{\prime} \\
\log C_{t^{\prime}}=\int_{0}^{1} \log \left[\sum_{a=0}^{A_{t^{\prime}}(j)} Q(j, a) x_{t^{\prime}}(j, a)\right] d j,
\end{gathered}
$$

where $\rho$ represents the subjective discount rate, $C_{t}$ is the aggregate consumption, and $x_{t}(j, a)$ and $Q(j, a)$ are the consumption and quality of version $a$ of product $j$, respectively. The quality evolves as

$$
Q(j, a)=\prod_{a^{\prime}=0}^{a} q\left(j, a^{\prime}\right), \quad q\left(j, a^{\prime}\right)>1 \quad \forall a^{\prime}, j,
$$

where $q\left(j, a^{\prime}\right)$ is the quality update created by each innovation.

In the current model setting, we focus on an extensive margin to explain firm growth. By an extensive margin, we mean a change in the number of product lines that firms produce. Because our model assumes unit elasticity of substitution between different product lines and infinite elasticity of substitution between products in the same product line, as in Grossman and Helpman (1991), firms' sales relative

\footnotetext{
${ }^{11}$ Our results are essentially the same even if we assume that a central bank sets a certain inflation target instead of controlling $n$. See Oikawa and Ueda (2018). They also consider the case of deflation.
} 
to nominal aggregate expenditure never grow as long as they engage in production of a single product. Changes in the intensive margin, that is, an improvement in productivity or a quality update in the same product line, cannot increase firms' sales. Incumbent firms can grow their sales size only by changing the extensive margin, that is, taking the market share of other firms and producing more than one product line. For this reason, we need multi-product firms to obtain a dispersed distribution. ${ }^{12}$ This model strategy is consistent with the finding by Cao et al. (2018) that firms grow by adding new establishments (extensive margin) rather than by increasing employment per establishment (intensive margin). Certainly, we do not intend to argue that the intensive margin is unimportant. For example, the models in Luttmer (2007) and Lucas and Moll (2014) generate firm-size distribution with the intensive margin, often through heterogeneous and exogenous changes in productivity.

\subsection{Firms' Decisions about Price Revisions}

This part is based on Oikawa and Ueda (2018). The only difference is that a firm has to pay a menu cost when it enters the market. ${ }^{13}$ Price setting requires the menu cost:

$$
\kappa E_{t} / P_{t}
$$

at time $t$ in real terms that is paid with consumption goods.

Suppose that nominal prices are reset at $t_{i}$ for $i=-1,0,1, \cdots$. If nominal price $p_{t_{-1}}$ posted at time $t_{-1}$ is not revised thereafter, its real price, say $\xi$, decreases with the growth rate of nominal production costs (wage, $\left.W_{t}\right), n$. Let $\xi_{t_{-1}, \tau} \equiv p_{t_{-1}} e^{-n\left(t_{-1}+\tau\right)} \equiv$ $\xi_{-1} e^{-n \tau}$, where $\tau$ is the elapsed time since the last price revision and $\xi_{i}$ is the revised real price at $t_{i}$ (i.e., $\xi_{t_{i}, 0} \equiv \xi_{i}$ ).

Then, when the price is reset at $t$, the real value of each product line is expressed as

$V_{t}=\max _{\left\{t_{i}, \xi_{i}\right\}_{i=1}^{\infty}} \sum_{i=0}^{\infty}\left(\int_{t_{i}}^{t_{i+1}} \Pi\left(\xi_{t_{i}, t^{\prime}-t_{i}} e^{-n\left(t^{\prime}-t_{i}\right)} \mid q\right) \frac{E_{t^{\prime}}}{P_{t^{\prime}}} e^{-(\rho+g+\delta)\left(t^{\prime}-t\right)} d t^{\prime}-\frac{\kappa E_{t_{i}}}{P_{t_{i}}} e^{-(\rho+g+\delta)\left(t_{i}-t\right)}\right)$

\footnotetext{
${ }^{12}$ The extensive margin also plays an important role in reallocation in the model of Melitz (2003) in which firms expand their sales via exports. Using product- and firm-level data, Argente et al. (2018) show that firms grow only by adding new products.

${ }^{13}$ If the menu cost is not paid at entry for each product line, a sufficiently low $q$ firm operates for a while and exits without price revision. Our setup avoids this complication.
} 
where $\delta$ is the rate of creative destruction, $\Pi(\cdot) E_{t} / P_{t}$ represents the real period profit, and $t_{0}=t$. The second term represents menu-cost payments at $t_{i}$. Because of the recursive structure of the price adjustment problem, this maximization problem can be reduced to the following problem by controlling the interval of price revision, $\Delta$, and the reset level of real price, $\xi_{0}$, in which we drop the absolute time subscript from $\xi_{t_{i}, \tau}$. Let $\nu_{\tau}(q \mid \delta, n)$ be the normalized value of product line, $P_{t} V_{t} / E_{t}$, with elapsed time $\tau=t-t_{i} \in[0, \Delta]$ for some $i$. The problem (7) can be reduced to

$$
\begin{aligned}
& \nu_{0}(q \mid \delta, n)=\max \left\{\tilde{\nu}_{0}(q \mid \delta, n), 0\right\} \\
& \tilde{\nu}_{0}(q \mid \delta, n)=\max _{\Delta, \xi_{0}} \sum_{i=0}^{\infty} e^{-(\rho+\delta) i \Delta}\left(\int_{0}^{\Delta} \Pi\left(\xi_{0} e^{-n \tau} \mid q\right) e^{-(\rho+\delta) \tau} d \tau-\kappa\right),
\end{aligned}
$$

where $\tilde{\nu}_{0}$ is the value of a product line just before setting the price, which can be negative because of the menu cost. If it is negative, the firm decides not to produce or not to enter the market. Firms choose the optimal interval of price revision $\Delta$ and real reset price $\xi_{0}$ as $\Delta(q \mid \delta, n)$ and $\xi_{0}(q \mid \delta, n)$, respectively. They both depend on their quality step $q$ so that the types of price revisions are also heterogeneous among firms.

To simplify the pricing strategy, we assume that knowledge on outdated technologies is automatically in the public domain. With this assumption, firms with secondary technology, if any, are under perfect competition and thus their prices are always the marginal cost, $W$. Hence, the limit price of a leading firm is $q W{ }^{14}$

From equation (5), the demand for goods with leading technology in period $t$ is given by $E_{t} / p_{t}=1 / \xi_{t}$ when $\xi_{t} \leq q W_{t}$, and zero otherwise. We assume that each good is produced by linear technology with productivity of one. Then, we obtain $\Pi(\xi \mid q)=(\xi-W) / \xi$ when $\xi \leq q W$, and zero otherwise.

From the log utility, the optimal (re)set real price is

$$
\xi_{0}(q \mid \delta, n)=q W
$$

Note that $\Delta(q \mid \delta, 0)=\infty$ because firms do not need to reset prices when real produc-

\footnotetext{
${ }^{14}$ Although New Keynesian models often assume time-dependent (Calvo-, Rotemberg-, or Taylortype) price stickiness, a state-dependent (e.g., menu cost) pricing model is necessary to embed creative destruction with vertical competition. In particular, in Calvo or Taylor-type models, there is a possibility that a leading firm maintains its price at a level higher than $q W$, which makes firms with secondary technology steal all its business.
} 
tion costs do not change. The optimal choice of price revision is expressed by

$$
\frac{d}{d \Delta} \tilde{\nu}_{0}(q \mid \delta, n)=0=-(\rho+\delta) \tilde{\nu}_{0}+\Pi\left(\xi_{0} e^{-n \Delta} \mid q\right)
$$

Substituting this into equation (9), we obtain the maximized value of a product line for type- $q$ firm as

$$
\tilde{\nu}_{0}(q \mid \delta, n)= \begin{cases}\frac{1}{\rho+\delta}\left(1-\frac{e^{n \Delta(q \mid \delta, n)}}{q}\right) & \text { for } n>0 \\ \frac{1}{\rho+\delta}\left(1-\frac{1}{q}\right)-\kappa & \text { for } n=0\end{cases}
$$

Appendix B shows that $\tilde{\nu}_{0}(q \mid \delta, n)$ strictly increases with $q$ and strictly decreases with $\delta$ and $n$. Moreover, the second-order cross-derivative of $\tilde{\nu}_{0}(q \mid \delta, n)$ with respect to $q$ and $n$ is positive.

The reasoning is as follows. Rapid nominal growth (high $n$ ) implies frequent price resets (low $\Delta$ ) and high menu cost payments that lead to the lower value of a product line $\left(\tilde{\nu}_{0}\right)$. The burden from a rise in menu cost payments, which is triggered by an increase in $n$, is relatively smaller for firms with greater $q$, because menu costs are independent of $q$, while the return from the price reset increases with $q$. Higher- $q$ firms have a larger markup and choose a larger time interval, $\Delta$. These attributes increase the sensitivity of such firms' profits to a change in $n$, which causes more frequent price changes when $n$ increases (i.e., $\left.\left(d^{2} \Delta\right) /(d q d n)<0\right)$.

The product line value for low-quality firms can be negative when there are positive menu costs, $\kappa>0$. Here, we denote $\underline{q}(\delta, n)$ as the threshold level of $q$,

$$
\underline{q}(\delta, n)=\max \left\{q \mid \tilde{\nu}_{0}(q \mid \delta, n) \leq 0\right\}
$$

Proposition 1 shows that $\underline{q}(\delta, n)$ uniquely exists if $\kappa$ is sufficiently small, and it is increasing in $n$ when $n \geq 0$, implying that faster nominal growth pushes inferior firms out of the market.

Proposition 1 If $\kappa<\frac{1}{\rho+\delta}$, then $\underline{q}(\delta, n)$ uniquely exists and $\underline{q}(\delta, n)$ is increasing in $n$ for $n \geq 0$.

All proofs are in Appendix B.3. Throughout the study, we assume that the menu cost parameter $\kappa$ is small enough for Proposition 1 to hold. 


\subsection{Incumbent Firms' R\&D}

Here, we consider incumbents' R\&D decisions by taking the optimal pricing decision as given. This subsection is based on Lentz and Mortensen (2005, 2008). We assume that the size of quality improvement, $q$, is firm-specific and unchanged over time for each incumbent.

Suppose that an incumbent firm is type $q$ and supplies $k \geq 1$ products. The R\&D cost is $k W_{t} c(\gamma)$, where $\gamma \geq 0$ is the $\mathrm{R} \& \mathrm{D}$ intensity. With probability $k \gamma$, the firm comes up with a new idea in a randomly chosen product line. The function $c(\gamma)$ is increasing and strictly convex with $c(0)=0$. We define the real wage as $w \equiv W / E$.

The Bellman equation for the incumbent's problem is a bit complicated, because profits from a product line depend on the elapsed time from the last price revision. However, the resultant value function is similar to that in Lentz and Mortensen (2008). Let $T_{k} \equiv\left\{\tau_{j}\right\}_{j=1}^{k}$ be the set of elapsed times from the last price revision. The real value of the firm with $q, k$, and $T_{k}$ under the environment of $(\delta, w, n)$, say $v_{k}\left(T_{k}, q \mid \delta, w, n\right)$, satisfies the following Bellman equation:

$$
\begin{aligned}
\rho v_{k}\left(T_{k}, q \mid \delta, w, n\right)=\max _{\gamma} \sum_{j \notin \Omega} & {\left[\Pi^{0}\left(\xi_{0} e^{-n \tau_{j}} \mid q\right)+\frac{\partial v_{k}\left(T_{k}^{\prime}, q \mid \delta, w, n\right)}{\partial \tau_{j}}\right] } \\
& +\sum_{j \in \Omega}\left[\Pi^{0}\left(\xi_{0} e^{-n \tau_{j}} \mid q\right)-\kappa+\frac{\partial v_{k}\left(T_{k}^{\prime}, q \mid \delta, w, n\right)}{\partial \tau_{j}}\right] \\
& -k w c(\gamma) \\
+ & k \gamma\left[v_{k+1}\left(\left\{T_{k}^{\prime}, 0\right\}, q \mid \delta, w, n\right)-v_{k}\left(T_{k}^{\prime}, q \mid \delta, w, n\right)\right] \\
+ & k \delta\left[\frac{1}{k} \sum_{j=1}^{k} v_{k-1}\left(T_{k-1,<j>}^{\prime}, q \mid \delta, w, n\right)-v_{k}\left(T_{k}^{\prime}, q \mid \delta, w, n\right)\right],
\end{aligned}
$$

where $\Omega \equiv\left\{j \mid \tau_{j}=\Delta(q \mid \delta, n)\right\}$ represents the set of products whose prices are to be revised, and $T_{k}^{\prime} \equiv\left\{\tau_{j}^{\prime}\right\}_{j=1}^{k}$ consists of $\tau_{j}^{\prime}=0$ if $j \in \Omega$, and $\tau_{j}^{\prime}=\tau_{j}$ if not. $T_{k-1,<j>}$ is the set that comprises the elapsed time of the firm when it exits from $j$-th product market. On the right-hand side of equation (14), the first and second lines represent the real period profit when the nominal prices are not reset and when the nominal prices are reset, respectively. The real period profit decreases as $\tau$ lengthens. The third line represents $R \& D$ investment costs that are proportional to the number of product lines $k$. The fourth and fifth lines represent the changes in its real value when 
the firm increases and decreases its product lines by one, respectively.

Appendix B.1 shows that the value function, $v_{k}$, is solved as

$$
v_{k}\left(T_{k}, q \mid \delta, w, n\right)=\sum_{i=1}^{k} \nu_{\tau_{i}}(q \mid \delta, n)+k \psi(q \mid \delta, w, n),
$$

where $k \psi(q \mid \delta, w, n)$ is the value from $\mathrm{R} \& \mathrm{D}$ in the future that depends on the current number of product lines, or knowledge level, because it contributes to the probability of success in $R \& D$. The appendix also shows that incumbents make the following optimal R\&D intensity choice, $\gamma$ :

$$
w c^{\prime}(\gamma)=\max _{\gamma \in[0, \rho+\delta)} \frac{(\rho+\delta) \nu_{0}(q \mid \delta, n)-w c(\gamma)}{\rho+\delta-\gamma}
$$

The next proposition summarizes the properties of the optimal $\gamma$. It shows that firms with greater $q$ have a higher R\&D intensity and there is a complementarity effect among $q$ and $n$. Since more rapid nominal growth monotonically decreases the $R \& D$ intensity for any firm, the decline in R\&D intensity under higher $n$ is relatively small for firms with greater $q$.

Proposition 2 Fix $n$ and $\delta>0 . \quad \gamma(q \mid \delta, w, n)$ uniquely exists for sufficiently large $w$. If such $\gamma$ exists, $\gamma(q \mid \delta, w, n)$ is increasing in $q$ and decreasing in $n, \delta$, and $w$. Moreover, for $n \neq 0$,

$$
\frac{\partial^{2} \gamma(q \mid \delta, w, n)}{\partial q \partial n}>0 \quad \text { and } \quad \frac{\partial^{2} \gamma(q \mid \delta, w, n)}{\partial q \partial w}<0
$$

The optimal choice $\gamma(q \mid \delta, w, n)$ increases with $\nu_{0}(q \mid \delta, n)$. Hence, higher $q$ implies a higher value of a product line and, at the same time, greater $R \& D$ investment.

\subsection{Firm Entry}

The entry stage consists of two steps. First, a measure $h$ of potential entrants make $\mathrm{R} \& \mathrm{D}$ decisions before knowing their own $q$. The exogenous density of types of potential entrants is $\bar{\phi}(q)$ on $[1, \bar{q}]$, where $\bar{q}$ can be infinite. We assume that $\bar{\phi}(q)$ is continuous on its support. Second, some of the firms that observe $q<\underline{q}(\delta, n)$, defined in equation (13), call off their entry, because menu costs make them worse off. Here, 
for simplicity, we do not allow for the possibility that such firms coordinate with their incumbents to enter the market. While entrants give up their entry, incumbents continue to monopolize the market. We denote the ex post distribution of $q$ for the entrants as

$$
\phi(q \mid \delta, n)= \begin{cases}0 & \text { for } q<\underline{q}(\delta, n), \\ \frac{\bar{\phi}(q)}{1-\bar{\Phi}(\underline{q}(\delta, n))} & \text { for } q \geq \underline{q}(\delta, n),\end{cases}
$$

where $\bar{\Phi}$ is the cumulative distribution associated with $\bar{\phi}$.

We assume free entry to the market. Let $\eta$ denote the ex post entry rate. In equilibrium, we have the following free-entry (FE) condition:

$$
\begin{aligned}
\int_{1}^{\infty} \bar{\phi}(q) v_{1}(\{0\}, q \mid \delta, w, n) d q & =w c^{\prime}\left(\gamma_{\eta}(\delta, w, n)\right) \\
\gamma_{\eta}(\delta, w, n) & \equiv \frac{\eta(\delta, w, n)}{1-\bar{\Phi}(\underline{q}(\delta, n))} \frac{1}{h}
\end{aligned}
$$

where $v_{1}(\{0\}, q \mid \delta, w, n)$ is the firm value of an entrant, and $\gamma_{\eta}(\delta, w, n)$ is the entrants' R\&D intensity that yields $\eta$. The R\&D cost function $c$ for potential entrants is the same as that for incumbents.

\subsection{Firm Distribution}

\subsubsection{Price Distribution}

Because of the $S s$-pricing rule due to menu costs, firms set heterogeneous prices even within those with the same $q$. From Oikawa and Ueda (2018), the stationary density of real prices among type- $q$ firms is

$$
f(\xi(\tau) \mid q, n)=\frac{\delta e^{-\delta \tau}}{1-e^{-\delta \Delta(q \mid \delta, n)}} \quad \text { for } \tau \in[0, \Delta(q \mid \delta, n)]
$$

\subsubsection{Firm Size and Quality}

Let $M_{k}(q \mid \delta, w, n)$ be the measure of type- $q$ firms that produce $k$ products under the environment $(\delta, w, n)$. Following Lentz and Mortensen (2005), the stationary 
distribution satisfies

$$
\begin{aligned}
& \gamma(q \mid \delta, w, n)(k-1) M_{k-1}(q \mid \delta, w, n)+\delta(k+1) M_{k+1}(q \mid \delta, w, n) \\
& =(\gamma(q \mid \delta, w, n)+\delta) k M_{k}(q \mid \delta, w, n) \quad \text { for } k \geq 2,
\end{aligned}
$$

with

$$
\begin{aligned}
\phi(q \mid \delta, n) \eta & =\delta M_{1}(q \mid \delta, w, n) \\
\phi(q \mid \delta, n) \eta+2 \delta M_{2}(q \mid \delta, w, n) & =(\gamma(q \mid \delta, w, n)+\delta) M_{1}(q \mid \delta, w, n) .
\end{aligned}
$$

Based on Appendix B.2, we derive the following equation:

$$
1=\eta \int_{\underline{q}(\delta, n)}^{\infty} \frac{\phi(q \mid \delta, n)}{\delta-\gamma(q \mid \delta, w, n)} d q
$$

Equation (24) pins down the entry rate in equilibrium, $\eta(\delta, w, n)$. Because the measure of products supplied by type- $q$ firms is represented by

$$
K(q \mid \delta, w, n) \equiv \frac{\eta(\delta, w, n) \phi(q \mid \delta, n)}{\delta-\gamma(q \mid \delta, w, n)}
$$

condition (24) is equivalent to the condition that the total measure of product lines must be one.

The equilibrium entry rate, $\eta(\delta, w, n)$, has the following properties. First, $\eta$ increases with $w$, because $\partial \gamma / \partial w<0$ for any $q>q(\delta, n)$ so that the integral in equation (24) decreases with $w$. Second, the relation between $\delta$ and $\eta$ is ambiguous. In response to an increase in $\delta, \delta-\gamma(q \mid \delta, w, n)$ increases for any $q>\underline{q}(\delta, n)$ because $\partial \gamma / \partial \delta<0$, but at the same time, $\phi\left(q \mid \delta_{1}, n\right)$ stochastically dominates $\phi\left(q \mid \delta_{2}, n\right)$ if $\delta_{1}>\delta_{2}$. The former effect reduces the integral in equation (24) but the latter distribution effect enlarges it. Although it is possible that the distribution effect dominates and $\eta$ decreases with $\delta$ if we consider the ad hoc distribution for $\bar{\phi},{ }^{15}$ we assume that the distribution

\footnotetext{
${ }^{15}$ This situation can arise when the increase in $\underline{q}(\delta, n)$ in response to an increase in $\delta$ eliminates a large mass of firms, as indicated by the following example. Suppose that $\bar{\phi}$ is defined on a discrete space and has two mass points with equal probabilities at $\left\{q_{1}, q_{2}\right\}$, and there are negligible probabilities at the other $q$. Suppose $\underline{q}$ is very close to $q_{1}$ so that $\gamma\left(q_{1}\right)$ is almost zero. In addition, suppose $\gamma\left(q_{2}\right)=\frac{\delta}{2}$. Now consider the effect of an increase in $\delta$ to $\delta^{\prime}$, where the increase is tiny but enough to eliminate $q_{1}$-type firms from the market. Before the change, the integral in equation $(24)$, or the expected value of $(\delta-\gamma(q))^{-1}$, is approximately $\frac{1.5}{\delta}$. After the change, it becomes
} 
effect does not dominate in the following analyses, meaning, roughly speaking, that we assume that $\bar{\phi}$ is sufficiently smooth.

Substituting $\eta(\delta, w, n)$ into the free-entry condition, equation (18), we obtain Proposition 3 that shows that the free-entry condition is depicted as a downwardsloping curve on the $\delta$ - $w$ space unless the distribution effect is too strong.

Proposition 3 For given $\delta$, the wage $w$ that satisfies the free-entry condition uniquely exists. Moreover, as long as $\eta(\delta, w, n)$ is increasing in $\delta$, the free-entry condition ensures a negative association between $\delta$ and $w$.

The intuition behind the negative association between $\delta$ and $w$ is as follows. A greater creative destruction rate should be at least partly driven by a higher entry rate. On the other hand, it implies a lower expected firm value after entry, which dampens innovation incentives for both entrants and incumbents. Then, we should have a decline in wages to keep the FE condition because it increases post-entry firm value and decreases the entry cost.

\subsection{Labor Market}

Labor consists of three groups of workers: production workers $L_{X}, \mathrm{R} \& \mathrm{D}$ workers hired by incumbents $L_{R, i n c}$, and R\&D workers hired by entrants $L_{R, e n t}$. There is no skill difference across sectors.

Production workers are represented by

$$
L_{X}(\delta, w, n)=\int_{\underline{q}(\delta, n)}^{\infty} K(q \mid \delta, w, n) L_{X, q}(q \mid \delta, w, n) d q,
$$

where $L_{X, q}(q \mid \delta, w, n)$ is the production labor demanded by type- $q$ firms that is derived from the price density function (20), such as

$$
L_{X, q}(q \mid \delta, w, n)=\int_{0}^{\Delta(q \mid \delta, n)} f(\xi(\tau)) \frac{1}{\xi(\tau)} d \tau=\frac{\delta}{\delta-n} \frac{1}{w q} \frac{1-e^{-(\delta-n) \Delta(q \mid \delta, n)}}{1-e^{-\delta \Delta(q \mid \delta, n)}} .
$$

approximately $\frac{2}{\delta^{\prime}}$. If $\delta^{\prime} / \delta$ is sufficiently small, then $\eta$ is decreasing in $\delta$ around the current $\delta$. 
The two types of R\&D labor demands are written as

$$
\begin{aligned}
& L_{R, i n c}(\delta, w, n)=\int_{\underline{q}(\delta, n)}^{\infty} K(q \mid \delta, w, n) c(\gamma(q \mid \delta, w, n)) d q, \\
& L_{R, \text { ent }}(\delta, w, n)=h c\left(\gamma_{\eta}(\delta, w, n)\right) .
\end{aligned}
$$

The labor market clearing (LMC) condition is expressed as

$$
L=L_{X}(\delta, w, n)+L_{R, i n c}(\delta, w, n)+L_{R, e n t}(\delta, w, n) \equiv L_{D}(\delta, w, n)
$$

As discussed in Appendix B.4, the total labor demand does not necessarily have monotonic relation between $w$ and $\delta$. Avoiding technical details, below we consider the case with natural distributions that give us

$$
\frac{\partial L_{D}}{\partial \delta}>0 \text { and } \frac{\partial L_{D}}{\partial w}<0
$$

and, therefore, the LMC is depicted as an upward-sloping curve on the $\delta$ - $w$ space.

\section{Stationary Equilibrium}

\subsection{Equilibrium}

Given the exogenous $\{n, \bar{\phi}(q)\}$, a stationary equilibrium consists of constant endogenous variables $\left\{\nu_{0}(q \mid \delta, n), \Delta(q \mid \delta, n), \xi_{0}(q, \delta, w, n), \gamma(q \mid \delta, w, n), w, \delta, \eta\right\}$ and they satisfy the producers' optimal $S s$-pricing (10) and (11), firm value (12), incumbents' optimal R\&D intensity choice (16), the free-entry condition (18), the entry/exit rate equation (24), and the labor market clearing condition (29) as well as stationary distributions $\left\{M_{k}(q \mid \delta, w, n), \phi(q \mid \delta, n)\right\}$ that satisfy equations (17) and (21)-(23).

Figure 1 illustrates a typical loci of the FE and LMC curves with the curve of $\underline{w}(\delta, n)$, which is defined in Appendix B.2, above which a nondegenerated quality distribution exists in the stationary state. The left edge of the LMC curve should coincide with a point on the curve of $\underline{w}(\delta, n)$. This is because $L_{D}(\delta, \underline{w}(\delta, n), n)$ is continuous in $\delta$ and

$$
\lim _{\delta \rightarrow 0} L_{D}(\delta, \underline{w}(\delta, n), n)=0<L<\lim _{\delta \rightarrow \frac{1}{\kappa}+\rho} L_{D}(\delta, \underline{w}(\delta, n), n)
$$


where the upper bound of $\delta$ is defined as having a finite $q .{ }^{16}$

Since the locus of the FE curve is always above $\underline{w}(\delta, n)$, we can show the existence of a stationary equilibrium as in the next proposition.

Proposition 4 For given $n \geq 0$, a stationary equilibrium exists and the entry rate in a stationary state is strictly positive.

The existence of the stationary state does not depend on our supposition about the monotonicity of the FE and LMC curves. However, the uniqueness of the equilibrium depends on the monotonicity of the labor demand function. Multiple equilibria may occur under some kind of potential distribution, $\bar{\phi}$. We do not dwell on this possibility because, according to our simulation based on smooth potential distributions, this nonmonotonicity does not arise.

\subsection{Welfare}

Using the endogenous variables in the stationary equilibrium, we can pin down other endogenous variables as well: $\{C, P, \pi, g, U\}$.

The goods market is cleared at

$$
\begin{aligned}
E= & P C+\kappa E \int d q \sum_{k=1}^{\infty} M_{k}(q \mid \delta, w, n) k f\left(\xi_{0}(q, n)\right) \\
& \Rightarrow \quad C=\frac{E}{P}\left(1-\kappa \delta \int \frac{K(q \mid \delta, w, n)}{1-e^{-\delta \Delta(q \mid \delta, n)}} d q\right)
\end{aligned}
$$

where the second term in the parenthesis is the total menu costs.

Referring to Oikawa and Ueda (2018), the aggregate price level and the inflation rate are given by

$$
\begin{aligned}
\log P & =\int K(q \mid \delta, w, n)\left\{\log \xi_{0}(q, n)+n \Delta \frac{e^{-\delta \Delta(q \mid \delta, n)}}{1-e^{-\delta \Delta(q \mid \delta, n)}}-\frac{n}{\delta}\right\} d q, \\
\pi & =n-\delta \int K(q \mid \delta, w, n) \log q d q .
\end{aligned}
$$

Then, the real growth rate $g$ is

$$
g=n-\pi=\delta \int_{\underline{q}(\delta, n)}^{\infty} K(q \mid \delta, w, n) \log q d q .
$$

\footnotetext{
${ }^{16}$ Note that $\lim _{\delta \rightarrow 0} \underline{w}(\delta)=\infty$ and $\lim _{\delta \rightarrow \frac{1}{\kappa}+\rho} L_{R, \text { ent }}=\infty$ because $\underline{q}\left(\frac{1}{\kappa}+\rho, n\right)=\infty$.
} 
The intertemporal utility of the representative household at $t=0$ is given by

$$
U=\int_{0}^{\infty} e^{-\rho t} \log C_{t} d t=\frac{g}{\rho^{2}}+\frac{\log C}{\rho} .
$$

\section{Impacts of Nominal Growth}

The current model depicts monetary policy as described as a change in the nominal growth rate, $n$. We simply assume that the central bank chooses $n$ and compare the stationary states across different $n .^{17}$

\subsection{Reallocation Effects on the Real Growth Rate}

Nonzero nominal growth has two kinds of reallocation effects. First, it pushes lowquality firms out of the market because of the greater burden of menu costs $(\partial \underline{q} / \partial n>$ $0)$. Second, it causes higher quality firms to hold more product lines, because $\partial^{2} \gamma / \partial n \partial q>0$ : the decline in R\&D intensity caused by an upward shift in $n$ is relatively small for firms with greater $q$. Moreover, the increase in the product line share owned by high- $q$ firms benefits the aggregate efficiency in R\&D investment, because the probability of success is $k \gamma$. These reallocation effects are interpreted as the "cleansing effect" that was coined by Caballero and Hammour (1994). The reallocation effects are positive for the real growth rate, $g$.

At the same time, there is a negative effect on $g$ from faster nominal growth, which is examined in the Oikawa and Ueda (2018) model that abstracts the firm heterogeneity in firm quality. When the economy grows faster in nominal terms, firms revise their prices more frequently and pay more menu costs that lead to lower values and lower innovation incentives.

The overall effect of faster nominal growth on real growth is determined by the balance between these effects. As shown in equation (33), the real growth rate is determined by the creative destruction rate, $\delta$, multiplied by the weighted average of quality gaps, $\log q$. Even though the creative destruction rate decreases with $n$, when the reallocation effect is sufficiently large, the increase in the weighted average

\footnotetext{
${ }^{17}$ The current model conforms to Lentz and Mortensen (2008) if there is no menu cost, or $\kappa=0$. When $n=0$, the current model becomes like that in Lentz and Mortensen (2008) with a fixed cost of entry to product line.
} 
quality gap, $\int K(q \mid \delta, w, n) \log q d q$, dominates the negative effect on $\delta$, and then the real growth rate, $g$, starts increasing with the nominal growth rate, $n$.

\subsection{Reallocation Effects on Welfare}

Here, we compare the welfare in two balanced growth paths that are distinct only in the nominal growth rate. The effects on welfare consist of several factors. As equations (30) and (34) show, the effects should be divided into the real-growth channel, menu-cost channel, and price channel.

As seen in equation (30), an increase in nominal growth contributes to an improvement in welfare if it is accompanied by an increase in real growth, that is, with the sufficient reallocation effect argued in the previous subsection. To see the importance of the reallocation effect, we compare the current model with the single-product model in Oikawa and Ueda (2018). Without the reallocation effect, the real growth rate attains its maximum when $n=0$, and therefore, a strictly positive nominal growth rate can be socially optimal only if $R \& D$ is overinvested. With the reallocation effect as in the current model, the real growth rate can increase as $n$ increases, so that a strictly positive optimal nominal growth does not rely on $R \& D$ overinvestment.

Whether higher real growth improves welfare is affected by both positive and negative externalities, which commonly appear in Schumpeterian growth models. A greater share of innovative (high $q$ ) firms in the markets leads to greater intertemporal knowledge spillover because the subsequent quality improvement is built on the current innovator's shoulder. Meanwhile, the business-stealing effect, a negative externality, works in a complicated way. Less frequent creative destruction under higher $n$ reduces the opportunity of business stealing, but at the same time, more high- $q$ products in equilibrium imply a greater destructed firm value at each creative destruction. Because the business-stealing effect gets smaller relative to the knowledge spillover effect as $q$ increases, the total externality effect is likely to be positive when higher nominal growth increases aggregate $q$.

The menu-cost channel has an ambiguous effect on welfare. An increase in $n$ imposes more frequent menu cost payments for all firms. However, at the same time, an increase in $n$ brings less creative destruction (and less entry) that reduces the total menu cost. Moreover, a greater $n$ makes $K(q \mid \delta, w, n)$ be denser with higher $q$. Because the frequency of price revisions is relatively low for high- $q$ firms, the total 
menu cost payments may decrease under rapid nominal growth.

The price channel is two-fold and both paths have ambiguous effects. The first one comes from a change in markups. The markup rate just after price revision is high among the products supplied by high- $q$ firms. Because distribution $K(q \mid \delta, w, n)$ becomes denser with a higher $q$ when we have a higher $n$, the real prices are high. However, this effect is canceled out partly or fully by a lower rate of entry and a rapid decline in real prices that is caused by an increase in $n$. The second path is derived from a change in wage, $w$. The price level $P$ monotonically increases with $w$ but the equilibrium value of $w$ can decrease and increase with $n$ according to the labor market conditions. If a smaller $w$ is realized by an increase in $n$, it positively affects welfare.

\section{Simulations}

In this section, we present the results of numerical simulations.

\subsection{Calibration}

We calibrate the model to the economy of Japan. We normalize both the total number of workers, $L$, and the nominal aggregate output in period $t=0, E$, to one. The nominal growth rate $n$ is fixed at 0.021 , which equals the average of the annual per-capita nominal GDP growth rates from 1980 to $2006{ }^{18}$

The left-hand column in Table 4 shows the moments we targeted for the calibration. Real growth rate $g$ is 0.017 , which equals the average of the annual per-capita real GDP growth rates from 1980 to 2006. The nominal interest rate $R$ is 0.034 , which we calculate from the average of nominal interest rates for government bonds with 10-year maturities for the same period. ${ }^{19}$ The interval between price revisions $\Delta$ is 1.42 year, which is taken from the study of CPI micro data by Higo and Saita (2007). The other nine moments that characterize firm distribution are chosen following Lentz and Mortensen (2008) and calculated by using the aforementioned firm-level

\footnotetext{
${ }^{18}$ We choose the target for the nominal growth rate on the balanced growth path before the global financial crisis, or before the long-term nominal interest rate becomes zero, which may cause a structural change that is not introduced in the current model.

${ }^{19}$ We use the 9-year government bonds from 1980 to 1985 because the 10 -year rates are not available during those years.
} 
data, "the Basic Survey of Japanese Business Structure and Activities" for the year of 1995. The firm distribution does not change much when we use other years. The moments include the ratio of the median of sales to the mean of sales, the ratio of the median wage bill to the mean wage bill, the correlation coefficient between labor productivity and employment, and the mean of real sales growth. Employment is quality adjusted as in Lentz and Mortensen (2008). In total, the number of targeted moments is 12 .

Parameter values are calibrated to minimize the weighted distance between data moments and simulated moments. See Appendix C for the details. We calibrate seven parameter values: discount rate $\rho$, two values for the density of types of potential entrants $\bar{\phi}(q)$, two values for the R\&D cost function, measure of potential entrants $h$, and menu cost $\kappa$. We assume that $\bar{\phi}(q)$ obeys the truncated Pareto distribution, ${ }^{20}$ and calibrate not only the shape parameter $\zeta$ but also the maximum of $q$. The truncated distribution is introduced because, as nominal growth increases, the importance of high- $q$ firms in the right tail increases, which worsens the computational error if we assume an infinite bound. Moreover, this additional parameter helps increase the fit of the moments. The form of the R\&D cost function is $c(\gamma)=c_{0} \times \gamma^{1+c_{1}}$, as in Lentz and Mortensen (2008).

Although our approach is based on Lentz and Mortensen (2008), we do not claim that we estimate the model. We do not provide standard errors for the estimates like their paper, and admittedly better estimates to minimize the weighted distance may exist because we did not calculate it for a sufficiently global parameter set. Moreover, the number of moments we use for the calibration is much smaller than those that Lentz and Mortensen (2008) use for the structural estimation: 37. There are three reasons. First and foremost, our model does not embed an idiosyncratic demand shock, unlike the model of Lentz and Mortensen (2008). Thus, there is not much heterogeneity among firms once we control for quality step $q$ and firm size $k$, except for that coming from price dispersion due to menu costs. Consequently, the correlation coefficient between sales and wage bill is nearly one, and almost no within-firm labor productivity improvement exists regarding the growth decomposition of aggregate labor productivity. For this reason, we limit the target moments to the extent that our model can explain their heterogeneity. Second, the number of calibrated parameters

\footnotetext{
${ }^{20}$ Studies, such as Lucas (1978), Melitz (2003), and Luttmer (2007), often assume a Pareto distribution.
} 
is seven that is much smaller than that in Lentz and Mortensen (2008) who estimate 16. While Lentz and Mortensen (2008) introduce three discrete types of firms that have distinct distributions of $q$ to explain the large heterogeneity for the reason stated above, we assume only one density and continuous types. The third reason for the smaller number of moments is that we do not calibrate $E$ and $L$ because they only matter for standardization. Instead of targeting the mean, median, and standard deviation of the variables, we target the ratio of median to mean and the ratio of standard deviation to mean.

Moreover, we target $g$ and $\Delta$, while Lentz and Mortensen (2008) do not. We target $g$ because the effect of nominal growth on $g$ is our particular interest, so it is important to have a quantitatively plausible value. The reason for $\Delta$ is because it helps pin down the menu cost parameter $\kappa$ that the model of Lentz and Mortensen (2008) does not have.

As Table 4 shows, the model fits particularly well for the three aggregate variables. For the distributional variables, the fit is reasonably good, although the model yields a slightly larger value for the ratio of the median to the mean and a smaller value for the standard deviation of sales growth than the data indicate.

Table 4 also shows calibrated parameters. The discount rate $\rho$ is calibrated as 0.013 , which is essentially derived from $R$ minus $n$. The size of the menu cost $\kappa$ equals 0.015, which is comparable to Midrigan (2011) who reports 0.022. Instead of discussing the size of the other parameters such as $c_{1}$ and $h$, it is economically more meaningful to discuss the steady-state levels of some of the key endogenous variables. Creative destruction rate $\delta$ is 0.050 , entry rate $\eta$ is 0.007 , and the lower threshold of $q$ for entry $\underline{q}$ is 1.031. Lentz and Mortensen (2008) obtain $\delta=0.071$ and $\eta=0.045 .^{21}$

\subsection{Simulation Results}

Comparison with Empirical Evidence We conduct the model calibration without using information on how a nominal change influences the aggregate economy and firm distribution. Therefore, comparing how they respond to a change in nominal growth between the model and the data serves as a useful validity check for the model.

\footnotetext{
${ }^{21}$ We assume unit elasticity of substitution across product lines and inelastic labor supply following Lentz and Mortensen (2008). Appendix D presents a generalized model that relaxes these assumptions.
} 
We show simulation results that are analogous to our empirical findings reported in Section 2. First, in the left (right) panel of Figure 2, we calculate the ratio of sales (employment) per firm for the top $0.1 \%, 1 \%$, and $10 \%$ firms to those for a median firm for a different $n .^{22}$ The sales distribution in the model coincides with the distribution of the number of products a firm produces, $k$. Employment includes that for both production and $R \& D$ investment. The lines have positive slopes with respect to $n$ that indicates larger firms are likely to grow more rapidly than smaller firms when the nominal growth rate, $n$, increases.

This simulation result is consistent with that from the Japanese firm-level data reported in Table 1 in Section 2: the difference between the size of large and small firms becomes wider as the rate of changes in firms' input price increases. Note that this rate is analogous to the rate of changes in firms' production costs $n$, or more precisely, $\pi=n-g$.

Second, Figure 3 shows how sales growth conditional on size reacts to a change in $n$, which is comparable to the regression result in Table 2 , in which the negative effect of inflation is smaller for larger firms. To draw the figure, we calculate the distribution of sales growth for each firm with size $k$ and quality $q$ for a certain $n$ and aggregate it by using the steady-state distribution for $k$ and $q$. Because it is hard to calculate exact transition dynamics in the present model, we set the initial firm size distribution as that in the stationary state under $n=0.02$ (the historical average in Japan) and simulate firm growth with equilibrium variables under different $n$. Relative to the mean firm growth under $n=0.02$, higher nominal growth $(n=0.04)$ leads to lower firm growth and the growth gap between two different $n$ 's decreases as sales size increases, which is consistent with our empirical finding. Conversely, when nominal growth decreases to $n=0$, firm growth increases, that is particularly favorable for smaller firms, and the gap decreases as sales increase. The effects of nominal growth are slightly asymmetric: larger when $n$ decreases than when $n$ increases.

Third, for R\&D investment, our simulation results are also consistent with the regression results reported in Table 3. Figure 4 shows how changes in the nominal growth rate $n$ influence the aggregate economy. Particularly, the bottom right-hand panel indicates that R\&D investment, $\gamma(q)$, decreases as $n$ increases, and only the

\footnotetext{
${ }^{22}$ In our calibrated model, the bottom half of firms produce only the lowest amount of products. Thus, for example, the ratio of sales for the top $1 \%$ of firms to the bottom $1 \%$ of firms is almost equal to the ratio of sales for the top $1 \%$ of firms to a median firm.
} 
high- $q$ firms invest in $\mathrm{R} \& \mathrm{D}$ for a sufficiently high $n$. This heterogeneous response of R\&D investment implies that the coefficients for inflation and the cross-term of inflation and lagged sales are negative and positive, respectively, when we regress the R\&D investment, which we indeed confirm in Table 3. Furthermore, this simulation result confirms Proposition 2 in which the ratio of $R \& D$ investment by high- $q$ firms to that by low- $q$ firms widens as $n$ increases. This change in R\&D investment results in the widening of the ratio of sales for large firms to those for small firms in theory.

Finally, we check the response of the exit rate. In Table 3, we find that the exit rate increases as inflation increases, while it decreases as firm size increases. The latter response is model-consistent, since a firm exits the market when its sales becomes sufficiently small (i.e., the number of supplying products, $k$, decreases from 1 to 0$).{ }^{23}$ As for the former, simulation shown in the top right-hand panel of Figure 4 shows that the creative destruction rate $\delta$ decreases as $n$ increases. This result may seem to contradict the empirical result, if we interpret $\delta$ as a proxy for the exit rate. However, we can point out that the bottom left-hand panel of Figure 4 shows the lower threshold of $q$ for the firm entry, $q$, increases with $n$. This increase works to increase the exit rate as inflation increases.

Growth-Maximizing and Optimal Nominal Growth The top left-hand panel of Figure 4 demonstrates that the real growth rate, $g$, increases with $n$ up to a level of around 0.03. Two opposing effects lie behind this, as discussed in Section 5.

A negative effect of an increase in $n$ reflects a decrease in the creative destruction rate, $\delta$. Because a higher $n$ implies greater burden of menu costs, incentives to innovate decrease (innovation incentive effect). As a result, the entry rate, $\eta$, as well as R\&D investment, $\gamma(q)$, decrease with $n$.

However, there is a positive reallocation effect. The average quality improvement $(\log q)$ increases because a greater $n$ implies that $K(q \mid \delta, w, n)$ has more weight for a higher $q$ while firms with relatively small $q$ cannot survive. Indeed, the lower threshold of $q$ for the firm entry, $\underline{q}$, increases with $n$. Thus, the average firm size, $k$, increases with $n$, while the size gap widens for firms with different $q$. Despite greater menu

\footnotetext{
${ }^{23}$ In our model, the size-conditional exit rate is independent of $q$. However, in the regression, the coefficient for the cross-term of inflation and lagged sales is significantly negative, although we control for firm size. This inconsistency can be resolved by introducing discrete time setup as in our empirical analysis. Under discrete time, higher $q$ firms have lower exit rates, because the pace of expanding their variety is greater, and thus, they escape from the threshold of exit more easily.
} 
cost payments, the R\&D investment, $\gamma(q)$, for high- $q$ firms does not decrease so much with $n$, while low- $q$ firms make no R\&D investment when $n$ is high. As a result, the average $\log q$ increases, while the average markup also increases. This markup increase lowers the demand for production workers. Combined with a decrease in the demand for $\mathrm{R} \& \mathrm{D}$ workers for possible entrants, this decreased demand results in an increase in demand for R\&D workers for incumbents, because of the labor market clearing condition. In the calibrated model, the latter reallocation effect dominates the former innovation incentive effect up to a certain $n$. Until $n$ reaches around 0.03 , the real growth rate increases with the nominal growth rate.

Intertemporal utility, $U$, also peaks at positive $n$. This result is in sharp contrast to the model without firm reallocation. Oikawa and Ueda (2018) show that real growth is maximized at $n=0$ and, thus, the growth-maximizing inflation rate is negative. By contrast, in the model with firm reallocation, $U$ increases under positive $n$, mainly because the real growth rate, $g$, increases with $n$. However, too high an $n$ decreases welfare because of increased menu costs. Welfare is the highest at around $n=0.03$.

It should be noted that this value is sensitive to economic circumstances, as we discuss below. Moreover, our model does not incorporate household heterogeneity or the financial sector that should also matter for the design of optimal monetary policy. In that regard, the contribution of our study lies in demonstrating a new mechanism that influences optimal monetary policy rather than providing any exact number for the optimal inflation rate.

Firm Distributions To discuss how distributions change depending on the value of the nominal growth rate, $n$, we show in Figure 5 the cumulative distribution for sales and employment per firm. We depict the distribution on the log-log scale and calculate the tail distribution (one minus the cumulative distribution) of sales or employment. We find from the figure that both sales and employment per firm have heavier tails under positive nominal growth.

\subsection{Does Menu Cost Improve Welfare?}

It is sometimes said that it would be illogical for labour to resist a reduction of money-wages but not to resist a reduction of real wages. For 
reasons given below, this might not be so illogical as it appears at first; and, as we shall see later, fortunately so [emphasis added].

- Keynes $(1936)^{24}$

Because of the reallocation effect, price stickiness may improve welfare. To observe this, in Figure 6, we calculate the effects of nominal growth on welfare by the varying values of the menu cost parameter, $\kappa$, for $0,0.01$, and 0.015 . The welfare levels for each $\kappa$ are slightly different even at $n=0$, because we assume that firms pay menu costs at the first price setting.

The figure shows that price stickiness indeed improves welfare. Even with a slight menu cost value $(\kappa>0)$, welfare improves relative to the case with no menu cost $(\kappa=0)$ for $n>0$. As Keynes says, it is fortunate for an economy to have nominal rigidity.

In the current model, menu costs are proportional to the nominal aggregate output, and its proportion is constant and independent of real economic growth. However, allowing for feedback from real economic growth to the efficiency of price revisions would be a natural inclination. If this feedback is present, it mitigates the real growth effect of the change in the nominal growth rate, because the burden of menu costs decreases as the real economy grows. Importantly, such feedback is not necessarily desirable, as Figure 6 shows.

\subsection{Growth Decomposition}

In this subsection, we decompose the effect of nominal growth on the real growth rate, that is, $g(n)-g(0)$ into four components. First, following Lentz and Mortensen (2008), we examine the composition of the real growth rate at $n=0$, as the reference point, into the entry/exit effect, the selection effect, and the within (residual) effect:

$$
\begin{aligned}
g(0)= & \int_{\underline{q}(0)}^{\infty} \eta(0) \phi(q \mid 0) \log q d q \\
& +\int_{\underline{q}(0)}^{\infty}[K(q \mid 0)-\phi(q \mid 0)] \gamma(q \mid 0) \log q d q \\
& +\int_{\underline{q}(0)}^{\infty} \phi(q \mid 0) \gamma(q \mid 0) \log q d q .
\end{aligned}
$$

\footnotetext{
${ }^{24}$ Chapter 2-II on p.9 in the 1997 version published by Prometheus Books. We thank Prof. Katsuhito Iwai for pointing out the last two words in the quote.
} 
The first term represents the net entry effect by entrants. The second term represents the selection effect, which indicates the contribution to real growth through heterogeneous firm growth that depends on quality. The last term represents the within effect that Lentz and Mortensen (2008) call the residual effect: the contribution to real growth under the assumption that the share of products by firms is the same as that at entry.

In our calibrated model, the entry/exit effect, the selection effect, and the within effect account for $7.8 \%, 72.1 \%$, and $20.1 \%$ of the real growth at $n=0$, respectively. This contribution breakdown is comparable to that in Lentz and Mortensen (2008) for Denmark, in which the selection effect accounts for the largest share (52.8\%), followed by the within effect $(26.8 \%)$ and the entry/exit effect $(21.1 \%)$. The selection effect is more prominent and the entry effect is smaller in Japan than in Denmark because the potential entrants, $h$, calibrated to the Japanese economy is smaller than those of Denmark. Subsection 6.5 discusses more on the difference between Japan and Denmark.

Having positive nominal growth, $n>0$, we can write down the change in the real growth as follows:

$$
\begin{aligned}
g(n)-g(0)= & -\delta(0) \int_{\underline{q}(0)}^{\underline{q}(n)} K(q \mid 0) \log q d q \\
& +\int_{\underline{q}(n)}^{\infty}\{\eta(n) \phi(q \mid n)-\eta(0) \phi(q \mid 0)\} \log q d q \\
& +\int_{\underline{q}(n)}^{\infty}\{[K(q \mid n)-\phi(q \mid n)] \gamma(q \mid n)-[K(q \mid 0)-\phi(q \mid 0)] \gamma(q \mid 0)\} \log q d q \\
& +\int_{\underline{q}(n)}^{\infty}\{\phi(q \mid n) \gamma(q \mid n)-\phi(q \mid 0) \gamma(q \mid 0)\} \log q d q .
\end{aligned}
$$

Equation (36) shows the growth decomposition of the real growth rate at $n$ minus that at $n=0$, that is, $g(n)-g(0)$. A new component appears in the first term on the right-hand side of the equation that we call the entry barrier effect. This effect is one of the two reallocation effects in our model. An increase in $n$ causes low-quality firms to exit the market owing to the greater burden of menu costs $(\partial \underline{q} / \partial n>0)$. Because these firms would contribute to economic growth if they were in the market, the sign of the entry barrier effect becomes negative. The second to fourth effects are labeled in the same way as before: the entry/exit effect, the selection effect, and the within effect, respectively. However, they differ in that the effects are measured relative to 
those under no nominal growth, $n=0$.

Consider how these effects change when the nominal growth rate, $n$, increases. The selection effect increases real growth, because the ex post distribution has more density for greater $q$ than does the ex ante distribution. The within effect on real growth is positive, because the average $q$ as well as the gap in R\&D intensity between highand low- $q$ firms increase with $n$. The entry/exit effect on real growth is ambiguous, because the entry rate $\eta$ decreases with $n$, while the average $q$ rises.

Figure 7 shows the growth decomposition of $g(n)-g(0)$. The selection effect makes the largest contributions to the change in real growth. Both the entry/exit effect and the entry barrier effect negatively influence the real growth rate. Adam and Weber (2019) argue that the optimal inflation rate is around 1-2\% in a model in which firms are heterogeneous. Compared with their model, our model highlights the additional effects of monetary policy that work through reallocations. In particular, both the selection effect, which arises because the firms' heterogeneity is endogenous, and the within effect, which arises because the firms' R\&D is endogenous, suggest that the optimal inflation rate is even higher.

\subsection{Further Issues}

Comparison of Japan and Denmark Our baseline simulation is based on parameters that are calibrated to the Japanese economy. For comparison, we conduct another simulation using parameters that are calibrated to the Danish economy by following the work of Lentz and Mortensen (2008). There, nominal growth rate $n$ is fixed at 0.050, which equals the average of the annual per-capita nominal GDP growth rates from 1980 to 2006 for Denmark. The real growth rate $g$ equals the average of the annual per-capita real GDP growth rates, while the nominal interest rate $R$ is the average of 10-year government bond yields. ${ }^{25}$ The interval of price revision $\Delta$ is 1.292 years, which is taken from the study of CPI micro data by Hansen and Hansen (2006). The other moments that characterize firm distribution are taken from Lentz and Mortensen (2008).

Table 5 shows the moments and calibrated parameters, and Figure 8 shows the simulation results. The positive effects of nominal growth on real growth and welfare

\footnotetext{
${ }^{25}$ Since the data on 10-year government bond yields are available only from 1987 , we use the immediate rates for less than 24 hours from 1980 to 1986 and add the average difference between the two data in $1987(+4.2 \%$ points $)$ as a proxy.
} 
are increased. Intertemporal utility is the highest around $n=0.15$, while the real growth rate is the highest around $n=0.20$.

While there are many differences in parameter values, the most important difference seems to be the measure of potential entrants, $h$ (0.69 for Japan and 2.51 for Denmark). This difference brings out a difference in the entry rate $(\eta$ : 0.007 for Japan and 0.030 for Denmark) as well as the creative destruction rate $(\delta: 0.050$ for Japan and 0.073 for Denmark). In other words, entrants are more important in Denmark than in Japan, while incumbents are more important in Japan than in Denmark.

Figure 9 shows a simulation of the Danish economy with only the potential entrants, $h$, replaced with the lower value of the Japanese economy. Since incumbents become more important and they tend to have a higher $q$ than entrants, both the real growth rate and welfare increase from the case of the Danish economy. However, the marginal positive effects of nominal growth on real growth and welfare are greatly weakened, and the optimal $n$ decreases to around $n=0.01$ that is close to that in the Japanese economy. In a country with low $h$, large incumbents play a dominant role, and there is not much room for welfare improvement by reinforcing the reallocation effect through the nominal growth.

This simulation exercise does not necessarily mean that inflation is good for Denmark but bad for Japan. An important implication is that the effects of nominal growth depend on circumstances.

Inflation Indexation and Economies of Scope in Adjusting Prices In the current model, we have not considered inflation indexation of final goods prices. Although the basic mechanism of the model holds unless the nominal prices are perfectly linked to the nominal growth rate $n$, incumbents may be able to determine a price schedule in advance to save menu costs in a deterministic economy like this model. Such inflation indexation weakens the nominal rigidity and, in turn to mitigates or eliminates the effects of monetary policy on the real growth and firm size distribution.

However, there is a possibility that the reallocation effects of monetary policy are reinforced, when firms face economies of scope in price revisions, as Midrigan (2011) and Bhattarai and Schoenle (2014) argue. There, firms save a menu cost by changing the prices of multiple products simultaneously, so the menu cost per product decreases as the firm size increases. Similarly, inflation indexation may be more likely to be introduced to larger firms, and the burden of menu costs per the number of products 
becomes relatively heavy for small firms. Under these economies of scope in price revisions, high nominal growth more strongly discourages R\&D investment and future growth by small firms than large firms, which generates higher firm heterogeneity in response to inflation than our calibrated model indicates.

\section{Concluding Remarks}

In this study, we built an endogenous growth model with firm heterogeneity and nominal rigidity to analyze the effects of monetary policy on long-run economic growth and welfare through reallocation. Our results showed that nominal growth can enhance real growth and welfare if the reallocation effect is sufficiently strong. Beyond theoretical possibility, we found that this effect is indeed the case in the model that is calibrated to Japan. According to the model, the optimal nominal growth rate is strictly positive. Menu cost burdens suppress entry of least innovative firms and, moreover, reallocate $R \& D$ resources from low-quality to high-quality firms among the survivors.

Furthermore, this reallocation effect works selectively, while nominal growth or inflation through monetary policy is a purely aggregate phenomenon. Selection occurs because menu costs at each price revision are independent of firm quality, while the return from the price reset is higher for high quality firms.

The present model only considers firm heterogeneity while household heterogeneity is also important. Bhandari et al. (2018) argue that the social planner has an incentive to mitigate inequality between dividend earners and wage workers, which is enlarged by higher markups. Because our model implies that higher inflation leads to more concentration in big firms with high markups, there is an interaction between firm and household heterogeneities according to the distribution of share holdings, especially when the financial market is incomplete. Therefore, a central bank faces a trade-off to set an inflation rate in the sense that a higher inflation rate drives up real growth accompanied with a rise in income inequality. This is important for future work to combine both kinds of heterogeneity and their interaction to determine the optimal monetary policy.

Our model postulates nondirected R\&D, and thus, incumbents do not invest in improving the quality of the products they currently produce. Garcia-Macia et al. (2016) point out that a significant share of innovations is due to incumbents' quality 
updates of their own products. We consider that the reallocation effect in the current model holds at least partly even after introducing incumbents' quality updates to their own product lines, because such an extension does not directly change the effect of nominal growth on product or firm values. However, it is important to study how incorporating directed R\&D will change our results quantitatively.

\section{References}

Acemoglu, D., U. Akcigit, H. Alp, N. Bloom, and W. Kerr (2018). Innovation, reallocation, and growth. American Economic Review 108(11), 3450-91.

Adam, K. and H. Weber (2019). Optimal Trend Inflation. American Economic Review 109(2), 702-737.

Aghion, P. and P. Howitt (1992). A Model of Growth through Creative Destruction. Econometrica 60(2), 323-51.

Ai, C. and E. C. Norton (2003). Interaction terms in logit and probit models. Economics Letters 80(1), 123 - 129.

Alfaro, L., A. Charlton, and F. Kanczuk (2009, December). Plant-Size Distribution and Cross-Country Income Differences. In NBER International Seminar on Macroeconomics 2008, NBER Chapters, pp. 243-272. National Bureau of Economic Research, Inc.

Arawatari, R., T. Hori, and K. Mino (2018). On the nonlinear relationship between inflation and growth: A theoretical exposition. Journal of Monetary Economics 94(C), 79-93.

Argente, D., M. Lee, and S. Moreira (2018). Innovation and product reallocation in the great recession. Journal of Monetary Economics 93, 1 - 20.

Baily, M. N., C. Hulten, and D. Campbell (1992). Productivity dynamics in manufacturing plants. Brookings Papers on Economic Activity. Macroeconomics.

Bartelsman, E. and M. Doms (2000). Understanding productivity: Lessons from longitudinal microdata. Journal of Economic Literature 38, 569-594. 
Bartelsman, E., J. Haltiwanger, and S. Scarpetta (2004). Microeconomic evidence of creative destruction in industrial and developing countries. IZA Discussion Papers.

Bernard, A. B., J. Eaton, J. B. Jensen, and S. Kortum (2003). Plants and productivity in international trade. American Economic Review 93(4), 1268-1290.

Bhandari, A., D. Evans, M. Golosov, and T. J. Sargent (2018). Inequality, business cycles, and monetary-fiscal policy. Working Paper 24710, National Bureau of Economic Research.

Bhattarai, S. and R. Schoenle (2014). Multiproduct Firms and Price-setting: Theory and Evidence from U.S. Producer Prices. Journal of Monetary Economics 66, 178 $-192$.

Bilbiie, F. O., I. Fujiwara, and F. Ghironi (2014). Optimal monetary policy with endogenous entry and product variety. Journal of Monetary Economics 64(0), 1 20.

Burstein, A. and C. Hellwig (2008). Welfare costs of inflation in a menu cost model. American Economic Review 98(2), 438-43.

Caballero, R. and M. L. Hammour (1994). The cleansing effect of recessions. American Economic Review 84(5), 1350-68.

Cao, D., T. Mukoyama, and E. Sager (2018). Firm growth through new establishments.

Chu, A. C. and G. Cozzi (2014). R\&D and Economic Growth in a Cash-in-Advance Economy. International Economic Review 55, 507-524.

Chu, A. C., G. Cozzi, Y. Furukawa, and C.-H. Liao (2017). Inflation and economic growth in a Schumpeterian model with endogenous entry of heterogeneous firms. European Economic Review 98(C), 392-409.

Coibion, O., Y. Gorodnichenko, and J. Wieland (2012). The Optimal Inflation Rate in New Keynesian Models: Should Central Banks Raise Their Inflation Targets in Light of the Zero Lower Bound? Review of Economic Studies 79(4), 1371-1406. 
Fukao, K. and H. U. Kwon (2006). Why Did Japan's TFP Growth Slow Down in the Lost Decade? An Empirical Analysis based on Firm-level Data of Manufacturing Firms. The Japanese Economic Review 57(2), 195-228.

Garcia-Macia, D., C.-T. Hsieh, and P. J. Klenow (2016). How destructive is innovation? NBER Working Paper 22953.

Golosov, M. and R. E. Lucas, Jr. (2007). Menu Costs and Phillips Curves. Journal of Political Economy 115, 171-199.

Goodfriend, M. and R. King (1997). The New Neoclassical Synthesis and the Role of Monetary Policy. In NBER Macroeconomics Annual 1997, Volume 12, NBER Chapters, pp. 231-296. National Bureau of Economic Research, Inc.

Gornemann, N., K. Kuester, and M. Nakajima (2016). Doves for the Rich, Hawks for the Poor? Distributional Consequences of Monetary Policy. (1167).

Grossman, G. M. and E. Helpman (1991). Innovation and Growth in the Global Economy. MIT Press.

Hall, B. H., J. Mairesse, and P. Mohnen (2010). Measuring the Returns to RESD, Volume 2 of Handbook of the Economics of Innovation, Chapter 24, pp. 1033-1082. Elsevier.

Hansen, B. W. and N. L. Hansen (2006). Price Setting Behaviour in Denmark: A Study of CPI Micro Data 1997-2005. Working Papers 39, Danmarks Nationalbank Working Papers.

Higo, M. and Y. Saita (2007). Price Setting in Japan: Evidence from CPI Micro Data. Bank of Japan Working Paper Series 07-E-20, Bank of Japan.

Hopenhayn, H. A. (1992). Entry, Exit, and Firm Dynamics in Long Run Equilibrium. Econometrica 60(5), 1127-1150.

Hsieh, C.-T. and P. J. Klenow (2009). Misallocation and Manufacturing TFP in China and India. The Quarterly Journal of Economics 124(4), 1403-1448.

Hsieh, C.-T. and P. J. Klenow (2018). The Reallocation Myth. Working Papers 18-19, Center for Economic Studies, U.S. Census Bureau. 
Iacoviello, M. (2005). House Prices, Borrowing Constraints, and Monetary Policy in the Business Cycle. American Economic Review 95(3), 739-764.

Keynes, J. M. (1936). The General Theory of Employment, Interest and Money. Palgrave Macmillan.

Khan, A., R. G. King, and A. L. Wolman (2003). Optimal Monetary Policy. Review of Economic Studies 70(4), 825-860.

Klette, T. J. and S. Kortum (2004). Innovating Firms and Aggregate Innovation. Journal of Political Economy 112(5), 986-1018.

Kuroda, H. (2017). Opening remarks. At the 2017 BOJ-IMES Conference Hosted by the Institute for Monetary and Economic Studies, Bank of Japan.

Lentz, R. and D. T. Mortensen (2005). Productivity Growth And Worker Reallocation. International Economic Review 46(3), 731-749.

Lentz, R. and D. T. Mortensen (2008). An Empirical Model of Growth Through Product Innovation. Econometrica 76 (6), 1317-1373.

Lucas, Jr., R. E. (1978). On the Size Distribution of Business Firms. Bell Journal of Economics 9(2), 508-523.

Lucas, Jr., R. E. and B. Moll (2014). Knowledge growth and the allocation of time. Journal of Political Economy 122(1), 1-51.

Luttmer, E. G. J. (2007). Selection, Growth, and the Size Distribution of Firms. The Quarterly Journal of Economics 122(3), 1103-1144.

Malerba, F. and L. Orsenigo (1999). Technological entry, exit and survival: an empirical analysis of patent data. Research Policy 28(6), 643-660.

Melitz, M. J. (2003). The Impact of Trade on Intra-Industry Reallocations and Aggregate Industry Productivity. Econometrica 71(6), 1695-1725.

Midrigan, V. (2011). Menu costs, multiproduct firms, and aggregate fluctuations. Econometrica 79(4), 1139-1180.

Oikawa, K. and K. Ueda (2018). The optimal inflation rate under Schumpeterian growth. Journal of Monetary Economics 100(C), 114-125. 
Poschke, M. (2018). The firm size distribution across countries and skill-biased change in entrepreneurial technology. American Economic Journal: Macroeconomics 10(3), 1-41.

Restuccia, D. and R. Rogerson (2013). Misallocation and productivity. Review of Economic Dynamics 16(1), 1-10.

Santarelli, E., L. Klomp, and A. R. Thurik (2006). Gibrat's Law: An Overview of the Empirical Literature, pp. 41-73. Boston, MA: Springer US.

Schmitt-Grohé, S. and M. Uribe (2010). The Optimal Rate of Inflation. In B. M. Friedman and M. Woodford (Eds.), Handbook of Monetary Economics, Volume 3 of Handbook of Monetary Economics, Chapter 13, pp. 653-722. Elsevier.

Sheshinski, E. and Y. Weiss (1977). Inflation and Costs of Price Adjustment. Review of Economic Studies 44(2), 287-303.

Tybout, J. (2014). The missing middle: Correspondence. Journal of Economic Perspectives 28(4), 235-36.

Wooldridge, J. M. (2010). Econometric Analysis of Cross Section and Panel Data (2nd ed.). Cambridge MA: MIT Press.

Yellen, J. L. (2016). Macroeconomic research after the crisis. At "The Elusive 'Great' Recovery: Causes and Implications for Future Business Cycle Dynamics" 60th Annual Economic Conference sponsored by the Federal Reserve Bank of Boston, Boston, Massachusetts. 
Table 1: Inflation and Reallocation

(a) Sales distribution:

\begin{tabular}{lccc|ccc}
\hline \hline & \multicolumn{3}{c|}{ Top/Middle ratio } & \multicolumn{3}{c}{ Top/Bottom ratio } \\
& $(1)$ & $(2)$ & $(3)$ & $(4)$ & $(5)$ & $(6)$ \\
& OLS & OLS & 2SLS & OLS & OLS & 2 SLS \\
\hline$\hat{\pi}^{\text {input }}\left(\bar{\pi}^{\text {input }}\right.$ for OLS) & $76.19^{* * *}$ & $82.24^{* * *}$ & $107.6^{* * *}$ & $262.9^{* * *}$ & $274.0^{* * *}$ & $447.0^{* * *}$ \\
& $(27.15)$ & $(27.97)$ & $(40.04)$ & $(84.54)$ & $(87.11)$ & $(125.4)$ \\
Financing DI gap (T/M or T/B) & & -0.113 & -0.0632 & & -0.209 & 0.106 \\
& & $(0.182)$ & $(0.199)$ & & $(0.498)$ & $(0.566)$ \\
Financing DI & & -0.358 & $-0.596^{* *}$ & & $-1.224^{*}$ & $-2.044^{* * *}$ \\
& & $(0.229)$ & $(0.252)$ & & $(0.714)$ & $(0.789)$ \\
Industry RS & & 3.979 & 7.561 & & 0.746 & 4.135 \\
& & $(5.939)$ & $(7.650)$ & & $(18.44)$ & $(23.88)$ \\
Constant & 2.441 & -45.81 & -84.74 & 11.37 & 8.541 & -15.22 \\
& $(5.556)$ & $(75.38)$ & $(97.50)$ & $(17.30)$ & $(234.0)$ & $(304.0)$ \\
\hline Year/Industry FE & yes/yes & yes/yes & yes/yes & yes/yes & yes/yes & yes/yes \\
Obs. & 322 & 316 & 274 & 322 & 316 & 274 \\
$\bar{R}^{2}$ & 0.480 & 0.479 & 0.485 & 0.668 & 0.667 & 0.660 \\
$F$ & 9.228 & 8.420 & 8.216 & 18.96 & 17.19 & 15.96 \\
First stage test stats. & & & & & & \\
$\quad$ Underidentification & & & 26.69 & & & 26.70 \\
$\quad$ Weak Identification & & & & & & 166.3 \\
Overidentifiation & & & & & & \\
\hline \hline
\end{tabular}

(b) Employment distribution:

\begin{tabular}{|c|c|c|c|c|c|c|}
\hline & \multicolumn{3}{|c|}{ Top/Middle ratio } & \multicolumn{3}{|c|}{ Top/Bottom ratio } \\
\hline & $\begin{array}{l}(1) \\
\text { OLS }\end{array}$ & $\begin{array}{l}(2) \\
\text { OLS }\end{array}$ & $\begin{array}{c}(3) \\
2 \mathrm{SLS}\end{array}$ & $\begin{array}{l}(4) \\
\text { OLS }\end{array}$ & $\begin{array}{l}(5) \\
\text { OLS }\end{array}$ & $\begin{array}{c}(6) \\
2 \mathrm{SLS}\end{array}$ \\
\hline$\hat{\pi}^{\text {input }}\left(\bar{\pi}^{\text {input }}\right.$ for OLS $)$ & $\begin{array}{c}0.608 \\
(1.371)\end{array}$ & $\begin{array}{l}1.656 \\
(1.332)\end{array}$ & $\begin{array}{l}7.788^{* * *} \\
(1.870)\end{array}$ & $\begin{array}{c}0.907 \\
(3.684)\end{array}$ & $\begin{array}{c}3.544 \\
(3.662)\end{array}$ & $\begin{array}{c}19.26^{* * *} \\
(5.190)\end{array}$ \\
\hline Financing DI gap (T/M or $\mathrm{T} / \mathrm{B})$ & & $\begin{array}{l}-0.0243^{* * *} \\
(0.00829)\end{array}$ & $\begin{array}{l}-0.0198^{* *} \\
(0.00950)\end{array}$ & & $\begin{array}{c}0.0202 \\
(0.0208)\end{array}$ & $\begin{array}{c}0.0356 \\
(0.0235)\end{array}$ \\
\hline Financing DI & & $\begin{array}{c}-0.0241^{* *} \\
(0.0109)\end{array}$ & $\begin{array}{c}-0.0257^{* *} \\
(0.0118)\end{array}$ & & $\begin{array}{l}-0.0483 \\
(0.0300)\end{array}$ & $\begin{array}{c}-0.0464 \\
(0.0326)\end{array}$ \\
\hline Industry RS & & $\begin{array}{c}1.121^{* * *} \\
(0.282)\end{array}$ & $\begin{array}{c}1.678^{* * *} \\
(0.356)\end{array}$ & & $\begin{array}{c}2.748^{* * *} \\
(0.773)\end{array}$ & $\begin{array}{l}4.488^{* * *} \\
(0.984)\end{array}$ \\
\hline Constant & $\begin{array}{l}4.459^{* * *} \\
(0.280)\end{array}$ & $\begin{array}{c}-9.438^{* * *} \\
(3.571)\end{array}$ & $\begin{array}{c}-15.69^{* * *} \\
(4.537)\end{array}$ & $\begin{array}{c}11.06^{* * *} \\
(0.754)\end{array}$ & $\begin{array}{r}-23.54^{* *} \\
(9.800)\end{array}$ & $\begin{array}{c}-45.21^{* * *} \\
(12.49)\end{array}$ \\
\hline Year/Industry FE & yes/yes & yes/yes & yes/yes & yes/yes & yes/yes & yes/yes \\
\hline Obs. & 322 & 316 & 274 & 322 & 316 & 274 \\
\hline $\bar{R}^{2}$ & 0.688 & 0.720 & 0.694 & 0.763 & 0.777 & 0.752 \\
\hline$F$ & 20.68 & 21.75 & 18.55 & 29.64 & 29.21 & 24.40 \\
\hline $\begin{array}{l}\text { First stage test stats. } \\
\text { Underidentification }\end{array}$ & & & 166.2 & & & 166.2 \\
\hline Weak Identification & & & 26.67 & & & 26.68 \\
\hline Overidentifiation & & & 32.22 & & & 20.78 \\
\hline
\end{tabular}

Notes: Standard errors are in the parentheses $\left({ }^{*} p<0.10,{ }^{* *} p<0.05,{ }^{* * *} p<0.01\right)$. The reported identification test statistics in the 2SLS regressions are Anderson canonical correlations LM statistics for underidentification tests, Cragg-Donald Wald F statistics for weak identification tests, and Sagan statistics for overidentification tests. 
Table 2: Inflation and Firm Growth

\begin{tabular}{|c|c|c|c|c|}
\hline & \multicolumn{2}{|c|}{ Sales growth } & \multicolumn{2}{|c|}{ Employment growth } \\
\hline & $(1)$ & $(2)$ & $(3)$ & (4) \\
\hline & OLS & 2SLS & OLS & 2SLS \\
\hline$\hat{\pi}^{\text {input }}\left(\bar{\pi}^{\text {input }}\right.$ for OLS $)$ & $\begin{array}{c}-3.092^{* * *} \\
(0.338)\end{array}$ & $\begin{array}{c}-2.505^{* * *} \\
(0.394)\end{array}$ & $\begin{array}{c}-1.437^{* * *} \\
(0.135)\end{array}$ & $\begin{array}{c}-1.836^{* * *} \\
(0.158)\end{array}$ \\
\hline Lagged sales & $\begin{array}{l}-0.885^{* * *} \\
(0.00588)\end{array}$ & $\begin{array}{l}-0.884^{* * *} \\
(0.00589)\end{array}$ & $\begin{array}{l}-0.141^{* * *} \\
(0.00235)\end{array}$ & $\begin{array}{l}-0.141^{* * *} \\
(0.00236)\end{array}$ \\
\hline Lagged sales $\times \hat{\pi}^{\text {input }}\left(\bar{\pi}^{\text {input }}\right)$ & $\begin{array}{l}0.298^{* * *} \\
(0.0367)\end{array}$ & $\begin{array}{l}0.284^{* * *} \\
(0.0419)\end{array}$ & $\begin{array}{l}0.155^{* * *} \\
(0.0147)\end{array}$ & $\begin{array}{l}0.199^{* * *} \\
(0.0168)\end{array}$ \\
\hline Financing DI & $\begin{array}{l}0.00495^{* * *} \\
(0.000240)\end{array}$ & $\begin{array}{l}0.00476^{* * *} \\
(0.000241)\end{array}$ & $\begin{array}{c}0.00278^{* * *} \\
(0.0000959)\end{array}$ & $\begin{array}{c}0.00279^{* * *} \\
(0.0000963)\end{array}$ \\
\hline Industry RS & $\begin{array}{c}-0.0340^{* * *} \\
(0.00567)\end{array}$ & $\begin{array}{c}-0.0292^{* * *} \\
(0.00571)\end{array}$ & $\begin{array}{r}-0.000986 \\
(0.00227)\end{array}$ & $\begin{array}{l}-0.00125 \\
(0.00228)\end{array}$ \\
\hline Lagged leverage & $\begin{array}{c}0.102^{* * *} \\
(0.00471)\end{array}$ & $\begin{array}{c}0.102^{* * *} \\
(0.00471)\end{array}$ & $\begin{array}{c}0.00548^{* * *} \\
(0.00188)\end{array}$ & $\begin{array}{c}0.00557^{* * *} \\
(0.00188)\end{array}$ \\
\hline Constant & $\begin{array}{l}7.793^{* * *} \\
(0.0824)\end{array}$ & $\begin{array}{l}7.732^{* * *} \\
(0.0829)\end{array}$ & $\begin{array}{l}1.234^{* * *} \\
(0.0330)\end{array}$ & $\begin{array}{l}1.241^{* * *} \\
(0.0332)\end{array}$ \\
\hline Year/Firm FE & yes/yes & yes/yes & yes/yes & yes/yes \\
\hline Obs. & 189447 & 189447 & 189447 & 189447 \\
\hline Num. firms & 19703 & 19703 & 19703 & 19703 \\
\hline \multicolumn{5}{|l|}{$R^{2}$} \\
\hline within & 0.139 & 0.139 & 0.0381 & 0.0382 \\
\hline overall & 0.00182 & 0.00179 & 0.000130 & 0.000132 \\
\hline$F$ & 1144.7 & 1142.3 & 279.8 & 280.9 \\
\hline$F_{f}$ & 3.905 & 3.902 & 3.333 & 3.334 \\
\hline
\end{tabular}

Notes: Standard errors are in the parentheses $\left({ }^{*} p<0.10,{ }^{* *} p<0.05,{ }^{* * *} p<0.01\right) . F_{f}$ represents the $\mathrm{F}$ test statistics with the null hypothesis that all firm fixed effects are zero. 
Table 3: R\&D, exit

\begin{tabular}{|c|c|c|c|c|c|c|c|c|c|c|}
\hline & \multicolumn{5}{|c|}{ OLS } & \multicolumn{5}{|c|}{ 2SLS } \\
\hline & (1) & (2) & (3) & (4) & (5) & (6) & (7) & (8) & (9) & (10) \\
\hline & $\log R \& D$ & $\frac{R \& D}{\text { Sales }}$ & $\log \frac{R \& D}{\text { Wage }}$ & $\log \frac{R \& D}{\text { Total salary }}$ & Exit & $\log R \& D$ & $\frac{R \& D}{\text { Sales }}$ & $\log \frac{R \& D}{\text { Wage }}$ & $\log \frac{R \& D}{\text { Total salary }}$ & Exit \\
\hline$\hat{\pi}^{\text {input }}\left(\bar{\pi}^{\text {input }}\right.$ for OLS $)$ & $\begin{array}{c}-0.913^{* * *} \\
(0.348)\end{array}$ & $\begin{array}{c}-0.0740^{* * *} \\
(0.0234)\end{array}$ & $\begin{array}{c}-3.760^{* * *} \\
(0.745)\end{array}$ & $\begin{array}{c}-0.903^{* * *} \\
(0.0892)\end{array}$ & $\begin{array}{l}0.408^{* * *} \\
(0.0937)\end{array}$ & $\begin{array}{c}-1.204^{* * *} \\
(0.415)\end{array}$ & $\begin{array}{c}-0.0982^{* * *} \\
(0.0279)\end{array}$ & $\begin{array}{c}-4.348^{* * *} \\
(0.888)\end{array}$ & $\begin{array}{c}-1.236^{* * *} \\
(0.106)\end{array}$ & $\begin{array}{c}0.535^{* * *} \\
(0.108)\end{array}$ \\
\hline Lagged sales & $\begin{array}{c}0.247^{* * *} \\
(0.00645)\end{array}$ & $\begin{array}{c}0.000649 \\
(0.000433)\end{array}$ & $\begin{array}{l}0.434^{* * *} \\
(0.0138)\end{array}$ & $\begin{array}{l}0.0237^{* * * *} \\
(0.00165)\end{array}$ & $\begin{array}{c}-0.0217^{* * *} \\
(0.00167)\end{array}$ & $\begin{array}{c}0.246^{* * *} \\
(0.00646)\end{array}$ & $\begin{array}{c}0.000613 \\
(0.000434)\end{array}$ & $\begin{array}{l}0.432^{* * *} \\
(0.0138)\end{array}$ & $\begin{array}{l}0.0232^{* * *} \\
(0.00165)\end{array}$ & $\begin{array}{c}-0.0215^{* * *} \\
(0.00167)\end{array}$ \\
\hline Lagged sales $\times \hat{\pi}^{\text {input }}\left(\bar{\pi}^{\text {input }}\right)$ & $\begin{array}{l}0.0601^{*} \\
(0.0342)\end{array}$ & $\begin{array}{c}0.00672^{* * *} \\
(0.00230)\end{array}$ & $\begin{array}{l}0.349^{* * *} \\
(0.0733)\end{array}$ & $\begin{array}{l}0.0866^{* * *} \\
(0.00877)\end{array}$ & $\begin{array}{c}-0.0425^{* * *} \\
(0.0102)\end{array}$ & $\begin{array}{c}0.0642 \\
(0.0397)\end{array}$ & $\begin{array}{c}0.00932^{* * *} \\
(0.00267)\end{array}$ & $\begin{array}{l}0.394^{* * *} \\
(0.0850)\end{array}$ & $\begin{array}{l}0.120^{* * *} \\
(0.0102)\end{array}$ & $\begin{array}{c}-0.0574^{* * *} \\
(0.0115)\end{array}$ \\
\hline Financing DI & $\begin{array}{c}-0.000600^{* *} \\
(0.000255)\end{array}$ & $\begin{array}{c}-0.0000725^{* *} \\
(0.0000171)\end{array}$ & $\begin{array}{l}0.00181^{* * *} \\
(0.000545)\end{array}$ & $\begin{array}{c}-0.000556^{* * *} \\
(0.0000652)\end{array}$ & $\begin{array}{l}-0.0000749 \\
(0.0000664)\end{array}$ & $\begin{array}{c}-0.000518^{* * *} \\
(0.000256)\end{array}$ & $\begin{array}{c}-0.0000710^{* * *} \\
(0.0000172)\end{array}$ & $\begin{array}{l}0.00187^{* * *} \\
(0.000548)\end{array}$ & $\begin{array}{c}-0.000535^{* * *} \\
(0.0000655)\end{array}$ & $\begin{array}{l}-0.0000742 \\
(0.0000666)\end{array}$ \\
\hline Industry RS & $\begin{array}{l}0.0642^{* * *} \\
(0.00621)\end{array}$ & $\begin{array}{l}0.00123^{* * *} \\
(0.000417)\end{array}$ & $\begin{array}{c}0.0361^{* * *} \\
(0.0133)\end{array}$ & $\begin{array}{c}0.00489^{* * *} \\
(0.00159)\end{array}$ & $\begin{array}{l}-0.00170 \\
(0.00159)\end{array}$ & $\begin{array}{l}0.0620^{* * *} \\
(0.00625)\end{array}$ & $\begin{array}{l}0.00123^{* * *} \\
(0.000420)\end{array}$ & $\begin{array}{c}0.0346^{* * *} \\
(0.0134)\end{array}$ & $\begin{array}{c}0.00466^{* * *} \\
(0.00160)\end{array}$ & $\begin{array}{l}-0.00172 \\
(0.00159)\end{array}$ \\
\hline Lagged leverage & $\begin{array}{c}-0.0149^{* * *} \\
(0.00504)\end{array}$ & $\begin{array}{l}-0.000184 \\
(0.000339)\end{array}$ & $\begin{array}{c}-0.0278^{* *} \\
(0.0108)\end{array}$ & $\begin{array}{c}-0.00354^{* * *} \\
(0.00129)\end{array}$ & $\begin{array}{c}-0.00566^{* * *} \\
(0.00134)\end{array}$ & $\begin{array}{c}-0.0148^{* * *} \\
(0.00504)\end{array}$ & $\begin{array}{l}-0.000175 \\
(0.000339)\end{array}$ & $\begin{array}{c}-0.0274^{* *} \\
(0.0108)\end{array}$ & $\begin{array}{c}-0.00340^{* * *} \\
(0.00129)\end{array}$ & $\begin{array}{c}-0.00569^{* * *} \\
(0.00134)\end{array}$ \\
\hline Constant & $\begin{array}{c}-2.097^{* * *} \\
(0.0911)\end{array}$ & $\begin{array}{l}-0.00423 \\
(0.00612)\end{array}$ & $\begin{array}{c}-2.051^{* * *} \\
(0.195)\end{array}$ & $\begin{array}{c}-0.174^{* * *} \\
(0.0233)\end{array}$ & $\begin{array}{l}0.181^{* * *} \\
(0.0231)\end{array}$ & $\begin{array}{c}-2.065^{* * *} \\
(0.0917)\end{array}$ & $\begin{array}{l}-0.00387 \\
(0.00616)\end{array}$ & $\begin{array}{c}-2.021^{* * *} \\
(0.196)\end{array}$ & $\begin{array}{c}-0.167^{* * *} \\
(0.0235)\end{array}$ & $\begin{array}{l}0.180^{* * *} \\
(0.0232)\end{array}$ \\
\hline Year/Firm FE & yes/yes & yes/yes & yes/yes & yes/yes & yes/yes & yes/yes & yes/yes & yes/yes & yes/yes & yes/yes \\
\hline Obs. & 58445 & 58445 & 58418 & 58418 & 175463 & 58445 & 58445 & 58418 & 58418 & 175463 \\
\hline Num. firms & 14474 & 14474 & 14473 & 14473 & 18865 & 14474 & 14474 & 14473 & 14473 & 18865 \\
\hline \multicolumn{11}{|l|}{$R^{2}$} \\
\hline within & 0.0637 & 0.00849 & 0.0537 & 0.0453 & 0.0284 & 0.0639 & 0.00854 & 0.0537 & 0.0462 & 0.0285 \\
\hline overall & 0.652 & 0.0384 & 0.617 & 0.261 & 0.00349 & 0.652 & 0.0361 & 0.616 & 0.258 & 0.00348 \\
\hline$F$ & 124.5 & 15.69 & 103.8 & 86.90 & 199.3 & 124.9 & 15.78 & 103.8 & 88.55 & 199.6 \\
\hline$F_{f}$ & 24.42 & 12.16 & 16.13 & 11.52 & 3.940 & 24.42 & 12.16 & 16.08 & 11.53 & 3.941 \\
\hline
\end{tabular}

Notes: Standard errors are in the parentheses $\left({ }^{*} p<0.10,{ }^{* *} p<0.05,{ }^{* * *} p<0.01\right) . F_{f}$ represents the $\mathrm{F}$ test statistics with the null hypothesis that all firm fixed effects are zero. 
Table 4: Moments: Data and Model for Japan

Target moments

Calibrated parameters

\begin{tabular}{|c|c|c|c|c|c|}
\hline & Data & Model & & & values \\
\hline$g$ & 0.017 & 0.017 & $\rho$ & discount factor & 0.013 \\
\hline$R$ & 0.034 & 0.034 & $\max q$ in & $\bar{\phi}(q)$ & 1.457 \\
\hline$\Delta$ & 1.42 & 1.44 & $\zeta$ & & 3.610 \\
\hline $\operatorname{Med}[W L] / \mathrm{E}[W L]$ & 0.26 & 0.32 & $c_{0}$ & $R \& D$ cost & 47.21 \\
\hline $\operatorname{Std}[W L] / E[W L]$ & 5.53 & 5.89 & $c_{1}$ & & 0.795 \\
\hline $\operatorname{Med}[Y] / \mathrm{E}[Y]$ & 0.18 & 0.32 & $h$ & mass of entrants & 0.688 \\
\hline $\operatorname{Std}[Y] / \mathrm{E}[Y]$ & 7.06 & 5.79 & $\kappa$ & menu cost & 0.015 \\
\hline $\operatorname{Cor}[Y / L, L]$ & 0.19 & -0.10 & & & \\
\hline $\operatorname{Cor}[Y, W L]$ & 0.74 & 1.00 & & & \\
\hline $\mathrm{E}[d Y / Y]$ & 0.07 & 0.01 & \multicolumn{3}{|c|}{ Key variables inferred from the calibration } \\
\hline $\operatorname{Std}[d Y / Y]$ & 1.25 & 0.12 & & & values \\
\hline \multirow[t]{3}{*}{$\operatorname{Cor}[d Y / Y, Y]$} & 0.00 & -0.01 & $\delta$ & creative destruction rate & 0.050 \\
\hline & & & $\eta$ & entry rate & 0.007 \\
\hline & & & $\underline{q}$ & threshold of $q$ & 1.031 \\
\hline
\end{tabular}

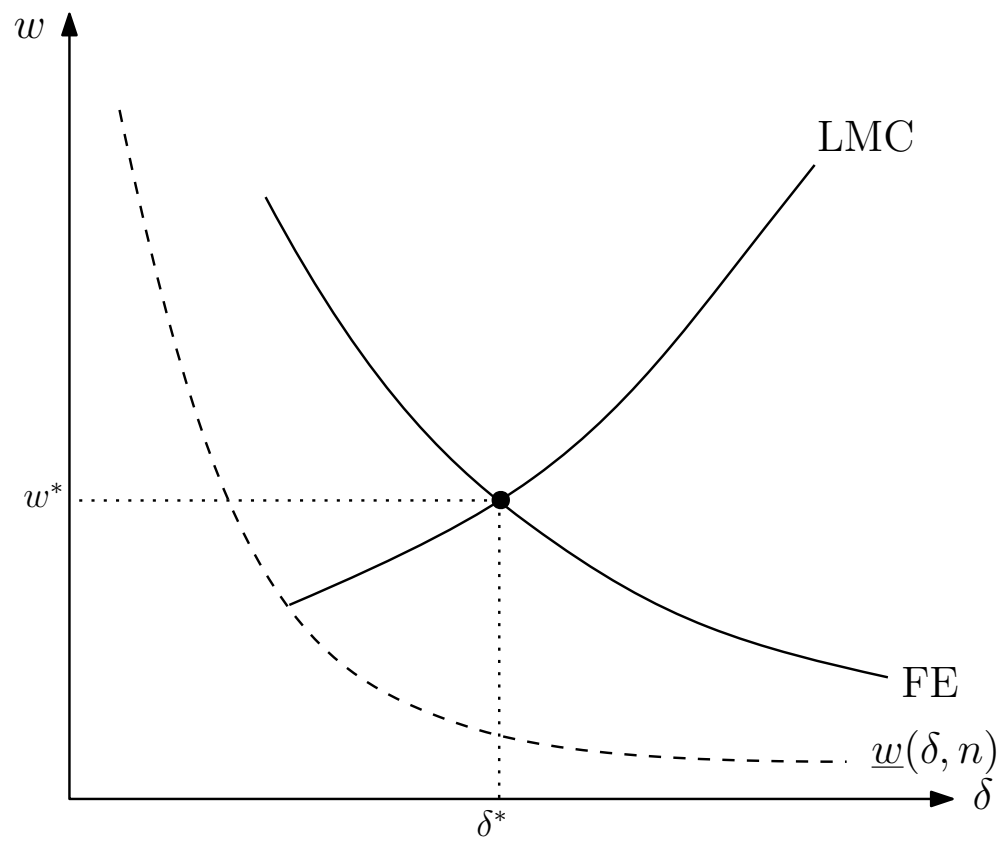

Figure 1: Stationary Equilibrium. FE and LMC stand for the free-entry condition and the labor market clearing condition, respectively. 
Table 5: Moments: Data and Model for Denmark

Target moments

\begin{tabular}{ccc} 
& Data & Model \\
\hline$g$ & 0.019 & 0.019 \\
$R$ & 0.085 & 0.085 \\
$\Delta$ & 1.29 & 1.28
\end{tabular}

$\begin{array}{ccc}\operatorname{Med}[W L] / \mathrm{E}[W L] & 0.54 & 0.58 \\ \operatorname{Std}[W L] / \mathrm{E}[W L] & 2.30 & 1.50\end{array}$

$\operatorname{Med}[Y] / \mathrm{E}[Y] \quad 0.51 \quad 0.55$

$\operatorname{Std}[Y] / \mathrm{E}[Y] \quad 2.01 \quad 1.52$

Cor $[Y / L, L] \quad 0.20 \quad 0.12$

Cor $[Y, W L] \quad 0.85 \quad 1.00$

$\mathrm{E}[d Y / Y] \quad-0.03 \quad 0.09$

$\begin{array}{ccc}\operatorname{Std}[d Y / Y] & 0.55 & 0.22 \\ \operatorname{Cor}[d Y / Y, Y] & -0.06 & 0.12\end{array}$

Calibrated parameters

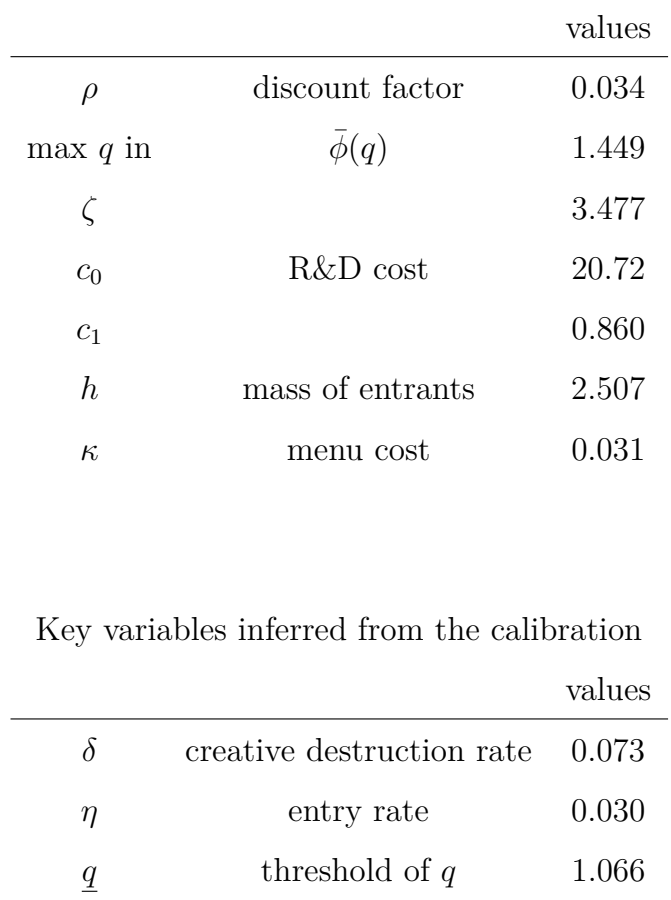
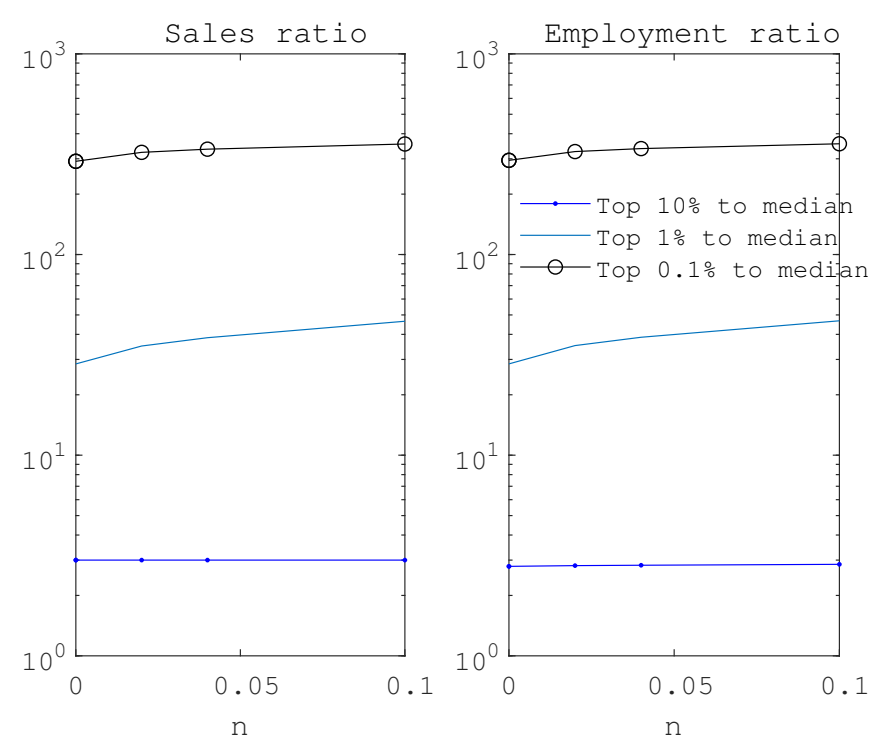

Figure 2: Sales and Employment Dispersion for Changes in the Nominal Growth Rate Note: The figures show changes in economic variables when the nominal growth rate, $n$, changes. 


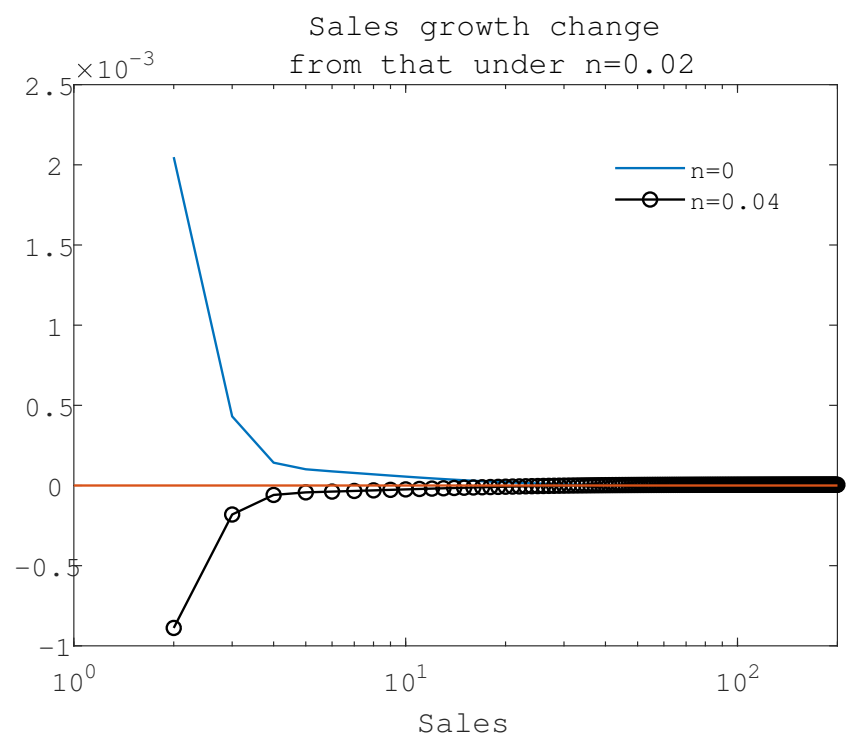

Figure 3: Sales Growth Difference Relative to the Case with $n=0.02$, by Firm Size
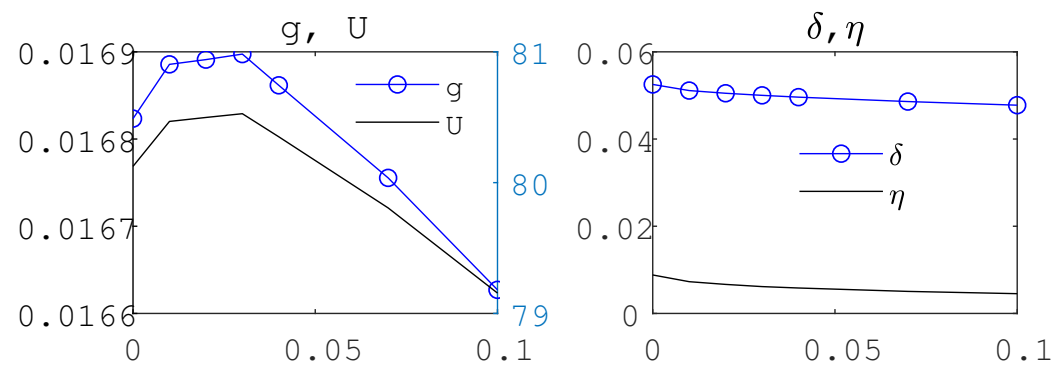

n

n
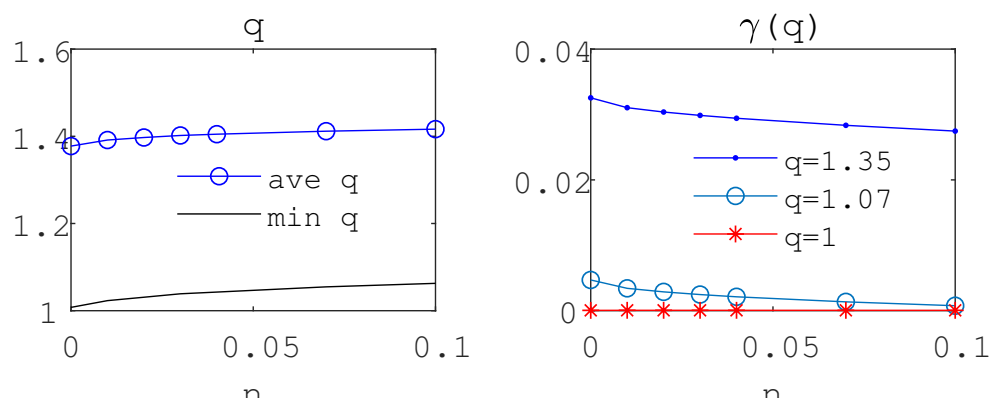

Figure 4: Effects of Nominal Growth 

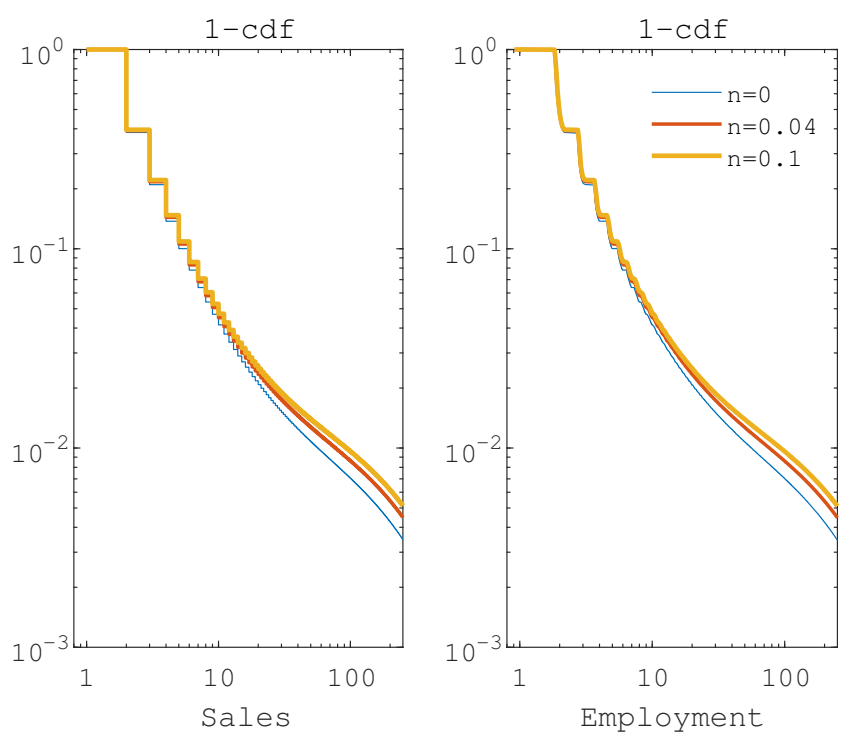

Figure 5: Changes in the Tail Distributions of Sales and Employment for Changes in the Nominal Growth Rate

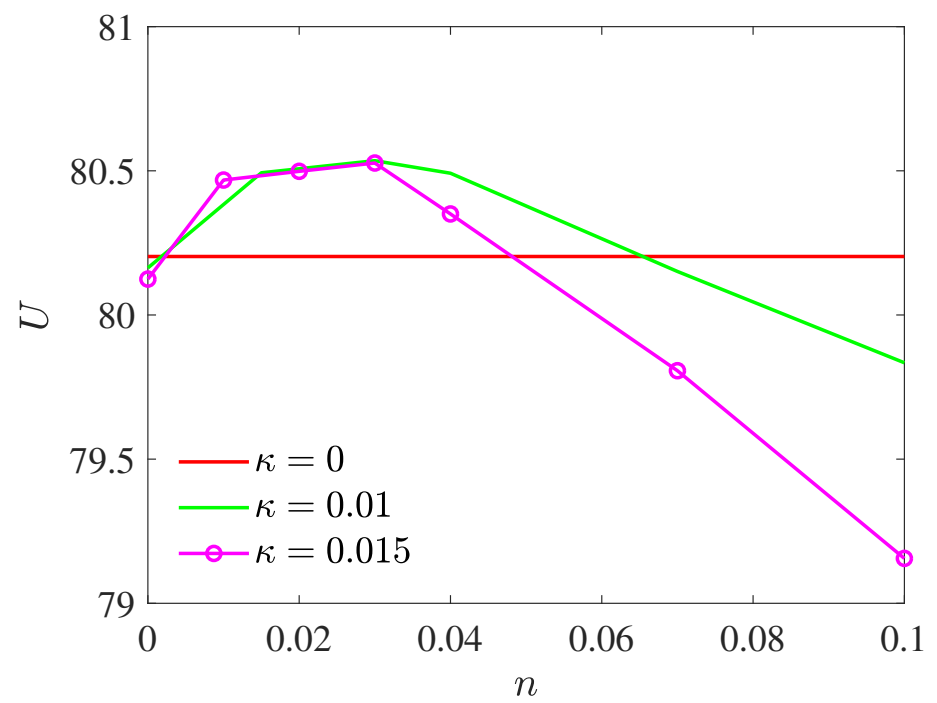

Figure 6: Effects of Nominal Growth on Welfare for Different Menu Cost Values 


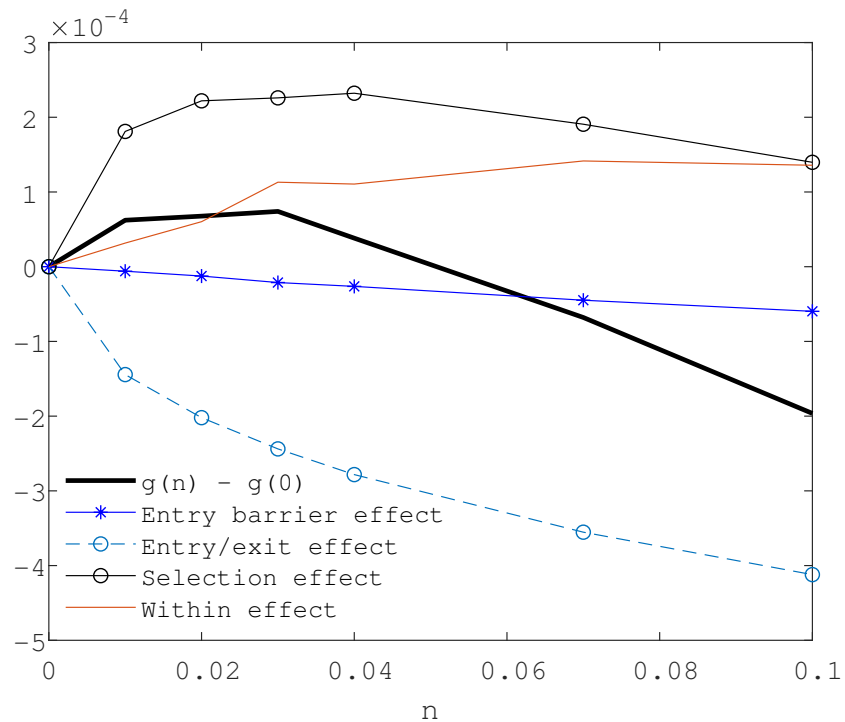

Figure 7: Growth Decomposition of $g(n)-g(0)$
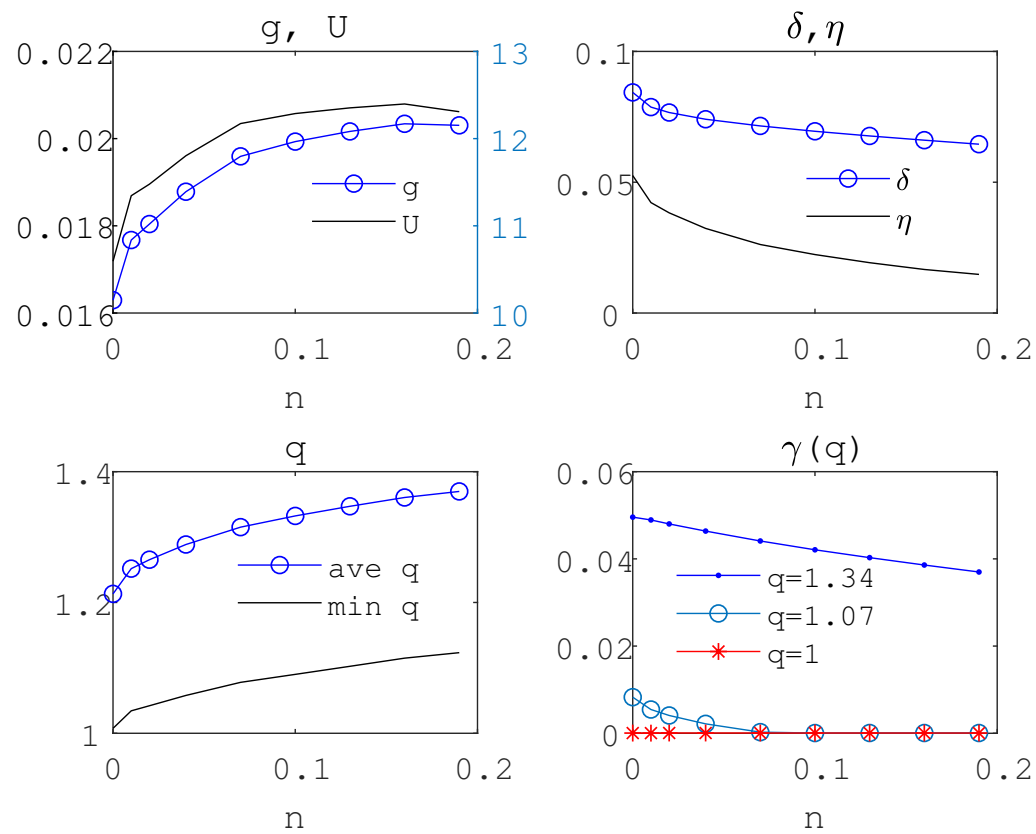

Figure 8: Effects of Nominal Growth for Denmark 

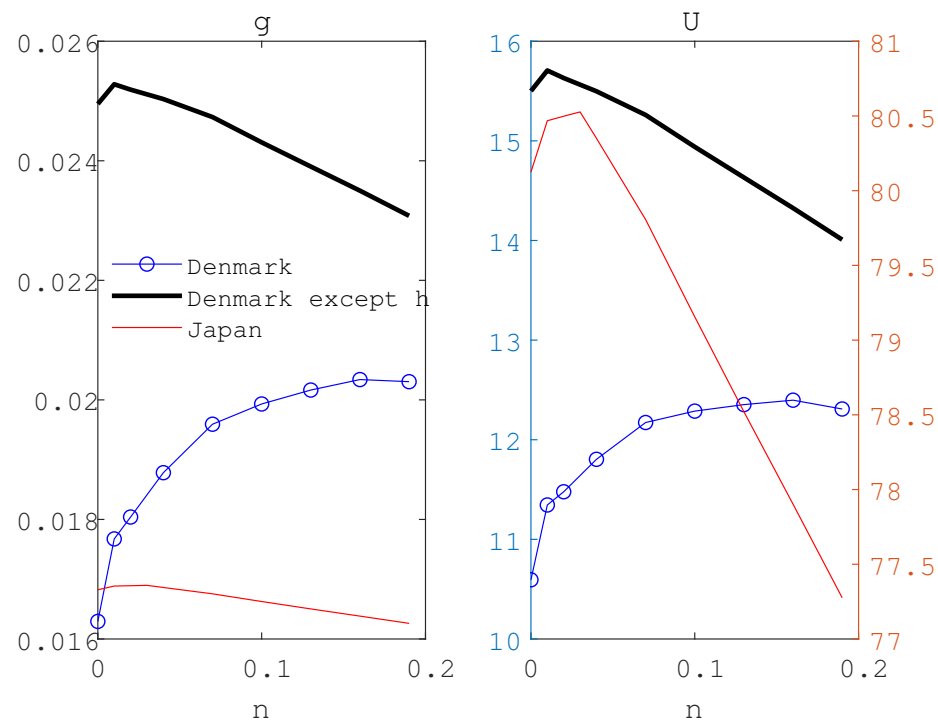

Figure 9: Danish Economy with Potential Entrants, $h$, in Japan Note: Intertemporal utility $U$ is plotted on the left axis for Denmark except $h$ and on the right axis for Japan. 


\title{
Appendix for "Reallocation Effects of Monetary Policy"
}

\author{
${\text { Daisuke Miyakawa* } \text { Koki Oikawa }^{\dagger} \text { Kozo Ueda }}^{\ddagger}$
}

June 3, 2020

*Hitotsubashi University (Email: dmiyakawa@hub.hit-u.ac.jp)

†Waseda University (Email: oikawa.koki@gmail.com)

${ }^{\ddagger}$ Waseda University and Centre for Applied Macroeconomic Analysis (CAMA) (Email: kozo.ueda@waseda.jp) 


\section{A Data Summary and Robustness Checks}

\section{A.1 Summary Statistics}

Table A.1 summarizes the basic statistics of the data, while Table A.2 shows the input inflation and firm-size dispersion measures for 14 manufacturing industries that are examined in Section 2.

\section{A.2 Robustness Checks}

In this subsection, we check the robustness of the main results reported in Section 2. In the following regressions, we use the sales growth regression in Column (2) of Table 2 as the benchmark specification and investigate its robustness when we take additional factors into account.

\section{Firm Age}

In the benchmark regression, we do not consider age effects to see the relation between firm performance and inflation. However, as Jovanovic (1982) argues that older firms tend to show better performance, pooling ages might lead to the case that they work as a compounding factor for the relation between inflation and growth. Thus, we split the sample of firms into four firm-age groups by quartiles in the pooled sample and rerun the sales growth regression for each group. We calculate the ages using the years since establishment of the firm.

Table A.3 shows the regression results that indicate the signs and significance levels of the coefficients are highly consistent across age groups.

\section{High vs Low Leverage Ratio}

To investigate the effect of credit constraints further, we split firms into high and low-leveraged groups. Table A.4 shows the regression results, in which the left two columns use the median of leverage ratios in the pooled sample as the threshold, and the right two columns use the 75 percentile point as the threshold. All results are consistent with our benchmark result. Notably, firms in the highest leveraged class are relatively more sensitive to inflation as seen in Column (4). 


\section{Other Year-windows to Define Trend Inflation}

In the benchmark case, we use the 3-year average of input price inflation to obtain trend inflation. Here, we check the robustness of our results using different yearwindows: 1-year and 5-year average. Year-windows for the real sales growth and the instrument variable (international primary commodity price) and the number of lags for firm size and leverage are adjusted consistently. As seen in Table A.5, the results for the 5-year average are similar with both the OLS and 2SLS. On the other hand, the effects of inflation are relatively weak when we take the 1-year lagged inflation, for which the coefficient of the interaction term is significantly positive with the 2SLS, while the coefficient of inflation is negative but insignificant. This result indicates that it is important to consider trend inflation, not a temporary inflation volatility, as a trigger of the reallocation effect.

\section{Wage Inflation}

Our theoretical model considers labor as the only input to produce final goods, while ignoring intermediate goods. Thus, the use of wage inflation rather than input price inflation is more consistent for the model. Here, we confirm that the main empirical result is robust when we use wage inflation as the inflation variable. Using data on the total salary and the number of employees in each firm, we calculate the average wage and its change (3-year average) in each industry and size (10 size-groups by deciles), and rerun the regression by replacing the input price inflation with wage inflation. Because whether the inflation in international primary commodity prices is a good instrumental variable is unclear, we also try two other variables separately as instruments. The first alternative is the country-level unemployment rate obtained from Labor Force Survey by the Ministry of Internal Affairs and Communications, and the second alternative is the change in the number of new job applications from General Employment Placement Situation by the Ministry of Health, Labor and Welfare (we use the IVs corresponding to the same year-window to capture wage trend inflation). Both instruments are exogenous at the firm level but it affects industry-level wage inflation. Because both variables are not sectoral variables, we multiply them by industry dummies to define the instruments.

Table A.6 shows that the cross-term positively and significantly affects firm-level sales growth with each IV setting, implying that the negative effect of wage inflation 
is partly offset when lagged sales are large, which is consistent with our benchmark result. ${ }^{1}$

\section{Non-manufacturing Sector}

Although the limited availability of input price data prevents us from extending our sample to non-manufacturing, we can do so if we use wage inflation as the inflation variable. Now, the sample includes all non-manufacturing industries in our dataset as long as the Tankan financing position D.I. are reported by the Bank of Japan. The list of industries are construction, real estate, lease, retail, wholesale, transportation and postal service, information and communication, and electricity and gas. We use wage inflation and the instruments described above.

Table A.7 shows that a similar result shows up for the relation between firm performance and inflation although the coefficients of wage inflation and the cross term are smaller in absolute terms than those in the manufacturing sector (Table A.6). This quantitative difference between the sectors is consistent with our story because non-manufacturing firms have relatively lower intensity in R\&D activity than manufacturing firms. Hence, the implication derived from the main text is applicable to the overall economy while the quantitative effect depends on the share of manufacturing and non-manufacturing sectors.

\section{Exit Measures under the Cut-off Problem}

In the main text, we set an exit flag of one for each firm if it disappears from the data and never reappears. Given such disappearance occurs when a new company appears through consolidation (in the Basic Survey of Japanese Business Structure and Activities, the Ministry of Economy, Trade and Industry assigns a new ID to the new company), we exclude the firms that experience an M\&A in the same years when they disappear from the dataset. ${ }^{2}$ Behind our definition of exit is the premise that going under the cut-off (i.e., 50 employees) indicates a significant risk of true exit so that our exit flag is informative.

\footnotetext{
${ }^{1}$ The signs of wage inflation and the interaction term in the OLS is the opposite to those in the 2SLS. Because wages are an endogenous variable, a regression without an IV may be subject to a bias.

${ }^{2}$ We identify M\&A by the RECOF data. We exclude a firm from the sample if it is listed as involved in any type of $\mathrm{M} \& \mathrm{~A}$ in its last year in our main dataset. About $5 \%$ of the "exits" are related to $\mathrm{M} \& \mathrm{~A}$.
} 
Here we check the robustness of the regression result on exit that is reported in Table 3 by using stricter exit measures so that we can double-check the abovementioned premise. The cut-off problem matters if a firm disappears at around the final year of the dataset, 2015. For example, a firm disappears in 2014 might just downsize temporarily and come back in the data in 2016. To exclude such a possible reappearance after the final year of the data, we set fixed years of allowance to measure exit, and we exclude the sample during those years of allowance. If we extend the years of allowance, the definition of exit becomes stricter at a cost of narrowed sample periods.

Table A.8 shows the regression results when the allowance years for exit definition are three, six, and nine years. The length of allowance is reasonable because the average years of the interval between disappearance and reappearance among firms that have temporary absence are about 3.5, and about $95 \%$ of those firms reappear within nine years. The regression results are robust to the choice of allowance years.

Although the fact that some firms reappear in the data is a pain in the neck, it also gives us an interesting picture on the heterogeneity of the exiting firms. To compare the final exit with the temporary exit, we redefine exit such that a firm exits in year $t$ if it exists in $t$ but disappears in $t+1$, following Nishimura et al. (2005). Then, we label each exit with a temporary exit if an exiting firm reappears later or with final exit if it never reappears. Figure A.1 shows distributions of the log of the number of employees at exit. The mean log employment at final exit and temporary exit are 4.7 and 5.0, respectively. We reject the null hypothesis that there is no gap in the mean employment sizes between the two groups, with a $t$-test with equal variances ( $t$-statistics is 31.9). Hence, temporary-exit firms frequently have larger employment than final-exit firms. We observe that sales at temporary exit are also greater than sales at final exit. These facts imply size-dependent heterogeneity in exiting behavior: larger firms are less likely to truly exit from the market even if it goes under the cut-off of the survey.

\section{Entry and Re-entry on the Dataset}

We find that inflation has a robust relation with neither industry-level nor economywide entry rates. We have two options to define entry. The first option is to use the data on establishment years. However, the entry rate based on this measure is incredibly low at $0.04 \%$ on average annually, most probably because of the cut-off 
constraint. The second option is to use the timing of the first appearance on the data. However, as naturally expected, there is a spike around 50 employees when we draw a histogram of the number of employees over firms at their first appearance. It is unusual that firms have 50 employees or more at entry. ${ }^{3}$

To see if entering firms hire more than 50 employees, we compare the size distributions of new entrants and re-entering firms. We define entry such that a firm enters in year $t$ if it appears in $t$ while it is not on the data in $t-1$, and separate samples into new entry and re-entry in our data. As shown in Figure A.2, re-entry tends to occur with a greater number of employees that rejects the null hypothesis of no gap in the $t$-test. It holds true when we take sales as an alternative measure of firm size.

This fact reinforces our conjecture that entrants tend to have fewer employees than the cut-off level. If the majority share of new entrants hire more than 50 at entry (and appear on the data from the beginning), there should be a much smaller or no gap between new entries and re-entries in our data for employment and sales.

Unlike exit, we do not have any information before entry. Because firm growth is heterogeneous and fluctuates especially when young, our dataset is not appropriate to estimate the timing of entry of each firm and the aggregate entry rate.

\section{Sample Size Harmonization at the First-Stage Estimation}

In the main text, we use firm-level explanatory variables such as lagged sales and lagged leverage at the first-stage regression to follow the standard IV method even though the dependent variable, input inflation, is measured at the industry level. Therefore, the estimates are obtained in a way that an industry $\times$ year with more observations has a larger weight. Basically, we do not consider that this weight causes a problem because our dataset is a complete survey of the target industries with a clear cut-off condition. Thus, there is no arbitrary sample selection. However, one concern might be about a possible bias on this instrumented inflation.

To check the robustness of the main results from this viewpoint, we make the numbers of observations within each industry $\times$ year all the same in the first-stage regression. Within each industry $\times$ year cell, we divide firms into 10 size-groups by

\footnotetext{
${ }^{3}$ According to Economic Census for Business Activity in 2016 by the Ministry of Internal Affairs and Communications and the Ministry of Economy, Trade and Industry, the average number of employees per establishment among all industries (including both incumbents and entrants) is 10.6 in Japan.
} 
deciles of real sales and define $\overline{\log (\text { Sales })}$ ist as the mean of log of real sales among firm in industry $i$, size-group $s$ and year $t$. Other explanatory variables $\mathbf{Z}_{i s t}$ are similarly defined. The first-stage equation regressed is

$$
\bar{\pi}_{i t}^{\text {input }}=\alpha_{0}+\alpha_{1 i} \bar{\pi}_{t}^{\mathrm{ipc}}+\alpha_{2} \overline{\log (\text { Sales })}_{i s t-3}+\overline{\mathbf{Z}}_{i s t}^{\prime} \alpha+\theta_{i s}+\theta_{t}+u_{i s t},
$$

where $\theta_{i s}$ is the industry $\times$ size-group fixed effect. With this modification, each bin of industry $\times$ year has 10 observations. Table A.9 shows the results of the second-stage regression that uses the instrumented inflation from the first-stage regression with (A.1). The estimates are consistent with Tables 2 and 3 in the main text in terms of signs, sizes, and significance levels.

\section{B Model Details}

\section{B.1 Derivation of Equation (16) in the Main Text}

The firm value comprises profit flows from each product plus the return from R\&D that depends on $k$. Let the present-discount value of the sum of profit flows for a product with $\tau_{i}$ be $\nu_{\tau_{i}}(q \mid \delta, n)$. Rewrite the bellman equation:

$$
\begin{aligned}
\rho v_{k}\left(T_{k}, q \mid \delta, w, n\right)=\max _{\gamma} \sum_{j \notin \Omega} & {\left[\Pi^{0}\left(\xi_{0} e^{-n \tau_{j}} \mid q\right)+\frac{\partial v_{k}\left(T_{k}^{\prime}, q \mid \delta, w, n\right)}{\partial \tau_{j}}\right] } \\
& +\sum_{j \in \Omega}\left[\Pi^{0}\left(\xi_{0} e^{-n \tau_{j}} \mid q\right)-\kappa+\frac{\partial v_{k}\left(T_{k}^{\prime}, q \mid \delta, w, n\right)}{\partial \tau_{j}}\right] \\
& -k w c(\gamma) \\
+ & k \gamma\left[v_{k+1}\left(\left\{T_{k}^{\prime}, 0\right\}, q \mid \delta, w, n\right)-v_{k}\left(T_{k}^{\prime}, q \mid \delta, w, n\right)\right] \\
+ & k \delta\left[\frac{1}{k} \sum_{j=1}^{k} v_{k-1}\left(T_{k-1,<j>}^{\prime}, q \mid \delta, w, n\right)-v_{k}\left(T_{k}^{\prime}, q \mid \delta, w, n\right)\right] .
\end{aligned}
$$

Thus, our guess for the value function is

$$
v_{k}\left(T_{k}, q \mid \delta, w, n\right)=\sum_{i=1}^{k} \nu_{\tau_{i}}(q \mid \delta, n)+k \psi(q \mid \delta, w, n)
$$


The guess of equation (A.3) yields

$$
\frac{1}{k} \sum_{i=1}^{k} v_{k-1}\left(T_{k-1,<i>}^{\prime}, q \mid \delta, w, n\right)=\left(1-\frac{1}{k}\right) \sum_{i=1}^{k} \nu_{\tau_{i}^{\prime}}(q \mid \delta, n)+(k-1) \psi(q \mid \delta, w, n),
$$

and thus,

$$
\frac{1}{k} \sum_{i=1}^{k} v_{k-1}\left(T_{k-1,<i>}^{\prime}, q \mid \delta, w, n\right)-v_{k}\left(T_{k}^{\prime}, q \mid \delta, w, n\right)=-\frac{1}{k} \sum_{i=1}^{k} \nu_{\tau_{i}^{\prime}}(q \mid \delta, n)-\psi(q \mid \delta, w, n) .
$$

Equation (A.2) is then written as

$$
\begin{aligned}
\rho \sum_{i=1}^{k} \nu_{\tau_{i}}(q \mid \delta, n)+\rho k \psi(q \mid \delta, w, n) \\
=\sum_{i=1}^{k}\left[\Pi^{0}\left(\xi_{0} e^{-n \tau_{i}}\right)-I\left\{\tau_{i}=\Delta(q \mid \delta, n)\right\} \kappa+\frac{\partial \nu_{\tau_{i}}(q \mid \delta, n)}{\partial \tau}\right] \\
\quad-\delta \sum_{i=1}^{k} \nu_{\tau_{i}^{\prime}}(q \mid \delta, n)-k \delta \psi(q \mid \delta, w, n) \\
\quad+k \max _{\gamma}\left\{\gamma\left[v_{k+1}\left(\left\{T_{k}^{\prime}, 0\right\}, q \mid \delta, w, n\right)-v_{k}\left(T_{k}^{\prime}, q \mid \delta, w, n\right)\right]-w c(\gamma)\right\}
\end{aligned}
$$

We observe that

$$
\rho \nu_{\tau_{i}}(q \mid \delta, n)= \begin{cases}\Pi^{0}\left(\xi_{0} e^{-n \tau_{i}}\right)+\frac{\partial \nu_{\tau_{i}}(q \mid \delta, n)}{\partial \tau}-\delta \nu_{\tau_{i}}(q \mid \delta, n) & \text { for } \tau_{i} \in[0, \Delta(q \mid \delta, n)), \\ \Pi^{0}\left(\xi_{0} e^{-n \tau_{i}}\right)-\kappa+\frac{\partial \nu_{0}(q \mid \delta, n)}{\partial \tau}-\delta \nu_{0}(q \mid \delta, n) & \text { for } \tau_{i}=\Delta(q \mid \delta, n) .\end{cases}
$$

Therefore, we have

$$
(\rho+\delta) \psi(q \mid \delta, w, n)=\max _{\gamma}\left\{\gamma\left[\nu_{0}(q \mid \delta, n)+\psi(q \mid \delta, w, n)\right]-w c(\gamma)\right\}
$$

The R\&D intensity is determined as

$$
\nu_{0}(q \mid \delta, n)+\psi(q \mid \delta, w, n)=w c^{\prime}(\gamma)
$$

Using equation (A.8) to eliminate $\psi$, this first-order condition can be rewritten as

$$
w c^{\prime}(\gamma)=\max _{\gamma \in[0, \rho+\delta)} \frac{(\rho+\delta) \nu_{0}(q \mid \delta, n)-w c(\gamma)}{\rho+\delta-\gamma}
$$


where the constraint $\gamma<\rho+\delta$ should hold because $\psi$ is not well defined otherwise.

\section{B.2 Firm Size and Quality Distribution}

The stationary distribution satisfies

$$
\begin{aligned}
& \gamma(q \mid \delta, w, n)(k-1) M_{k-1}(q \mid \delta, w, n)+\delta(k+1) M_{k+1}(q \mid \delta, w, n) \\
& =(\gamma(q \mid \delta, w, n)+\delta) k M_{k}(q \mid \delta, w, n) \quad \text { for } k \geq 2
\end{aligned}
$$

with

$$
\begin{aligned}
\phi(q \mid \delta, n) \eta & =\delta M_{1}(q \mid \delta, w, n), \\
\phi(q \mid \delta, n) \eta+2 \delta M_{2}(q \mid \delta, w, n) & =(\gamma(q \mid \delta, w, n)+\delta) M_{1}(q \mid \delta, w, n) .
\end{aligned}
$$

Equation (A.11) leads to

$$
M_{k}(q \mid \delta, w, n)=\frac{\phi(q \mid \delta, n) \eta}{\delta k}\left(\frac{\gamma(q \mid \delta, w, n)}{\delta}\right)^{k-1} .
$$

The mass of type- $q$ firms in the stationary state, $M(q \mid \delta, w, n)$, is $\sum_{k=1}^{\infty} M_{k}(q \mid \delta, w, n)$. If $\gamma(q \mid \delta, w, n)<\delta$ for almost all $q$, then $M(q \mid \delta, w, n)$ is well defined as

$$
M(q \mid \delta, w, n)=\frac{\eta}{\delta}\left[\log \left(\frac{\delta}{\delta-\gamma(q \mid \delta, w, n)}\right)\right] \frac{\delta \phi(q \mid \delta, n)}{\gamma(q \mid \delta, w, n)}
$$

The condition $\sup _{q} \gamma(q \mid \delta, w, n)<\delta$ is supported when $w$ is sufficiently large. The threshold level of $w$ is determined by the first-order condition of the maximization in equation (A.10). Let $\underline{w}(q \mid \delta, n)$ be the individual threshold wage level such that $\gamma(q \mid \delta, w, n)<\delta$ for $w>\underline{w}(q \mid \delta, n)$. The threshold wage in the whole economy is $\underline{w}(\delta, n) \equiv \sup _{q} \underline{w}(q \mid \delta, n)$. Since $\nu(q \mid \delta, n)$ is monotonically increasing in $q$ and $\lim _{q \rightarrow \infty} \nu(q \mid \delta, n)=\frac{1}{\rho+\delta}-\kappa$, we have

$$
\underline{w}(\delta, n)= \begin{cases}\frac{1-(\rho+\delta) \kappa}{c(\delta)+\rho c^{\prime}(\delta)} & \text { if } \bar{q} \rightarrow \infty \\ \frac{(\rho+\delta) \nu(\bar{q} \mid \delta, n)}{c(\delta)+\rho c^{\prime}(\delta)} & \text { if } \bar{q} \text { is finite. }\end{cases}
$$

Two remarks are in order. First, $\underline{w}$ is decreasing in the creative destruction rate $\delta$. 
This is because a decline in the creative destruction rate and a decline in the wage both stimulate incumbents' R\&D. Second, $\underline{w}$ is independent of $n$ if the support of $\bar{\phi}$ is not bounded, while greater nominal growth enlarges the admissible set otherwise.

Any equilibrium has $w>\underline{w}(\delta, n)$. Because the total mass of products is one, the creative destruction rate must equal the sum of the entry rate and the creation rates of all the incumbents. As long as $w>\underline{w}(\delta, n)$, we have

$$
\begin{aligned}
\delta & =\eta+\int_{\underline{q}(\delta, n)}^{\infty} d q \sum_{k=1}^{\infty} k M_{k}(q \mid \delta, w, n) \gamma(q \mid \delta, w, n) \\
& =\eta \int_{\underline{q}(\delta, n)}^{\infty} \frac{\delta \phi(q \mid \delta, n)}{\delta-\gamma(q \mid \delta, w, n)} d q
\end{aligned}
$$

which leads to the following equation:

$$
1=\eta \int_{\underline{q}(\delta, n)}^{\infty} \frac{\phi(q \mid \delta, n)}{\delta-\gamma(q \mid \delta, w, n)} d q
$$

\section{B.3 Proofs}

Lemma A.1 Suppose $n>0 . \Delta(q \mid \delta, n)$ is increasing in $q$ and decreasing in $|n| .|n| \Delta$ is increasing in $|n|$. Moreover, $\Delta(q \mid \delta, n)$ is increasing in $\delta$.

Proof of Lemma A.1 From equations (11) and (12) in the main text, we obtain

$$
q \kappa=\frac{e^{n \Delta}-e^{-(\rho+\delta-n) \Delta}}{\rho+\delta}-\frac{1-e^{-(\rho+\delta-n) \Delta}}{\rho+\delta-n} .
$$


The total differentiation of equation (A.18) is

$$
\begin{aligned}
\kappa d q- & \frac{n e^{n \Delta}\left(1-e^{-(\rho+\delta) \Delta}\right)}{\rho+\delta} d \Delta \\
= & {\left[e^{n \Delta}\left(\frac{\Delta e^{-(\rho+\delta) \Delta}}{\rho+\delta}-\frac{1-e^{-(\rho+\delta) \Delta}}{(\rho+\delta)^{2}}\right)-\left(\frac{\Delta e^{-(\rho+\delta-n) \Delta}}{\rho+\delta-n}-\frac{1-e^{-(\rho+\delta-n) \Delta}}{(\rho+\delta-n)^{2}}\right)\right] d \delta } \\
& +\left[\frac{\Delta e^{n \Delta}\left(1-e^{-(\rho+\delta) \Delta}\right)}{\rho+\delta}+\frac{\Delta e^{-(\rho+\delta-n) \Delta}}{\rho+\delta-n}-\frac{1-e^{-(\rho+\delta-n) \Delta}}{(\rho+\delta-n)^{2}}\right] d n \\
= & e^{-(\rho+\delta-n) \Delta}\left[\left(\frac{\Delta}{\rho+\delta}-\frac{e^{(\rho+\delta) \Delta}-1}{(\rho+\delta)^{2}}\right)-\left(\frac{\Delta}{\rho+\delta-n}-\frac{e^{(\rho+\delta-n) \Delta}-1}{(\rho+\delta-n)^{2}}\right)\right] d \delta \\
& +\left[q \kappa \Delta+\left(\frac{\Delta}{\rho+\delta-n}-\frac{1-e^{-(\rho+\delta-n) \Delta}}{(\rho+\delta-n)^{2}}\right)\right] d n \\
= & e^{-(\rho+\delta-n) \Delta}\left[h_{2}(\rho+\delta, \Delta)-h_{2}(\rho+\delta-n, \Delta)\right] d \delta+\left[q \kappa \Delta+h_{1}(\rho+\delta-n, \Delta)\right] d n
\end{aligned}
$$

where we substitute equation (A.18) in the second equality. Functions $h_{1}$ and $h_{2}$ are defined in Lemma A.2 below. Owing to Lemma A.2, the signs of the coefficients for $d \delta$ and $d n$ are determined uniquely; and we have $d \Delta / d q>0, d \Delta / d \delta>0$, and $d \Delta / d n<0$.

Lemma A.2 Define the following functions over $x \neq 0$ with $y \geq 0$ by

$$
\begin{aligned}
& h_{1}(x, y)=\frac{y}{x}-\frac{1-e^{-x y}}{x^{2}}, \\
& h_{2}(x, y)=\frac{y}{x}-\frac{e^{x y}-1}{x^{2}} .
\end{aligned}
$$

Then, for any $x \neq 0$ and $y \geq 0$, the following relationships hold:

$$
\begin{gathered}
h_{1}(x, y) \geq 0, \quad h_{2}(x, y) \leq 0, \\
\frac{\partial h_{1}(x, y)}{\partial x} \leq 0, \quad \frac{\partial h_{2}(x, y)}{\partial x} \leq 0,
\end{gathered}
$$

with equalities only when $y=0$. 
Proving the signs of the functions is straightforward:

$$
\begin{aligned}
& h_{1}(x, y)=\frac{x y-\left(1-e^{-x y}\right)}{x^{2}} \geq 0, \\
& h_{2}(x, y)=\frac{x y-\left(e^{x y}-1\right)}{x^{2}} \leq 0
\end{aligned}
$$

For the derivative of $h_{1}$, we have

$$
\frac{\partial h_{1}(x, y)}{\partial x}=-\frac{2\left(1+e^{-x y}\right)}{x^{3}}\left[\frac{x y}{2}-\frac{1-e^{-x y}}{1+e^{-x y}}\right] .
$$

Since $y \geq 0$ and

$$
\frac{x y}{2} \geq \frac{1-e^{-x y}}{1+e^{-x y}} \quad \text { if and only if } x y \geq 0,
$$

we have $\frac{\partial h_{1}(x, y)}{\partial x} \leq 0$.

Last, the partial derivative of $h_{2}$ is expressed as

$$
\frac{\partial h_{2}(x, y)}{\partial x}=-\frac{2\left(1+e^{x y}\right)}{x^{3}}\left[\frac{x y}{2}-\frac{1-e^{-x y}}{1+e^{-x y}}\right] .
$$

Thus, the sign of $\partial h_{2}(x, y) / \partial x$ is equivalent to that of $\partial h_{1}(x, y) / \partial x$.

Lemma A.3 $\tilde{\nu}_{0}(q \mid \delta, n)$ is strictly increasing in $q$ and strictly decreasing in $\delta$. For $n>0$,

$$
\frac{\partial \tilde{\nu}_{0}(q \mid \delta, n)}{\partial n}<0, \quad \frac{\partial^{2} \tilde{\nu}_{0}(q \mid \delta, n)}{\partial q \partial n}>0 .
$$

Proof of Lemma A.3 The former part of the proposition is evident: $\partial \tilde{\nu}_{0}(q \mid \delta, n) / \partial q>$ 0 and $\partial \widetilde{\nu}_{0}(q \mid \delta, n) / \partial \delta<0$. As for the latter part of the proposition,

$$
\begin{aligned}
\frac{\partial^{2} \tilde{\nu}_{0}(q \mid \delta, n)}{\partial q \partial n} & =\frac{\partial(n \Delta)}{\partial(n)} \frac{\partial^{2} \tilde{\nu}_{0}(q \mid \delta, n)}{\partial q \partial(n \Delta)}=-\frac{1}{\rho+\delta} \frac{\partial(n \Delta)}{\partial(n)} \frac{e^{n \Delta}}{q}\left(n \frac{\partial \Delta}{\partial q}-\frac{1}{q}\right) \\
& =-\frac{1}{\rho+\delta} \frac{\partial(n \Delta)}{\partial(n)} \frac{e^{n \Delta}}{q} \frac{(\rho+\delta) q \kappa-\left(e^{n \Delta}-e^{-(\rho+\delta-n) \Delta}\right)}{q\left(e^{n \Delta}-e^{-(\rho+\delta-n) \Delta}\right)} \\
& =\frac{1}{\rho+\delta} \frac{\partial(n \Delta)}{\partial(n)} \frac{e^{n \Delta}}{q} \frac{1}{q\left(e^{n \Delta}-e^{-(\rho+\delta-n) \Delta}\right)} \frac{\rho+\delta}{\rho+\delta-n}\left(1-e^{-(\rho+\delta-n) \Delta}\right) \\
& >0 .
\end{aligned}
$$


For the derivation of the last line, we use Lemma A.1.

Proof of Proposition 1 From equation (12) in the main text, $\kappa \geq \frac{1}{\rho+\delta}$ implies that $\underline{q}(\delta, n) \rightarrow \infty$ and no firm can yield profits. Thus, we assume $\kappa<\frac{1}{\rho+\delta}$ below.

When $n=0$, then $\underline{q}(\delta, 0)=\frac{1}{1-(\rho+\delta) \kappa}$.

When $n>0, \tilde{\nu}_{0}(q \mid \delta, n)<0$ implies that $\Delta(q \mid \delta, n)>\frac{\log q}{n} \equiv \bar{\Delta}$. From the first-order condition when choosing $\Delta$ :

$$
q \kappa=\frac{e^{n \Delta}-e^{-(\rho+\delta-n) \Delta}}{\rho+\delta}-\frac{1-e^{-(\rho+\delta-n) \Delta}}{\rho+\delta-n},
$$

$\underline{q}(\delta, n)$ is $q$ that satisfies

$$
\kappa=\frac{1-e^{-(\rho+\delta) \bar{\Delta}}}{\rho+\delta}-\frac{1 / q-e^{-(\rho+\delta) \bar{\Delta}}}{\rho+\delta-n}=\frac{1}{\rho+\delta}-\frac{q^{-1}-\frac{n}{\rho+\delta} q^{-\frac{\rho+\delta}{n}}}{\rho+\delta-n} .
$$

Let $A_{1}(q, n)$ be the right-hand side of equation (A.20). Note that $A_{1}(1, n)=0$ and $\lim _{q \rightarrow \infty} A_{1}(q, n)=\frac{1}{\rho+\delta}$.

Suppose $n \neq \rho+\delta$. Because of

$$
\frac{\partial A_{1}(q, n)}{\partial q}=\frac{\rho+\delta}{q^{2}} \frac{1-q^{1-\frac{\rho+\delta}{n}}}{\rho+\delta-n}>0
$$

$\underline{q}(\delta, n)$ uniquely exists. Next, $\partial \underline{q} / \partial n<0$ comes from

$$
\frac{\partial A_{1}(q, n)}{\partial n}=\frac{q^{-\frac{\rho+\delta}{n}}}{(\rho+\delta-n)^{2}}\left[1+\log q^{\frac{\rho+\delta}{n}-1}-q^{\frac{\rho+\delta}{n}-1}\right]<0 \quad \text { for } q>1
$$

Moreover, since $A_{1}(q, n)$ is continuous as $n \downarrow 0, \underline{q}(\delta, n)>1 /[1-(\rho+\delta) \kappa]$ for $n>0$. Thus, $\partial \underline{q}(\delta, n) / \partial n>0$.

For the case of $n=\rho+\delta, A_{1}(q, n)=\frac{1-1 / q}{\rho+\delta}$, which implies $A_{1}(q, n)$ is strictly increasing in $q$. Further, we have

$$
\lim _{n \rightarrow \rho+\delta} \frac{\partial A_{1}(q, n)}{\partial n}=\lim _{n \rightarrow \rho+\delta}-\frac{1}{2} \frac{\rho+\delta}{n^{2}} q^{-\frac{\rho+\delta}{n}}(\log q)^{2}=-\frac{(\log q)^{2}}{2 q(\rho+\delta)}<0 .
$$

Thus, $\underline{q}(\delta, n)$ uniquely exists and $\partial \underline{q}(\delta, n) / \partial n>0$. 
Proof of Proposition 2 From equation (A.10), the optimal $\gamma$ satisfies

$$
\frac{(\rho+\delta) \nu_{0}(q \mid \delta, n)}{w}=c(\gamma)+(\rho+\delta-\gamma) c^{\prime}(\gamma), \quad \gamma \in[0, \rho+\delta)
$$

From the strict convexity of $c(\gamma)$ and the assumption of $c(0)=0, \gamma$ has a unique interior solution if $w$ is sufficiently large. $\partial \gamma / \partial|n|<0$ and $\partial \gamma / \partial w<0$ result from the first-order condition. For the effect of $\delta,(\rho+\delta) \nu_{0}(q \mid \delta, n)$ is strictly decreasing in $\delta$ for $n \geq 0$ from Lemma A.1. Thus, $\partial \gamma / \partial \delta<0$. In addition,

$$
\begin{gathered}
\frac{\partial \gamma}{\partial q}=\frac{1}{w c^{\prime \prime}(\gamma)} \frac{\rho+\delta}{\rho+\delta-\gamma} \frac{\partial \nu_{0}(q \mid \delta, n)}{\partial q}>0 \\
\frac{\partial^{2} \gamma}{\partial q \partial n}=\frac{1}{w c^{\prime \prime}(\gamma)} \frac{\rho+\delta}{\rho+\delta-\gamma} \frac{\partial^{2} \nu_{0}(q \mid \delta, n)}{\partial q \partial n} \begin{cases}>0 & \text { for } n>0 \\
<0 & \text { for } n<0\end{cases} \\
\frac{\partial^{2} \gamma}{\partial q \partial w}=-\frac{1}{w^{2} c^{\prime \prime}(\gamma)} \frac{\rho+\delta}{\rho+\delta-\gamma} \frac{\partial \nu_{0}(q \mid \delta, n)}{\partial q}<0
\end{gathered}
$$

Proof of Proposition 3 The free-entry (FE) condition is given by

$$
\begin{aligned}
\int_{1}^{\infty} \bar{\phi}(q) v_{1}(\{0\}, q \mid \delta, w, n) d q & =w c^{\prime}\left(\gamma_{\eta}(\delta, w, n)\right) \\
\gamma_{\eta}(\delta, w, n) & \equiv \frac{\eta(\delta, w, n)}{1-\bar{\Phi}(\underline{q}(\delta, n))} \frac{1}{h}
\end{aligned}
$$

This equation can be rewritten as

$$
\int_{\underline{q}(\delta, n)}^{\infty} \bar{\phi}(q) c^{\prime}(\gamma(q \mid \delta, w, n)) d q=c^{\prime}\left(\gamma_{\eta}(\delta, w, n)\right)
$$

by substituting $\psi$ from equation (A.10).

Fix $\delta>0$ arbitrarily. The right-hand side of equation (A.26) is increasing in $w$ because $\eta(\delta, w, n)$ is increasing in $w$ and $c^{\prime}(\gamma)$ is positive. On the other hand, the lefthand side of the equation is decreasing in $w$ because $\gamma(q \mid \delta, w, n)$ is decreasing in $w$ for any $q>\underline{q}(\delta, n)$ in the admissible set. Hence, if $w$ satisfies the free-entry condition for a given $\delta$, then $w$ is unique. Its existence is guaranteed if we can prove that the 
right-hand side is zero at $\underline{w}(\delta, n)$, because the left-hand side is strictly positive at $\underline{w}(\delta, n)$ and both the left- and right-hand sides are continuous for $w \geq \underline{w}(\delta, n)$. The right-hand side is zero at $\underline{w}(\delta, n)$ because equation (A.14) implies that in the limit of $\delta=\gamma, \eta$ converges to zero to make the total measure of firms finite.

As long as $\eta$ is positively correlated with $\delta$ in condition (A.17), an increase in $\delta$ drives up $\gamma_{\eta}(\delta, w, n)$ for given $w$ and $n$, while it reduces the left-hand side of equation (A.26) through an increase in $\underline{q}(\delta, n)$ and declines in $\gamma(q \mid \delta, w, n)$ for any $q>\underline{q}(\delta, n)$. Thus, when $\delta$ increases, it is necessary to have a smaller $w$ to satisfy the FE, because $\gamma$ is decreasing in $w$ and $\gamma_{\eta}$ is increasing in $w$.

Proof of Proposition 4 Define $\delta_{F E}(w, n)$ as $\delta$ that satisfies equation (A.17) and the FE condition, (A.26). Consider $\eta\left(\delta_{F E}(w, n), w, n\right)$ by substituting $\delta_{F E}(w, n)$ into equation (A.17). As $w \rightarrow \infty, \underline{w}^{-1}(w, n)$ and the left-hand side of equation (A.26) go to zero, so that $\eta$ (and $\delta$ ) must be zero. Then, $\lim _{w \rightarrow \infty} \eta\left(\delta_{F E}(w, n), w, n\right)=0$. On the other hand, when $w \rightarrow 0, \delta_{F E}(w, n) \rightarrow \infty$ because $\underline{w}^{-1}(w, n) \rightarrow \infty$. Thus, $\lim _{w \rightarrow 0} \eta\left(\delta_{F E}(w, n), w, n\right)=\infty$. In terms of employment, when $w \rightarrow \infty$, we observe

$$
\lim _{w \rightarrow \infty} L_{R, \text { ent }}\left(\delta_{F E}(w, n), w, n\right)=0, \quad \lim _{w \rightarrow \infty} L_{R, i n c}=\lim _{w \rightarrow \infty} L_{X}=0
$$

which leads to $\lim _{w \rightarrow \infty} L_{D}\left(\delta_{F E}(w, n), w, n\right)=0$ for any $n \geq 0$. When $w \rightarrow 0$, $\lim _{w \rightarrow 0} L_{R, \text { ent }}\left(\delta_{F E}(w, n), w, n\right)=\infty$ for any $n \geq 0$, which implies $\lim _{w \rightarrow 0} L_{D}\left(\delta_{F E}(w, n), w, n\right)=$ $\infty$.

Because $L_{D}$ is continuous in $w$, at least one $w$ that satisfies $L_{D}\left(\delta_{F E}(w, n), w, n\right)=$ $L$ exists for any $n \geq 0$.

Since the FE curve lies above the curve of $\underline{w}$, any stationary state has a nondegenerate firm-size distribution. Such a distribution cannot be compatible with no entry, because $\eta=0$ implies that $\underline{q}$ should be the upper bound of the support of $q$ (or infinity) to satisfy the FE condition, (A.26).

\section{B.4 Labor Demand}

Lemma A.4 Fix $\delta>0$ and $n \geq 0$. The cumulative distribution of $K\left(q \mid \delta, w_{1}, n\right)$ stochastically dominates that of $K\left(q \mid \delta, w_{2}, n\right)$ if $w_{1}<w_{2}$. 
Proof of Lemma A.4 From equation (A.17) and the definition of $K, K(q \mid \delta, w, n)$ is increasing in $w$ if and only if

$$
\int_{\underline{q}(\delta, n)}^{\infty}-\frac{\partial \gamma\left(q^{\prime} \mid \delta, w, n\right)}{\partial w} \frac{K\left(q^{\prime} \mid \delta, w, n\right)}{\delta-\gamma\left(q^{\prime} \mid \delta, w, n\right)} d q^{\prime}>-\frac{\partial \gamma(q \mid \delta, w, n)}{\partial w} \frac{1}{\delta-\gamma(q \mid \delta, w, n)} .
$$

The left-hand side is a positive constant for any $q$, while the right-hand side is zero at $q=\underline{q}(\delta, n)$ and monotonically increasing in $q$ from Proposition 2. To keep $\int_{\underline{q}}^{\infty} K(q \mid \delta, w, n) d q=1, \hat{q}>\underline{q}$ exists such that $\partial K / \partial w>0$ if and only if $q<\hat{q}$.

Since $\frac{\partial}{\partial w} \int_{\underline{q}}^{\infty} K\left(q^{\prime} \mid \delta, w, n\right) d q^{\prime}$ must be zero by definition,

$$
0=\frac{\partial}{\partial w} \int_{\underline{q}}^{\hat{q}} K\left(q^{\prime} \mid \delta, w, n\right) d q^{\prime}+\frac{\partial}{\partial w} \int_{\hat{q}}^{\infty} K\left(q^{\prime} \mid \delta, w, n\right) d q^{\prime}
$$

Hence, for any $q \in(\hat{q}, \infty)$,

$$
\frac{\partial}{\partial w} \int_{\underline{q}}^{\hat{q}} K\left(q^{\prime} \mid \delta, w, n\right) d q^{\prime}>-\frac{\partial}{\partial w} \int_{\hat{q}}^{q} K\left(q^{\prime} \mid \delta, w, n\right) d q^{\prime}
$$

Therefore, $\frac{\partial}{\partial w} \int_{\underline{q}}^{q} K\left(q^{\prime} \mid \delta, w, n\right) d q^{\prime}>0$ for any finite $q$, which implies the stated stochastic dominance.

We assume that this effect does not dominate.

Proposition A.1 $L_{R, e n t}$ is increasing in $w . L_{R, \text { inc }}$ is decreasing in $w . L_{X}$ is decreasing in $w$ if the distribution effect is sufficiently weak.

Proof of Proposition A.1 Fix $\delta>0$ and $n$ arbitrarily. $L_{R, e n t}$ is increasing in $w$ because

$$
\frac{\partial \gamma_{\eta}(\delta, w, n)}{\partial w} \propto \frac{\partial \eta(\delta, w, n)}{\partial w}>0 .
$$

Next, the response of $L_{R, i n c}$ to an increase in $w$ is

$$
\begin{aligned}
\frac{\partial L_{R, i n c}}{\partial w}= & \int_{\underline{q}(\delta, n)}^{\infty} \frac{\partial K(q \mid \delta, w, n)}{\partial w} c(\gamma(q \mid \delta, w, n)) d q \\
& \quad+\int_{\underline{q}(\delta, n)}^{\infty} K(q \mid \delta, w, n) c^{\prime}(\gamma(q \mid \delta, w, n)) \frac{\partial \gamma(q \mid \delta, w, n)}{\partial w} d q
\end{aligned}
$$

The last term is negative according to Proposition 2. The first term on the righthand side depends on $\partial K / \partial w$. Because $c(\gamma(q))$ is an increasing function of $q$, Lemma 
A.4 implies that the first term on the right-hand side of equation (A.27) is negative. Hence, R\&D labor demand from incumbents is decreasing in $w$.

The effect of an increase in $w$ on $L_{X}$ is

$$
\frac{\partial L_{X}}{\partial w}=-\frac{L_{X}}{w}+\int_{\underline{q}(\delta, n)}^{\infty} \frac{\partial K(q \mid \delta, w, n)}{\partial w} L_{X, q}(q \mid \delta, w, n) d q
$$

The last term is positive because $L_{X, q}(q \mid \delta, w, n)$ is a decreasing function of $q$ and $K$ is stochastically dominated when $w$ increases, as shown in Lemma A.4. ${ }^{4}$ Thus, to have $L_{X}$ decreasing in $w$, the distribution effect is sufficiently small.

The LMC condition does not necessarily imply a monotonic relation between $\delta$ and $w$. Suppose that $w>\underline{w}(\delta, n)$ and $\eta(\delta, w, n)$ is increasing in $\delta$ in condition (A.17). Then, we have

$$
\begin{aligned}
& \frac{\partial L_{D}}{\partial \delta}=\underbrace{\frac{\partial L_{X}}{\partial \delta}}_{(+)}+\underbrace{\frac{\partial L_{R, i n c}}{\partial \delta}}_{-}+\underbrace{\frac{\partial L_{R, e n t}}{\partial \delta}}_{+} \\
& \frac{\partial L_{D}}{\partial w}=\underbrace{\frac{\partial L_{X}}{\partial w}}_{(-)}+\underbrace{\frac{\partial L_{R, i n c}}{\partial w}}_{-}+\underbrace{\frac{\partial L_{R, e n t}}{\partial w}}_{+}
\end{aligned}
$$

The signs of responses of $L_{X}$ in equations (A.29) are in parentheses because the signs do not hold in general. In equation (A.29a), with a rise in the creative destruction rate, firms extend the interval between price resets, leading to lower markups under positive nominal growth. This is the primary factor that increases production employment. However, a rise in $\delta$ also brings more takeover of product lines with the highest markups. Furthermore, there is a reallocation effect: $K(q \mid \delta, w, n)$ becomes less concentrated with higher $q$, because firm growth tends to be low under a high frequency of creative destruction ${ }^{5}$ but we have higher $q(\delta, n)$.

In equation (A.29b), $\partial L_{X} / \partial w$ could be positive when the reallocation effect is too strong. Lemma A.4 implies that higher $w$ leads to a reduction in average markup and thereby an increase in production.

\footnotetext{
${ }^{4} L_{X, q}(q \mid \delta, w, n)$ is decreasing in $q$ because the benefit from a price revision increases with $q$, and thus, a firm with greater $q$ never waits until the declining real price reaches the lower bound that is optimal for firms with smaller $q$. Hence, the lower bound of the real price, $e^{n \Delta(q \mid \delta, n)}$, is increasing in $q$. The average real price is definitely higher for high-quality firms.

${ }^{5}$ If $\delta$ is extremely high, $K(q \mid \delta, w, n)$ is close to $\phi(q \mid \delta, n)$.
} 


\section{B.5 Firm Size and Quality}

Relation to Market Concentration Firm size and firm quality are positively correlated. The expected number of product lines supplied by a type- $q$ firm is

$$
E[k \mid q]=\frac{K(q, \delta, w, n)}{M(q, \delta, w, n)}=\frac{\gamma(q \mid \delta, w, n)}{\delta-\gamma(q \mid \delta, w, n)} \frac{1}{\log \left(\frac{\delta}{\delta-\gamma(q \mid \delta, w, n)}\right)},
$$

which is strictly increasing in $q$ from Proposition 2. This relationship also implies that firm size and average markup are positively correlated, because $q$ determines the maximum markup rate.

Another important implication from equation (A.30) concerns the concentration of the market. If there are more high-quality firms, more product lines are produced by those firms and the degree of concentration increases.

Nominal Sales Distribution Because of the log utility, the nominal sales in each product line equal the nominal income, $E_{t}$, independent of prices. Hence, the sales distribution across firms is the same as the distribution of the number of products, $k$. This is why we examined the relationship between sales distribution and inflation in Section 2.

Let $R(k \mid \delta, w, n)$ be the density around the sales of $k E_{t}$,

$$
\begin{aligned}
R(k \mid \delta, w, n) & \equiv \int_{\underline{q}(\delta, n)}^{\infty} \phi(q \mid \delta, n) \frac{M_{k}(q \mid \delta, w, n)}{M(q \mid \delta, w, n)} d q \\
& =\frac{1}{k} \int_{\underline{q}(\delta, n)}^{\infty} \phi(q \mid \delta, n)\left(\frac{\gamma(q \mid \delta, w, n)}{\delta}\right)^{k}\left[\log \frac{\delta}{\delta-\gamma(q \mid \delta, w, n)}\right]^{-1} d q .
\end{aligned}
$$

\section{Calibration}

\section{C.1 Weighted Distance between Data Moments and Simu- lated Moments}

Define the vector of 12 moments by $\Gamma(\psi)$ that consist of the real growth rate $g$, nominal interest rate $R$, interval of price revision $\Delta$, the ratio of the median of wage bill to the mean of wage bill $(\operatorname{Med}[W L] / \mathrm{E}[W L])$, the ratio of the standard deviation of wage bill to the mean of wage bill $(\operatorname{Std}[W L] / \mathrm{E}[W L])$, the ratio of the median of real 
sales to the mean of real sales $(\operatorname{Med}[Y] / \mathrm{E}[Y])$, the ratio of the standard deviation of real sales to the mean of real sales $(\operatorname{Std}[Y] / \mathrm{E}[Y])$, the correlation coefficient between labor productivity and employment $(\operatorname{Cor}[Y / L, L])$, the correlation coefficient between real sales and wage bill (Cor $[Y, W L])$, the mean of real sales growth $(\mathrm{E}[d Y / Y])$, the standard deviation of real sales growth $(\operatorname{Std}[d Y / Y])$, and the correlation coefficient between real sales growth and real sales $(\operatorname{Cor}[d Y / Y, Y])$.

For the above 12 moments, we calculate model-based moments for a given parameter set $\theta$. Defining model-based moments by $\Gamma^{s}(\theta)$, we search for $\hat{\theta}$ to minimize the weighted distance between data moments and simulated moments:

$$
\theta=\arg \min _{\theta}\left(\Gamma^{s}(\theta)-\Gamma(\psi)\right)^{\prime} A^{-1}\left(\Gamma^{s}(\theta)-\Gamma(\psi)\right)
$$

Although this approach is based on Lentz and Mortensen (2008), we do not claim that we estimate the model. We do not provide standard errors for the estimates like their paper, and admittedly better estimates to minimize the weighted distance may exist because we did not calculate it for a sufficiently global parameter set. We calibrated the parameters as follows: searching for a good parameter set manually by using a grid search, and then using the FSOLVE function of the Matlab software with the parameter set as an initial value.

The variance-covariance matrix $A$ is calculated from that of the data moments. We estimate the distributional variables by bootstrapping the data as in Lentz and Mortensen (2008). As for $g$ and $R$, we assume that their variance-covariance is equal to their time-series variances from 1986 to 2006 and they are independent from other variables. For the variance of $\Delta$, we calculate it from the category-level $\Delta$ 's (e.g., unprocessed food and energy) reported in Chart 11 in Higo and Saita (2007). Furthermore, we find that these three variances are too large as compared with the variances of the distributional variables, so we multiply 10,000 for the latter to better fit with the moments of $g, R$, and $\Delta$ and to obtain quantitatively plausible implications for aggregate variables.

\section{C.2 Simulated Moments}

In this subsection, we explain how we calculate the model-based moments.

Real sales $Y:^{6}$ Given quality step $q$ and firm size $k$, the real sales of the firm equal

\footnotetext{
${ }^{6}$ While Lentz and Mortensen (2008) call this the value added, it is essentially the same.
} 
$k$. The corresponding frequency is given by $F(q, k)=\phi(q \mid n) \frac{M_{k}(q)}{M(q)}$ for $q \in[\underline{q}(n), \infty)$ and $k=1,2, \cdots$. Using this, we can calculate the moments. For example, the mean of real sales equals

$$
E[Y]=\int_{\underline{q}(n)}^{\infty} \phi(q \mid n) \sum_{k=1}^{\infty} \frac{M_{k}(q)}{M(q)} k .
$$

Wage bill $W L$ : Note that the density function of real prices among type- $q$ firms is

$$
f(\xi(\tau) \mid q)=\frac{\delta e^{-\delta \tau}}{1-e^{-\delta \Delta(q)}} \quad \text { for } \tau \in[0, \Delta(q)] .
$$

We approximate the price dispersion by dividing it into $N_{p}$ grids so that $\tau$ takes the value of $\tau\left(n_{p}\right)=n_{p} \Delta(q) /\left(N_{p}+1\right)$ for $n_{p}=1,2, \cdots, N_{p}$ with the frequency of

$$
\Gamma\left(n_{p}\right) \equiv \int_{\left(n_{p}-1\right) \Delta(q) / N_{p}}^{n_{p} \Delta(q) / N_{p}} f(\xi(\tau) \mid q) d \tau=\frac{e^{-\delta\left(n_{p}-1\right) \Delta(q) / N_{p}}-e^{-\delta n_{p} \Delta(q) / N_{p}}}{1-e^{-\delta \Delta(q)}} .
$$

For a firm of size $k$, we further approximate the frequency for the average price (i.e., $\left.\tau=\left(\tau\left(n_{p}^{1}\right)+\tau\left(n_{p}^{2}\right)+\cdots+\tau\left(n_{p}^{k}\right)\right) / k\right)$ by $\Gamma\left(n_{p}\right)^{k} / \Sigma_{n_{p}=1}^{N_{p}} \Gamma\left(n_{p}\right)^{k}$. Given $q, k$, and $\tau$, the real wage bill of the firm equals

$$
w k\left(L_{X, q}+L_{R, i n c, q}\right)=w k\left(\frac{1}{w q e^{-n \tau}}+c(\gamma(q))\right) .
$$

Labor productivity $Y / L$ : Given $q$ and $\tau$, the labor productivity is given by

$$
\Theta(q)=\left(\frac{1}{w q e^{-n \tau}}+c(\gamma(q))\right)^{-1}
$$

Future size evolution: Given $q$ and $k$, the expected real sales in the following year are expressed as

$$
\mathrm{E}\left[Y\left(k^{\prime}, q^{\prime} \mid k, q\right)\right]=\sum_{k^{\prime}} \operatorname{Pr}\left(k^{\prime} \mid k, q\right) Y\left(k^{\prime}, q\right)(1+n),
$$


where $\operatorname{Pr}\left(k^{\prime} \mid k, q\right)=\prod_{n^{\prime}=1}^{n} \operatorname{Pr}\left(k_{n^{\prime}+1} \mid k_{n^{\prime}}, q\right)$ with $k_{1}=k$, and

$$
\operatorname{Pr}\left(k_{2} \mid k_{1}, q\right)= \begin{cases}1-e^{-k_{1} \gamma(q) / n} & \text { if } k_{1}=k_{2}-1 \\ 1-\left(1-e^{-k_{1} \delta / n}\right)-\left(1-e^{-k_{1} \gamma(q) / n}\right) & \text { if } k_{1}=k_{2} \\ 1-e^{-k_{1} \delta / n} & \text { if } k_{1}=k_{2}+1\end{cases}
$$

provided $k_{1}>0$. If $k_{1}=0, \Pi\left(k_{2} \mid k_{1}, q\right)=0$. We assume $n=26$ as in Lentz and Mortensen (2008).

The interval of price revisions $\Delta$ : Given $q$, the interval of price revisions is given by $\Delta(q)$. We calculate its average using the firm-size weight (i.e. each product is assigned an equal weight):

$$
\int_{\underline{q}(\delta, n)}^{\infty} K(q \mid \delta, w, n) \Delta(q) d q
$$

\section{C.3 Cut-off}

"The Basic Survey of Japanese Business Structure and Activities" covers all firms with no less than 50 employees and no less than 30 million yen in capital. Considering this cut-off, we calculate model-based moments for the firms whose product size is no less than two $(k \geq 2)$. This strict cut-off may cause the over-representation of exits and under-representation of entries. On the other hand, the strict criterion may be suitable for our study because there are many dormant small firms in Japan that exist mainly for non-business purposes, as Nishimura et al. (2005) and Murao and Nirei (2011) argue.

\section{Generalization: Endogenous Labor Supply and Non-unit Elasticity of Substitution}

We generalize the model discussed in the main text in two directions. First, consumption is determined by the constant elasticity of substitution (CES) production function. Second, the labor supply is endogenous. 


\section{D.1 Generalized Model}

A representative household has the following preferences over all versions of $a \in$ $\left\{0,1, \cdots, A_{t}(j)\right\}$ for each product line $j \in[0,1]$ :

$$
\begin{gathered}
U_{t}=\int_{t}^{\infty} e^{-\rho\left(t^{\prime}-t\right)}\left(\log C_{t^{\prime}}-\chi \frac{L_{t^{\prime}}^{1+\omega}}{1+\omega}\right) d t^{\prime}, \\
C_{t^{\prime}}=\left[\int_{0}^{1}\left\{\sum_{a=0}^{A_{t^{\prime}}(j)} Q(j, a) x_{t^{\prime}}(j, a)\right\}^{(\sigma-1) / \sigma} d j\right]^{\sigma /(\sigma-1)},
\end{gathered}
$$

Parameter $\sigma \geq 1$ represents the elasticity of substitution, where we assumed $\sigma=1$ in the main text. Parameter $\omega$ represents the inverse of the elasticity of work, while $\chi$ is a scale factor. The budget constraint is given by $P_{t} C_{t}=W_{t} L_{t}+\Pi_{t}$, where the nominal household expenditure is again growing at the exogenous rate of $n$, and $\Pi_{t}$ represents a lump-sum transfer from firms.

This specification leads to the following changes in equilibrium conditions:

$$
\begin{gathered}
L=\left(\frac{W}{\chi P C}\right)^{1 / \omega}=\left\{\frac{w}{\chi}\left(1-\kappa \delta \int \frac{K(q \mid \delta, w, n)}{1-e^{-\delta \Delta(q \mid \delta, n)}} d q\right)^{-1}\right\}^{1 / \omega}, \\
\tilde{\nu}_{0}(q \mid \delta, n)=\max _{\Delta, \xi_{0}} \sum_{i=0}^{\infty} e^{-(\rho+\delta) i \Delta}\left(\int_{0}^{\Delta} \Pi\left(\xi_{0} e^{-n \tau}\right) e^{-(\rho+\delta) \tau} d \tau-\kappa\right),
\end{gathered}
$$

where $\Pi(\xi)=(1-W / \xi)(P / \xi)^{\sigma-1}$ if $\xi<q W$, and zero otherwise. The optimal (re)set real price satisfies $\xi_{0}(q \mid \delta, n)=q W$ if $\sigma /(\sigma-1) \geq q$. If $\sigma /(\sigma-1)<q$, the price is not explicitly clear, so we need to numerically solve not only $\Delta$ but also $\xi_{0}$. The optimal choice of price revision is expressed by

$$
\begin{aligned}
\frac{d}{d \xi_{0}} \tilde{\nu}_{0}(q \mid \delta, n) & =0=\int_{0}^{\Delta} \Pi^{\prime}\left(\xi_{0} e^{-n \tau}\right) e^{-(\rho+\delta+n) \tau} d \tau \quad \text { if } \xi_{0}<q W \\
\xi_{0} & =\min \left[\frac{\sigma}{\sigma-1} W \frac{e^{(n \sigma-\rho-\delta) \Delta}-1}{n \sigma-\rho-\delta} \frac{n \sigma-\rho-\delta-n}{e^{(n \sigma-\rho-\delta-n) \Delta}-1}, q W\right]
\end{aligned}
$$

as well as

$$
\frac{d}{d \Delta} \tilde{\nu}_{0}(q \mid \delta, n)=0=-(\rho+\delta) \tilde{\nu}_{0}+\Pi\left(\xi_{0} e^{-n \Delta}\right)
$$


Moreover, from equation (A.42), we have

$\tilde{\nu}_{0}(q \mid \delta, n)=\frac{1}{1-e^{-(\rho+\delta) \Delta}}\left[\left(\frac{\xi_{0}}{P}\right)^{1-\sigma} \frac{e^{(n \sigma-\rho-\delta-n) \Delta}-1}{n \sigma-\rho-\delta-n}-\frac{W}{P}\left(\frac{\xi_{0}}{P}\right)^{-\sigma} \frac{e^{(n \sigma-\rho-\delta) \Delta}-1}{n \sigma-\rho-\delta}-\kappa\right]$.

Labor demand for production is

$L_{X, q}(q \mid \delta, w, n)=\int_{0}^{\Delta(q \mid \delta, n)} f(\xi(\tau)) P^{\sigma-1} \xi(\tau)^{-\sigma} d \tau=\frac{\delta}{\delta-n \sigma} P^{\sigma-1} \xi_{0}^{-\sigma} \frac{1-e^{-(\delta-n \sigma) \Delta(q \mid \delta, n)}}{1-e^{-\delta \Delta(q \mid \delta, n)}}$

The intertemporal utility at $t=0$ is given by

$$
\begin{aligned}
U & =\int_{0}^{\infty} e^{-\rho t}\left(\log C_{t}-\chi \frac{L_{t}^{1+\omega}}{1+\omega}\right) d t=\frac{g}{\rho^{2}}+\frac{\log C}{\rho}-\frac{\chi}{\rho} \frac{L^{1+\omega}}{1+\omega} \\
& =\frac{g}{\rho^{2}}+\frac{\log C}{\rho}-\frac{\chi}{\rho} \frac{1}{1+\omega}\left(\frac{w}{\chi P C / E}\right)^{(1+\omega) / \omega} .
\end{aligned}
$$

The price level is given by

$$
P_{t}=\left[\int_{0}^{1} P_{t}(j)^{1-\sigma} d j\right]^{\frac{1}{1-\sigma}}
$$

where $P_{t}(j)$ represents the quality unit price. The price level at $t=0$ is

$$
\begin{aligned}
P & =\int K(q)\left[\int_{0}^{\Delta} f(\xi(\tau)) \xi(\tau)^{1-\sigma} d \tau\right]^{\frac{1}{1-\sigma}} d q \\
& =\int K(q) \xi_{0}\left[\frac{\delta}{1-e^{-\delta \Delta}} \frac{e^{(n \sigma-\delta-n) \Delta}-1}{n \sigma-\delta-n}\right]^{\frac{1}{1-\sigma}} d q \quad \text { if } \sigma>1 \\
\log P & =\int K(q)\left\{\log \xi_{0}+n \Delta \frac{e^{-\delta \Delta}}{1-e^{-\delta \Delta}}-\frac{n}{\delta}\right\} d q \quad \text { if } \sigma=1 .
\end{aligned}
$$

When $\sigma>1$, the real growth rate, $g$, is calculated as follows. Total production (consumption and menu costs) is given by

$$
Y_{t}=E_{t} / P_{t}
$$

Let $P_{t}(j)$ and $p_{t}(j)$ be the quality unit price and the quality-unadjusted goods price, respectively. Then, using equation (A.48), we have 


$$
Y_{t}=E_{t}\left[\int_{0}^{1}\left(\frac{Q(j)}{p_{t}(j)}\right)^{\sigma-1} d j\right]^{\frac{1}{\sigma-1}}=E\left[\int_{0}^{1}\left(\frac{Q_{t}(j)}{\xi_{t}(j)}\right)^{\sigma-1} d j\right]^{\frac{1}{\sigma-1}} .
$$

The change in $Q_{t}(j) / \xi_{t}(j)$ is

$$
\frac{Q_{t+d t}(j)}{\xi_{t+d t}(j)}= \begin{cases}\frac{q^{\prime} \xi_{t}(j)}{\xi_{0}\left(q^{\prime}\right)} \frac{Q_{t}(j)}{\xi_{t}(j)} & \text { with prob. } \delta d t \\ \frac{\xi_{t}(j)}{\xi_{t+d t}(j)} \frac{Q_{t}(j)}{\xi_{t}(j)} & \text { with prob. } 1-\delta d t\end{cases}
$$

where $q^{\prime}$ is the step-size of new innovation. Define $\Delta\left(Q_{t}(j) / \xi_{t}(j)\right) \equiv \frac{Q_{t+d t}(j)}{\xi_{t+d t}(j)}-\frac{Q_{t}(j)}{\xi_{t}(j)}$, so that

$$
\frac{Q_{t+d t}(j)}{\xi_{t+d t}(j)}=\left(1+\frac{\Delta\left(Q_{t}(j) / \xi_{t}(j)\right)}{Q_{t}(j) / \xi_{t}(j)}\right) \frac{Q_{t}(j)}{\xi_{t}(j)} .
$$

The growth rate is determined by

$$
\begin{aligned}
& \frac{Y_{t+d t}}{Y_{t}} \equiv 1+\frac{\Delta Y_{t}}{Y_{t}}=\left[\frac{\int_{0}^{1}\left(\frac{Q_{t+d t}(j)}{\xi_{t+d t}(j)}\right)^{\sigma-1} d j}{\int_{0}^{1}\left(\frac{Q_{t}(j)}{\xi_{t}(j)}\right)^{\sigma-1} d j}\right]^{\frac{1}{\sigma-1}} \\
& =\left[\int_{0}^{1}\left(1+\frac{\Delta\left(Q_{t}(j) / \xi_{t}(j)\right)}{Q_{t}(j) / \xi_{t}(j)}\right)^{\sigma-1}\left\{\frac{\left(\frac{Q_{t}(j)}{\xi_{t}(j)}\right)^{\sigma-1}}{\int_{0}^{1}\left(\frac{Q_{t}(h)}{\xi_{t}(h)}\right)^{\sigma-1} d h}\right\} d j\right]^{\frac{1}{\sigma-1}} \\
& =\left(\mathbb{E}\left\{\left(1+\frac{\Delta\left(Q_{t}(j) / \xi_{t}(j)\right)}{Q_{t}(j) / \xi_{t}(j)}\right)^{\sigma-1}\right\}\right)^{\frac{1}{\sigma-1}} \\
& =\left(\delta d t \mathbb{E}\left[\left(\frac{q^{\prime} \xi_{t}(j)}{\xi_{0}\left(q^{\prime}\right)}\right)^{\sigma-1}\right]+(1-\delta d t) \mathbb{E}\left[\left(\frac{\xi_{t}(j)}{\xi_{t+d t}(j)}\right)^{\sigma-1}\right]\right)^{\frac{1}{\sigma-1}} .
\end{aligned}
$$

The third equality comes because each product line has independent and identical distributions with respect to quality and price.

Conditional on survival, the real price changes as

$$
\xi_{t+d t}(j)= \begin{cases}\xi_{0}(j) & \text { with prob. } f(\Delta) d t \\ \xi_{t}(j) e^{-n d t} & \text { with prob. } 1-f(\Delta) d t\end{cases}
$$


Thus, we have

$$
\begin{aligned}
(1-\delta d t) \mathbb{E}\left[\left(\frac{\xi_{t}(j)}{\xi_{t+d t}(j)}\right)^{\sigma-1}\right] & =(1-\delta d t) \mathbb{E}\left[(1-f(\Delta) d t) e^{n(\sigma-1) d t}+f(\Delta) d t\left(\frac{\xi_{\Delta}(j)}{\xi_{0}(j)}\right)^{\sigma-1}\right] \\
& =\mathbb{E}\left[(1-\delta d t-f(\Delta) d t) e^{n(\sigma-1) d t}+f(\Delta) d t e^{-n(\sigma-1) \Delta}\right] .
\end{aligned}
$$

Substituting this back yields

$$
\frac{Y_{t+d t}}{Y_{t}}=\left(\delta d t \mathbb{E}\left[\left(\frac{q^{\prime} \xi_{t+d t}(j)}{\xi_{0}\left(q^{\prime}\right)}\right)^{\sigma-1}\right]+\mathbb{E}\left[(1-\delta d t-f(\Delta) d t) e^{n(\sigma-1) d t}+f(\Delta) d t e^{-n(\sigma-1) \Delta}\right]\right)^{\frac{1}{\sigma-1}}
$$

The real growth rate is expressed as

$$
\begin{aligned}
g & \equiv \lim _{d t \rightarrow 0} \frac{Y_{t+d t} / Y_{t}-1}{d t} \\
& =\frac{1}{\sigma-1}\left[\delta\left\{\mathbb{E}\left[\left(\frac{q^{\prime} \xi_{t}(j)}{\xi_{0}\left(q^{\prime}\right)}\right)^{\sigma-1}\right]-1\right\}+n(\sigma-1)-\mathbb{E}\left[f(\Delta)\left(1-e^{-n(\sigma-1) \Delta}\right)\right]\right],
\end{aligned}
$$

where the expectations terms are given by

$$
\mathbb{E}\left[\left(\frac{q^{\prime} \xi_{t}(j)}{\xi_{0}\left(q^{\prime}\right)}\right)^{\sigma-1}\right]=\int\left\{\int\left[\int_{0}^{\Delta}\left(\frac{q^{\prime} \xi_{\tau}}{\xi_{0}\left(q^{\prime}\right)}\right)^{\sigma-1} f\left(\xi_{\tau}\right) d \tau\right] K(q) d q\right\} K\left(q^{\prime}\right) d q^{\prime}
$$

and

$$
\mathbb{E}\left[f(\Delta)\left(1-e^{-n(\sigma-1) \Delta}\right)\right]=\int f(\Delta)\left(1-e^{-n(\sigma-1) \Delta}\right) K(q) d q .
$$

In the following two limiting cases, the real growth rate becomes

$$
g= \begin{cases}\frac{\delta}{\sigma-1}\left\{\mathbb{E}\left[\left(\frac{q^{\prime} \xi_{0}(j)}{\xi_{0}\left(q^{\prime}\right)}\right)^{\sigma-1}\right]-1\right\} & \text { for } n=0 \\ \delta \mathbb{E}[\log q] & \text { for } \sigma \rightarrow 1\end{cases}
$$


Note that, when $\sigma \rightarrow 1$, we have

$$
\begin{aligned}
\lim _{\sigma \rightarrow 1} g & =\lim _{\sigma \rightarrow 1} \frac{d}{d \sigma}\left[\delta\left\{\mathbb{E}\left[\left(\frac{q^{\prime} \xi_{t}(j)}{\xi_{0}\left(q^{\prime}\right)}\right)^{\sigma-1}\right]-1\right\}+n(\sigma-1)-\mathbb{E}\left[f(\Delta)\left(1-e^{-n(\sigma-1) \Delta}\right)\right]\right] \\
& =\delta \mathbb{E}\left[\log q e^{-n \tau}\right]+n-\mathbb{E}[n \Delta f(\Delta)] \\
& =\delta \mathbb{E}[\log q]+n\{1-(\delta \mathbb{E}[\tau]+\mathbb{E}[\Delta f(\Delta)])\} .
\end{aligned}
$$

Because

$$
\begin{aligned}
\mathbb{E}[\tau] & =\int K(q) d q \int_{0}^{\Delta} \tau \frac{\delta e^{-\delta \tau}}{1-e^{-\delta \Delta}} d \tau=\frac{1}{\delta} \int K(q) d q\left(1-\frac{\delta \Delta e^{-\delta \Delta}}{1-e^{-\delta \Delta}}\right), \\
\mathbb{E}[\Delta f(\Delta)] & =\int K(q) d q \frac{\delta \Delta e^{-\delta \Delta}}{1-e^{-\delta \Delta}},
\end{aligned}
$$

we have $g \rightarrow \delta \mathbb{E}[\log q]$ as $\sigma \rightarrow 1$.

The other equations do not change.

\section{D.2 Calibration of the Generalized Model}

In the calibration, we set the inverse of the elasticity of work, $\omega$, to 2 or the elasticity of substitution across different product lines, $\sigma$, to 1.5, although a number of different parameter values are empirically reported.

Figure A.3 shows the effects of nominal growth based on modified models, while Table A.10 shows the moments. As for the endogenous labor supply, a change in real wage $w$ induced by a change in the nominal growth rate $n$ influences the labor supply. In the calibrated model, an increase in $n$ decreases $w$ that decreases the labor supply. However, this effect is quantitatively small. There is almost no change observed between the benchmark model (in which $\omega$ is infinitely large) and the model with $\omega=2$.

An increase in the elasticity of substitution from one reinforces the reallocation effect under the current parameter setting. It has three effects. First, the markup has a cap at $\sigma /(\sigma-1)$ even though firms have high $q$, because a leading firm competes with not only firms with secondary technology in the same product line but also firms in different product lines. Second, higher $\sigma$ induces smaller firm-size dispersions if all other parameter values are equal. Since demand becomes more elastic, firms with 
high $q$ gain smaller sales. Third, more elastic demand decreases an incentive to revise prices for a given menu cost $\kappa$. Indeed, Table A.10 shows that both the standard deviation and the mean decrease relative to the median (Std/Med and Mean/Med calculated from the values in the table), and the reset price interval increases, when we use the same parameter values.

Figure A.3 shows that the positive reallocation effect of nominal growth is stronger. The nominal growth causes a gradual decline in the relative prices of products whose posted prices are not revised, leading to a gradual increase in the expenditure shares of those products. Because high- $q$ firms have constant prices with longer durations, the increase in the expenditure share toward high- $q$ products becomes more outstanding under a greater $\sigma$, which amplifies the positive effects on real growth and welfare. This effect is also reinforced by a decline in innovation frequency caused by the nominal growth because innovation is always accompanied with the price reset that increases the price and decreases sales. We obtain no finite value for the nominal growth to maximize welfare as well as the real growth rate: welfare increases as the optimal nominal growth increases. This result holds even when we recalibrate the parameter values to match the moments based on the model with $\sigma=1.5$.

\section{References}

Higo, M. and Y. Saita (2007). Price Setting in Japan: Evidence from CPI Micro Data. Bank of Japan Working Paper Series 07-E-20, Bank of Japan.

Jovanovic, B. (1982). Selection and the evolution of industry. Econometrica 50(3), 649-670.

Lentz, R. and D. T. Mortensen (2008). An Empirical Model of Growth Through Product Innovation. Econometrica 76 (6), 1317-1373.

Murao, T. and M. Nirei (2011). Entry Barriers, Reallocation, and Productivity Growth: Evidence from Japanese manufacturing firms. Discussion Paper Series 11-E-081, RIETI.

Nishimura, K. G., T. Nakajima, and K. Kiyota (2005). Does the natural selection mechanism still work in severe recessions?: Examination of the Japanese economy in the 1990s. Journal of Economic Behavior \& Organization 58(1), 53-78. 
Table A.1: Summary Table for Variables Used for Estimation

\begin{tabular}{|c|c|c|c|c|c|}
\hline Variable & Observation & Mean & Std. Dev. & Min & $\operatorname{Max}$ \\
\hline $\bar{\pi}^{\text {input }}$ & 322 & 0.0100076 & 0.0495548 & -0.1427733 & 0.2835882 \\
\hline Top/Middle (sales) & 322 & 11.04676 & 23.00279 & 3.848761 & 229.983 \\
\hline Top/Bottom (sales) & 322 & 43.26014 & 89.67692 & 11.27907 & 803.2036 \\
\hline Top/Middle (employment) & 322 & 4.612411 & 1.499788 & 2.576576 & 15.22388 \\
\hline Top/Bottom (employment) & 322 & 10.50473 & 4.61886 & 4.672131 & 38.53571 \\
\hline Industry real sales $(\log )$ & 322 & 11.86376 & 0.8597284 & 10.01801 & 13.44605 \\
\hline Financial DI & 316 & 0.9290612 & 11.05655 & -29.75 & 28.25 \\
\hline Financing DI by size class & 948 & 4.308456 & 14.36273 & -36 & 46.25 \\
\hline Sales growth & 189447 & 0.0567846 & 0.6869153 & -0.9948701 & 120.5996 \\
\hline Employment growth & 189447 & 0.0055831 & 0.268017 & -0.9760662 & 20.75385 \\
\hline Real R\&D expenditure (log) & 58445 & 0.8828367 & 1.387753 & 0 & 9.080056 \\
\hline$\frac{R \& D}{\text { Sales }}$ & 58445 & 0.018587 & 0.0421069 & 0 & 4.858796 \\
\hline $\log \frac{R \& D}{\text { Wage }}$ & 58418 & 2.251617 & 2.354766 & 0 & 11.64695 \\
\hline $\log \frac{\mathrm{R} \& \mathrm{D}}{\text { Total Salary }}$ & 58418 & 0.1036888 & 0.1769869 & 0 & 5.332719 \\
\hline Exit & 175463 & 0.0352154 & 0.1843244 & 0 & 1 \\
\hline Lagged sales (3 years, log) & 189447 & 8.50466 & 1.341011 & 3.218876 & 16.307 \\
\hline Lagged leverage (3 years, log) & 189447 & 3.235007 & 1.101904 & -5.521461 & 8.336737 \\
\hline
\end{tabular}


Table A.2: Summary Table for Input Inflation and Firm Size Dispersions by Industries

\begin{tabular}{|c|c|c|c|c|c|c|c|c|c|c|}
\hline & \multirow{2}{*}{\multicolumn{2}{|c|}{$\bar{\pi}^{\text {input }}$}} & \multicolumn{4}{|c|}{$\mathrm{T} / \mathrm{M}$ ratio } & \multicolumn{4}{|c|}{$\mathrm{T} / \mathrm{B}$ ratio } \\
\hline & & & \multicolumn{2}{|c|}{ Sales } & \multicolumn{2}{|c|}{ Employment } & \multicolumn{2}{|c|}{ Sales } & \multicolumn{2}{|c|}{ Employment } \\
\hline & mean & s.d. & mean & s.d. & mean & s.d. & mean & s.d. & mean & s.d. \\
\hline Foods & $0.21 \%$ & $1.73 \%$ & 6.48 & 0.32 & 4.43 & 0.15 & 24.45 & 1.72 & 10.57 & 0.65 \\
\hline Textile & $0.28 \%$ & $2.38 \%$ & 4.58 & 0.36 & 2.90 & 0.25 & 17.05 & 1.45 & 5.42 & 0.62 \\
\hline Pulp, paper and wooden products & $0.43 \%$ & $1.98 \%$ & 5.22 & 0.56 & 3.66 & 0.18 & 14.15 & 1.85 & 7.14 & 0.41 \\
\hline Chemical products & $2.07 \%$ & $3.72 \%$ & 9.00 & 0.65 & 6.40 & 0.55 & 35.47 & 4.55 & 16.59 & 1.25 \\
\hline Petroleum and coal products & $6.93 \%$ & $10.70 \%$ & 68.59 & 62.87 & 7.81 & 2.90 & 305.93 & 196.72 & 19.90 & 7.93 \\
\hline Ceramics, stone and clay products & $0.70 \%$ & $1.80 \%$ & 5.04 & 0.28 & 3.51 & 0.21 & 14.98 & 1.19 & 6.98 & 0.43 \\
\hline Steel & $2.92 \%$ & $5.92 \%$ & 5.61 & 0.51 & 4.34 & 0.42 & 23.30 & 3.81 & 9.10 & 0.95 \\
\hline Non-ferrous metal & $3.13 \%$ & $9.65 \%$ & 7.42 & 1.22 & 4.36 & 0.34 & 28.49 & 6.25 & 9.42 & 0.89 \\
\hline Metal products & $0.74 \%$ & $3.07 \%$ & 4.94 & 0.38 & 3.56 & 0.18 & 13.16 & 0.77 & 6.56 & 0.49 \\
\hline General machinery & $-0.07 \%$ & $1.29 \%$ & 6.59 & 0.48 & 4.26 & 0.21 & 19.27 & 1.90 & 8.94 & 0.46 \\
\hline Electrical machinery & $-2.04 \%$ & $1.48 \%$ & 9.30 & 0.63 & 5.14 & 0.27 & 35.17 & 2.14 & 12.81 & 0.59 \\
\hline Transportation equipments & $-0.53 \%$ & $1.08 \%$ & 8.96 & 0.51 & 5.69 & 0.25 & 34.94 & 3.04 & 14.98 & 0.87 \\
\hline Precision instruments & $-1.24 \%$ & $0.91 \%$ & 7.56 & 1.07 & 4.79 & 0.58 & 22.96 & 2.94 & 11.03 & 1.35 \\
\hline Miscellaneous & $0.49 \%$ & $1.94 \%$ & 5.35 & 0.25 & 3.72 & 0.10 & 16.32 & 1.08 & 7.61 & 0.23 \\
\hline
\end{tabular}


Table A.3: Effect of Inflation on Real Sales Growth within Firm Age Class

\begin{tabular}{|c|c|c|c|c|}
\hline Dep. var. & $\begin{array}{c}(1) \\
\text { below } 25 \% \\
\text { Sales growth }\end{array}$ & $\begin{array}{c}(2) \\
25-50 \% \\
\text { Sales growth }\end{array}$ & $\begin{array}{c}(3) \\
50-75 \% \\
\text { Sales growth }\end{array}$ & $\begin{array}{c}\text { (4) } \\
\text { above } 75 \% \\
\text { Sales growth }\end{array}$ \\
\hline$\hat{\pi}^{\text {input }}$ & $\begin{array}{c}-2.098^{* *} \\
(0.903)\end{array}$ & $\begin{array}{c}-2.452^{* * *} \\
(0.784)\end{array}$ & $\begin{array}{c}-5.192^{* * *} \\
(1.484)\end{array}$ & $\begin{array}{c}-1.128^{* * *} \\
(0.270)\end{array}$ \\
\hline Lagged sales & $\begin{array}{c}-1.113^{* * *} \\
(0.0104)\end{array}$ & $\begin{array}{c}-1.060^{* * *} \\
(0.0117)\end{array}$ & $\begin{array}{c}-1.842^{* * *} \\
(0.0244)\end{array}$ & $\begin{array}{l}-0.694^{* * *} \\
(0.00575)\end{array}$ \\
\hline Lagged sales $\times \hat{\pi}^{\text {input }}$ & $\begin{array}{l}0.313^{* * *} \\
(0.0987)\end{array}$ & $\begin{array}{l}0.330^{* * *} \\
(0.0863)\end{array}$ & $\begin{array}{c}0.602^{* * *} \\
(0.165)\end{array}$ & $\begin{array}{c}0.0793^{* * *} \\
(0.0275)\end{array}$ \\
\hline Financing DI & $\begin{array}{l}0.00798^{* * *} \\
(0.000503)\end{array}$ & $\begin{array}{l}0.00596^{* * *} \\
(0.000446)\end{array}$ & $\begin{array}{l}0.00475^{* * *} \\
(0.000826)\end{array}$ & $\begin{array}{l}0.00309^{* * *} \\
(0.000210)\end{array}$ \\
\hline Industry RS & $\begin{array}{c}-0.0555^{* * *} \\
(0.0111)\end{array}$ & $\begin{array}{c}-0.0617^{* * *} \\
(0.0104)\end{array}$ & $\begin{array}{l}-0.0158 \\
(0.0210)\end{array}$ & $\begin{array}{c}-0.0134^{* *} \\
(0.00529)\end{array}$ \\
\hline Lagged leverage & $\begin{array}{c}0.103^{* * *} \\
(0.00779)\end{array}$ & $\begin{array}{c}0.110^{* * *} \\
(0.00950)\end{array}$ & $\begin{array}{l}0.224^{* * *} \\
(0.0216)\end{array}$ & $\begin{array}{l}0.0526^{* * *} \\
(0.00453)\end{array}$ \\
\hline Constant & $\begin{array}{c}9.863^{* * *} \\
(0.155)\end{array}$ & $\begin{array}{c}9.331^{* * *} \\
(0.155)\end{array}$ & $\begin{array}{c}15.13^{* * *} \\
(0.317)\end{array}$ & $\begin{array}{l}6.308^{* * *} \\
(0.0810)\end{array}$ \\
\hline Year/Firm FE & yes/yes & yes/yes & yes/yes & yes/yes \\
\hline Obs. & 38864 & 43762 & 49204 & 57617 \\
\hline Num. firms & 6844 & 7698 & 8931 & 7216 \\
\hline \multicolumn{5}{|l|}{$R^{2}$} \\
\hline within & 0.298 & 0.222 & 0.138 & 0.281 \\
\hline overall & 0.00487 & 0.00108 & 0.00107 & 0.000535 \\
\hline$F$ & 566.2 & 427.9 & 268.4 & 820.3 \\
\hline$F_{f}$ & 7.911 & 2.923 & 2.551 & 6.150 \\
\hline
\end{tabular}

Notes: Standard errors are in the parentheses $\left({ }^{*} p<0.10,{ }^{* *} p<0.05,{ }^{* * *} p<0.01\right) . F_{f}$ represents the $\mathrm{F}$ test statistics with the null hypothesis that all firm fixed effects are zero. 
Table A.4: Effect of Inflation on Real Sales Growth within Leverage Ratio Class

\begin{tabular}{|c|c|c|c|c|}
\hline Dep. var. & $\begin{array}{c}\quad(1) \\
\leq \text { Median } \\
\text { Sales growth }\end{array}$ & $\begin{array}{c}(2) \\
>\text { Median } \\
\text { Sales growth }\end{array}$ & $\begin{array}{c}(3) \\
\leq 75 \% \text { tile } \\
\text { Sales growth }\end{array}$ & $\begin{array}{c}(4) \\
>75 \% \text { tile } \\
\text { Sales growth }\end{array}$ \\
\hline$\hat{\pi}^{\text {input }}$ & $\begin{array}{c}-2.643^{* * *} \\
(0.436)\end{array}$ & $\begin{array}{c}-2.281^{* * *} \\
(0.768)\end{array}$ & $\begin{array}{c}-2.454^{* * *} \\
(0.456)\end{array}$ & $\begin{array}{c}-4.798^{* * *} \\
(0.844)\end{array}$ \\
\hline Lagged sales & $\begin{array}{l}-0.898^{* * *} \\
(0.00739)\end{array}$ & $\begin{array}{l}-1.031^{* * *} \\
(0.00999)\end{array}$ & $\begin{array}{l}-0.964^{* * *} \\
(0.00741)\end{array}$ & $\begin{array}{l}-0.897^{* * *} \\
(0.00974)\end{array}$ \\
\hline Lagged sales $\times \hat{\pi}^{\text {input }}$ & $\begin{array}{l}0.310^{* * *} \\
(0.0447)\end{array}$ & $\begin{array}{l}0.245^{* * *} \\
(0.0858)\end{array}$ & $\begin{array}{l}0.285^{* * *} \\
(0.0480)\end{array}$ & $\begin{array}{l}0.525^{* * *} \\
(0.0930)\end{array}$ \\
\hline Financing DI & $\begin{array}{l}0.00401^{* * *} \\
(0.000301)\end{array}$ & $\begin{array}{l}0.00486^{* * *} \\
(0.000398)\end{array}$ & $\begin{array}{l}0.00445^{* * *} \\
(0.000303)\end{array}$ & $\begin{array}{l}0.00509^{* * *} \\
(0.000384)\end{array}$ \\
\hline Industry RS & $\begin{array}{c}-0.0342^{* * *} \\
(0.00715)\end{array}$ & $\begin{array}{c}-0.0334^{* * *} \\
(0.00912)\end{array}$ & $\begin{array}{c}-0.0291^{* * *} \\
(0.00702)\end{array}$ & $\begin{array}{c}-0.0267^{* * *} \\
(0.00953)\end{array}$ \\
\hline Lagged leverage & $\begin{array}{l}0.0633^{* * *} \\
(0.00573)\end{array}$ & $\begin{array}{c}0.143^{* * *} \\
(0.00924)\end{array}$ & $\begin{array}{l}0.0925^{* * *} \\
(0.00592)\end{array}$ & $\begin{array}{c}0.103^{* * *} \\
(0.00910)\end{array}$ \\
\hline Constant & $\begin{array}{c}8.116^{* * *} \\
(0.105)\end{array}$ & $\begin{array}{c}8.747^{* * *} \\
(0.134)\end{array}$ & $\begin{array}{c}8.412^{* * *} \\
(0.103)\end{array}$ & $\begin{array}{c}7.856^{* * *} \\
(0.138)\end{array}$ \\
\hline Year/Firm FE & yes/yes & yes/yes & yes/yes & yes/yes \\
\hline Obs. & 93932 & 95515 & 140371 & 49076 \\
\hline Num. firms & 11981 & 11570 & 16275 & 6429 \\
\hline \multicolumn{5}{|l|}{$R^{2}$} \\
\hline within & 0.180 & 0.135 & 0.140 & 0.204 \\
\hline overall & 0.00119 & 0.00281 & 0.00154 & 0.00408 \\
\hline$F$ & 747.1 & 547.9 & 843.7 & 455.5 \\
\hline$F_{f}$ & 4.778 & 3.200 & 3.640 & 4.281 \\
\hline
\end{tabular}

Notes: Standard errors are in the parentheses $\left({ }^{*} p<0.10,{ }^{* *} p<0.05,{ }^{* * *} p<0.01\right) . F_{f}$ represents the $\mathrm{F}$ test statistics with the null hypothesis that all firm fixed effects are zero. 
Table A.5: Alternative Trend Inflation

\begin{tabular}{|c|c|c|c|c|}
\hline \multirow[b]{4}{*}{ Dep. var. } & \multicolumn{2}{|c|}{1 year } & \multicolumn{2}{|c|}{5 years } \\
\hline & $(1)$ & $(2)$ & $(3)$ & $(4)$ \\
\hline & OLS & 2SLS & OLS & 2SLS \\
\hline & Sales growth & Sales growth & Sales growth & Sales growth \\
\hline$\hat{\pi}^{\text {input }}\left(\bar{\pi}^{\text {input }}\right.$ for OLS $)$ & $\begin{array}{l}-0.160 \\
(0.241)\end{array}$ & $\begin{array}{l}-0.308 \\
(0.318)\end{array}$ & $\begin{array}{c}-5.953^{* * *} \\
(0.550)\end{array}$ & $\begin{array}{c}-6.011^{* * *} \\
(0.599)\end{array}$ \\
\hline Lagged sales & $\begin{array}{l}-0.501^{* * *} \\
(0.00668)\end{array}$ & $\begin{array}{l}-0.501^{* * *} \\
(0.00668)\end{array}$ & $\begin{array}{l}-1.224^{* * *} \\
(0.00797)\end{array}$ & $\begin{array}{l}-1.224^{* * *} \\
(0.00798)\end{array}$ \\
\hline Lagged sales $\times \hat{\pi}^{\text {input }}\left(\bar{\pi}^{\text {input }}\right)$ & $\begin{array}{c}0.0248 \\
(0.0261)\end{array}$ & $\begin{array}{c}0.0619^{*} \\
(0.0335)\end{array}$ & $\begin{array}{l}0.532^{* * *} \\
(0.0603)\end{array}$ & $\begin{array}{l}0.602^{* * *} \\
(0.0651)\end{array}$ \\
\hline Financing DI & $\begin{array}{l}0.00363^{* * *} \\
(0.000283)\end{array}$ & $\begin{array}{l}0.00359^{* * *} \\
(0.000284)\end{array}$ & $\begin{array}{l}0.00443^{* * *} \\
(0.000313)\end{array}$ & $\begin{array}{l}0.00431^{* * *} \\
(0.000314)\end{array}$ \\
\hline Industry RS & $\begin{array}{c}-0.0190^{* * *} \\
(0.00641)\end{array}$ & $\begin{array}{c}-0.0175^{* * *} \\
(0.00644)\end{array}$ & $\begin{array}{c}-0.0369^{* * *} \\
(0.00767)\end{array}$ & $\begin{array}{c}-0.0310^{* * *} \\
(0.00772)\end{array}$ \\
\hline Lagged leverage & $\begin{array}{c}0.114^{* * *} \\
(0.00530)\end{array}$ & $\begin{array}{c}0.113^{* * *} \\
(0.00530)\end{array}$ & $\begin{array}{l}0.0833^{* * *} \\
(0.00635)\end{array}$ & $\begin{array}{l}0.0839^{* * *} \\
(0.00635)\end{array}$ \\
\hline Constant & $\begin{array}{l}4.206^{* * *} \\
(0.0931)\end{array}$ & $\begin{array}{l}4.192^{* * *} \\
(0.0934)\end{array}$ & $\begin{array}{c}10.79^{* * *} \\
(0.112)\end{array}$ & $\begin{array}{c}10.72^{* * *} \\
(0.113)\end{array}$ \\
\hline Year/Firm FE & yes/yes & yes/yes & yes/yes & yes/yes \\
\hline Obs. & 248474 & 248474 & 145635 & 145635 \\
\hline Num. firms & 23632 & 23632 & 16412 & 16412 \\
\hline$R^{2}$ & & & & \\
\hline within & 0.0283 & 0.0284 & 0.185 & 0.184 \\
\hline overall & 0.000906 & 0.000905 & 0.00167 & 0.00164 \\
\hline$F$ & 252.1 & 252.5 & 1331.3 & 1327.4 \\
\hline$F_{f}$ & 2.973 & 2.973 & 4.401 & 4.389 \\
\hline
\end{tabular}

Notes: Standard errors are in the parentheses $\left({ }^{*} p<0.10,{ }^{* *} p<0.05,{ }^{* * *} p<0.01\right) . F_{f}$ represents the $\mathrm{F}$ test statistics with the null hypothesis that all firm fixed effects are zero. 
Table A.6: Wage Inflation

\begin{tabular}{|c|c|c|c|c|}
\hline $\begin{array}{l}\text { Dep. var } \\
\text { IV }\end{array}$ & $\begin{array}{c}\text { OLS } \\
(1) \\
\text { Sales growth }\end{array}$ & $\begin{array}{l}\text { (2) } \\
\text { Sales growth } \\
\text { Int. com. price }\end{array}$ & $\begin{array}{c}\text { 2SLS } \\
(3) \\
\text { Sales growth } \\
\text { Unemployment }\end{array}$ & $\begin{array}{c}(4) \\
\text { Sales growth } \\
\Delta \text { Job application }\end{array}$ \\
\hline Wage inflation & $\begin{array}{l}0.216^{* * *} \\
(0.0583)\end{array}$ & $\begin{array}{c}-5.524^{* * *} \\
(0.236)\end{array}$ & $\begin{array}{c}-5.167^{* * *} \\
(0.225)\end{array}$ & $\begin{array}{c}-5.947^{* * *} \\
(0.216)\end{array}$ \\
\hline Lagged sales & $\begin{array}{l}-0.763^{* * *} \\
(0.00534)\end{array}$ & $\begin{array}{c}-0.716^{* * *} \\
(0.0160)\end{array}$ & $\begin{array}{c}-0.733^{* * *} \\
(0.0149)\end{array}$ & $\begin{array}{c}-0.673^{* * *} \\
(0.0142)\end{array}$ \\
\hline Lagged sales $\times$ Wage inflation & $\begin{array}{c}-0.0239^{* * *} \\
(0.00653)\end{array}$ & $\begin{array}{l}0.594^{* * *} \\
(0.0171)\end{array}$ & $\begin{array}{l}0.575^{* * *} \\
(0.0171)\end{array}$ & $\begin{array}{l}0.582^{* * *} \\
(0.0170)\end{array}$ \\
\hline Financing DI & $\begin{array}{l}0.00453^{* * *} \\
(0.000205)\end{array}$ & $\begin{array}{l}0.00549^{* * *} \\
(0.000330)\end{array}$ & $\begin{array}{l}0.00513^{* * *} \\
(0.000314)\end{array}$ & $\begin{array}{l}0.00622^{* * *} \\
(0.000305)\end{array}$ \\
\hline Industry RS & $\begin{array}{c}-0.0257^{* * *} \\
(0.00490)\end{array}$ & $\begin{array}{c}-0.0206^{* * *} \\
(0.00518)\end{array}$ & $\begin{array}{c}-0.0216^{* * *} \\
(0.00514)\end{array}$ & $\begin{array}{c}-0.0157^{* * *} \\
(0.00511)\end{array}$ \\
\hline Lagged leverage & $\begin{array}{l}0.0711^{* * *} \\
(0.00422)\end{array}$ & $\begin{array}{l}0.0774^{* * *} \\
(0.00463)\end{array}$ & $\begin{array}{l}0.0752^{* * *} \\
(0.00456)\end{array}$ & $\begin{array}{l}0.0831^{* * *} \\
(0.00453)\end{array}$ \\
\hline Constant & $\begin{array}{l}6.702^{* * *} \\
(0.0727) \\
\end{array}$ & $\begin{array}{c}6.110^{* * *} \\
(0.184) \\
\end{array}$ & $\begin{array}{c}6.285^{* * *} \\
(0.172) \\
\end{array}$ & $\begin{array}{c}5.621^{* * *} \\
(0.164) \\
\end{array}$ \\
\hline Year/Firm FE & yes/yes & yes/yes & yes/yes & yes/yes \\
\hline Obs. & 158898 & 158898 & 158898 & 158898 \\
\hline Num. firms & 17721 & 17721 & 17721 & 17721 \\
\hline \multicolumn{5}{|l|}{$R^{2}$} \\
\hline within & 0.161 & 0.168 & 0.167 & 0.168 \\
\hline overall & 0.00127 & 0.00181 & 0.00181 & 0.00175 \\
\hline$F$ & 1173.9 & 1235.6 & 1232.0 & 1235.4 \\
\hline$F_{f}$ & 3.339 & 3.353 & 3.345 & 3.361 \\
\hline
\end{tabular}

Notes: Standard errors are in the parentheses $\left({ }^{*} p<0.10,{ }^{* *} p<0.05,{ }^{* * *} p<0.01\right) . F_{f}$ represents the $\mathrm{F}$ test statistics with the null hypothesis that all firm fixed effects are zero. 
Table A.7: Non-manufacturing Sector

\begin{tabular}{|c|c|c|c|c|}
\hline $\begin{array}{l}\text { Dep. var } \\
\text { IV }\end{array}$ & $\begin{array}{c}\text { OLS } \\
(1) \\
\text { Sales growth }\end{array}$ & $\begin{array}{l}\text { (2) } \\
\text { Sales growth } \\
\text { Int. com. price } \\
\end{array}$ & $\begin{array}{c}\text { 2SLS } \\
(3) \\
\text { Sales growth } \\
\text { Unemployment }\end{array}$ & $\begin{array}{c}(4) \\
\text { Sales growth } \\
\Delta \text { Job application }\end{array}$ \\
\hline Wage inflation & $\begin{array}{c}0.130^{* *} \\
(0.0560)\end{array}$ & $\begin{array}{c}-1.378^{* * *} \\
(0.168)\end{array}$ & $\begin{array}{c}-1.311^{* * *} \\
(0.166)\end{array}$ & $\begin{array}{c}-1.462^{* * *} \\
(0.168)\end{array}$ \\
\hline Lagged sales & $\begin{array}{l}-0.679^{* * *} \\
(0.00429)\end{array}$ & $\begin{array}{l}-0.693^{* * *} \\
(0.00831)\end{array}$ & $\begin{array}{l}-0.695^{* * *} \\
(0.00809)\end{array}$ & $\begin{array}{l}-0.683^{* * *} \\
(0.00834)\end{array}$ \\
\hline Lagged sales $\times$ Wage inflation & $\begin{array}{l}-0.0147^{* *} \\
(0.00618)\end{array}$ & $\begin{array}{l}0.181^{* * *} \\
(0.0158)\end{array}$ & $\begin{array}{l}0.178^{* * *} \\
(0.0158)\end{array}$ & $\begin{array}{l}0.175^{* * *} \\
(0.0158)\end{array}$ \\
\hline Financing DI & $\begin{array}{l}0.00275^{* * *} \\
(0.000164)\end{array}$ & $\begin{array}{l}0.00273^{* * *} \\
(0.000166)\end{array}$ & $\begin{array}{l}0.00273^{* * *} \\
(0.000166)\end{array}$ & $\begin{array}{l}0.00278^{* * *} \\
(0.000166)\end{array}$ \\
\hline Industry RS & $\begin{array}{c}0.000743 \\
(0.00338)\end{array}$ & $\begin{array}{c}0.00696 \\
(0.00424)\end{array}$ & $\begin{array}{c}0.00795^{*} \\
(0.00418)\end{array}$ & $\begin{array}{c}0.00338 \\
(0.00425)\end{array}$ \\
\hline Lagged leverage & $\begin{array}{l}0.0435^{* * *} \\
(0.00291)\end{array}$ & $\begin{array}{l}0.0429^{* * *} \\
(0.00294)\end{array}$ & $\begin{array}{l}0.0428^{* * *} \\
(0.00294)\end{array}$ & $\begin{array}{l}0.0435^{* * *} \\
(0.00294)\end{array}$ \\
\hline Constant & $\begin{array}{l}6.066^{* * *} \\
(0.0724) \\
\end{array}$ & $\begin{array}{l}6.085^{* * *} \\
(0.0778) \\
\end{array}$ & $\begin{array}{l}6.098^{* * *} \\
(0.0774) \\
\end{array}$ & $\begin{array}{l}6.046^{* * *} \\
(0.0779) \\
\end{array}$ \\
\hline Year/Firm FE & yes/yes & yes/yes & yes/yes & yes/yes \\
\hline Obs. & 129325 & 129325 & 129325 & 129325 \\
\hline Num. firms & 17603 & 17603 & 17603 & 17603 \\
\hline \multicolumn{5}{|l|}{$R^{2}$} \\
\hline within & 0.216 & 0.217 & 0.217 & 0.217 \\
\hline overall & 0.000811 & 0.000894 & 0.000897 & 0.000879 \\
\hline$F$ & 1337.2 & 1344.3 & 1344.2 & 1343.7 \\
\hline$F_{f}$ & 6.522 & 6.533 & 6.532 & 6.532 \\
\hline
\end{tabular}

Notes: Standard errors are in the parentheses $\left({ }^{*} p<0.10,{ }^{* *} p<0.05,{ }^{* * *} p<0.01\right) . F_{f}$ represents the $\mathrm{F}$ test statistics with the null hypothesis that all firm fixed effects are zero. 
Table A.8: Strict Definition of Exit

\begin{tabular}{|c|c|c|c|}
\hline Dep. var. & $\begin{array}{c}(1) \\
3 \text { years } \\
\text { Exit flag }\end{array}$ & $\begin{array}{c}(2) \\
6 \text { years } \\
\text { Exit flag }\end{array}$ & $\begin{array}{c}(3) \\
9 \text { years } \\
\text { Exit flag }\end{array}$ \\
\hline$\hat{\pi}^{\text {input }}$ & $\begin{array}{c}0.501^{* * *} \\
(0.105)\end{array}$ & $\begin{array}{c}0.828^{* * *} \\
(0.121)\end{array}$ & $\begin{array}{l}0.493^{* *} \\
(0.217)\end{array}$ \\
\hline Lagged sales & $\begin{array}{c}-0.0230^{* * *} \\
(0.00180)\end{array}$ & $\begin{array}{c}-0.0228^{* * *} \\
(0.00222)\end{array}$ & $\begin{array}{c}-0.0222^{* * *} \\
(0.00280)\end{array}$ \\
\hline Lagged sales $\times \hat{\pi}^{\text {input }}$ & $\begin{array}{c}-0.0532^{* * *} \\
(0.0112)\end{array}$ & $\begin{array}{c}-0.0925^{* * *} \\
(0.0129)\end{array}$ & $\begin{array}{c}-0.0507^{* *} \\
(0.0236)\end{array}$ \\
\hline Financing DI & $\begin{array}{l}-0.0000908 \\
(0.0000686)\end{array}$ & $\begin{array}{l}-0.0000995 \\
(0.0000756)\end{array}$ & $\begin{array}{l}-0.0000618 \\
(0.0000872)\end{array}$ \\
\hline Industry RS & $\begin{array}{l}-0.00178 \\
(0.00166)\end{array}$ & $\begin{array}{l}-0.00275 \\
(0.00195)\end{array}$ & $\begin{array}{c}-0.00488^{* *} \\
(0.00244)\end{array}$ \\
\hline Lagged leverage & $\begin{array}{c}-0.00573^{* * *} \\
(0.00145)\end{array}$ & $\begin{array}{c}-0.00793^{* * *} \\
(0.00177)\end{array}$ & $\begin{array}{c}-0.00888^{* * *} \\
(0.00226)\end{array}$ \\
\hline Constant & $\begin{array}{l}0.196^{* * *} \\
(0.0245)\end{array}$ & $\begin{array}{l}0.218^{* * *} \\
(0.0291)\end{array}$ & $\begin{array}{l}0.249^{* * *} \\
(0.0361)\end{array}$ \\
\hline Year/Firm FE & yes/yes & yes/yes & yes/yes \\
\hline Obs. & 154967 & 125311 & 95823 \\
\hline Num. firms & 17906 & 16755 & 15403 \\
\hline \multicolumn{4}{|l|}{$R^{2}$} \\
\hline within & 0.0278 & 0.0298 & 0.0292 \\
\hline overall & 0.00341 & 0.00449 & 0.00482 \\
\hline$F$ & 186.4 & 184.9 & 161.2 \\
\hline$F_{f}$ & 3.958 & 3.763 & 3.683 \\
\hline
\end{tabular}

Notes: Standard errors are in the parentheses $\left({ }^{*} p<0.10,{ }^{* *} p<0.05,{ }^{* * *} p<0.01\right) . F_{f}$ represents the $\mathrm{F}$ test statistics with the null hypothesis that all firm fixed effects are zero. 
Table A.9: Industry-level Estimation at the First Stage

\begin{tabular}{|c|c|c|c|c|c|c|c|}
\hline & (1) & (2) & (3) & (4) & (5) & (6) & (7) \\
\hline & Sales growth & Emp. growth & Real R\&D & $\frac{\text { R\&D }}{\text { Sales }}$ & $\log \frac{\mathrm{R} \& \mathrm{D}}{\text { Wage }}$ & $\log \frac{\mathrm{R} \& \mathrm{D}}{\text { Total Salary }}$ & Exit \\
\hline$\hat{\pi}^{\text {input }}$ & $\begin{array}{c}-2.510^{* * *} \\
(0.387)\end{array}$ & $\begin{array}{c}-1.781^{* * *} \\
(0.155)\end{array}$ & $\begin{array}{c}-1.624^{* * *} \\
(0.404)\end{array}$ & $\begin{array}{c}-0.0839^{* * *} \\
(0.0271)\end{array}$ & $\begin{array}{c}-4.767^{* * *} \\
(0.865)\end{array}$ & $\begin{array}{c}-1.260^{* * *} \\
(0.103)\end{array}$ & $\begin{array}{c}0.422^{* * *} \\
(0.106)\end{array}$ \\
\hline Lagged sales & $\begin{array}{l}-0.884^{* * *} \\
(0.00588)\end{array}$ & $\begin{array}{l}-0.141^{* * *} \\
(0.00235)\end{array}$ & $\begin{array}{c}0.247^{* * *} \\
(0.00645)\end{array}$ & $\begin{array}{c}0.000658 \\
(0.000433)\end{array}$ & $\begin{array}{l}0.434^{* * *} \\
(0.0138)\end{array}$ & $\begin{array}{l}0.0236^{* * *} \\
(0.00165)\end{array}$ & $\begin{array}{c}-0.0217^{* * *} \\
(0.00167)\end{array}$ \\
\hline Lagged sales $\times \hat{\pi}^{\text {input }}$ & $\begin{array}{l}0.296^{* * *} \\
(0.0412)\end{array}$ & $\begin{array}{l}0.192^{* * *} \\
(0.0165)\end{array}$ & $\begin{array}{l}0.133^{* * *} \\
(0.0387)\end{array}$ & $\begin{array}{c}0.00805^{* * *} \\
(0.00260)\end{array}$ & $\begin{array}{l}0.440^{* * *} \\
(0.0830)\end{array}$ & $\begin{array}{c}0.126^{* * *} \\
(0.00992)\end{array}$ & $\begin{array}{c}-0.0468^{* * *} \\
(0.0113)\end{array}$ \\
\hline Financing DI & $\begin{array}{l}0.00476^{* * *} \\
(0.000242)\end{array}$ & $\begin{array}{c}0.00281^{* * *} \\
(0.0000967)\end{array}$ & $\begin{array}{c}-0.000502^{* *} \\
(0.000257)\end{array}$ & $\begin{array}{c}-0.0000707^{* * *} \\
(0.0000173)\end{array}$ & $\begin{array}{l}0.00199^{* * *} \\
(0.000550)\end{array}$ & $\begin{array}{c}-0.000517^{* * *} \\
(0.0000658)\end{array}$ & $\begin{array}{l}-0.0000695 \\
(0.0000669)\end{array}$ \\
\hline Industry RS & $\begin{array}{c}-0.0284^{* * *} \\
(0.00568)\end{array}$ & $\begin{array}{l}-0.00106 \\
(0.00227)\end{array}$ & $\begin{array}{l}0.0645^{* * *} \\
(0.00622)\end{array}$ & $\begin{array}{l}0.00126^{* * *} \\
(0.000418)\end{array}$ & $\begin{array}{c}0.0358^{* * *} \\
(0.0133)\end{array}$ & $\begin{array}{c}0.00503^{* * *} \\
(0.00159)\end{array}$ & $\begin{array}{l}-0.00200 \\
(0.00158)\end{array}$ \\
\hline Lagged leverage & $\begin{array}{c}0.102^{* * *} \\
(0.00471)\end{array}$ & $\begin{array}{c}0.00562^{* * *} \\
(0.00188)\end{array}$ & $\begin{array}{c}-0.0147^{* * *} \\
(0.00504)\end{array}$ & $\begin{array}{l}-0.000175 \\
(0.000339)\end{array}$ & $\begin{array}{c}-0.0271^{* *} \\
(0.0108)\end{array}$ & $\begin{array}{c}-0.00338^{* * *} \\
(0.00129)\end{array}$ & $\begin{array}{c}-0.00569^{* * *} \\
(0.00134)\end{array}$ \\
\hline Constant & $\begin{array}{l}7.720^{* * *} \\
(0.0823)\end{array}$ & $\begin{array}{l}1.234^{* * *} \\
(0.0329)\end{array}$ & $\begin{array}{c}-2.101^{* * *} \\
(0.0911)\end{array}$ & $\begin{array}{l}-0.00469 \\
(0.00612)\end{array}$ & $\begin{array}{c}-2.047^{* * *} \\
(0.195)\end{array}$ & $\begin{array}{c}-0.175^{* * *} \\
(0.0233) \\
\end{array}$ & $\begin{array}{l}0.184^{* * *} \\
(0.0231)\end{array}$ \\
\hline Year/Firm FE & yes/yes & yes/yes & yes/yes & yes/yes & yes/yes & yes/yes & yes/yes \\
\hline Obs. & 189447 & 189447 & 58445 & 58445 & 58418 & 58418 & 175463 \\
\hline Num. firms & 19703 & 19703 & 14474 & 14474 & 14473 & 14473 & 18865 \\
\hline \multicolumn{8}{|l|}{$R^{2}$} \\
\hline within & 0.139 & 0.0382 & 0.0637 & 0.00848 & 0.0538 & 0.0466 & 0.0284 \\
\hline overall & 0.00179 & 0.000137 & 0.653 & 0.0390 & 0.617 & 0.261 & 0.00351 \\
\hline$F$ & 1142.7 & 280.7 & 124.5 & 15.66 & 104.0 & 89.41 & 199.2 \\
\hline$F_{f}$ & 3.901 & 3.333 & 24.37 & 12.15 & 16.03 & 11.53 & 3.940 \\
\hline
\end{tabular}

Notes: Standard errors are in the parentheses $\left({ }^{*} p<0.10,{ }^{* *} p<0.05,{ }^{* * *} p<0.01\right) . F_{f}$ represents the $\mathrm{F}$ test statistics with the null hypothesis that all firm fixed effects are zero. 
Table A.10: Moments: Data, Benchmark Model, and Modified Models for Japan

\begin{tabular}{ccccc}
\multicolumn{5}{c}{ Target moments } \\
& Data & Benchmark model & $\omega=2$ & $\sigma=1.5$ \\
\hline$g$ & 0.017 & 0.017 & 0.017 & 0.018 \\
$R$ & 0.034 & 0.034 & 0.034 & 0.034 \\
$\Delta$ & 1.421 & 1.444 & 1.422 & 1.573 \\
$\operatorname{Med}[W L] / \mathrm{E}[W L]$ & 0.260 & 0.322 & 0.322 & 0.381 \\
$\operatorname{Std}[W L] / \mathrm{E}[W L]$ & 5.527 & 5.890 & 5.898 & 5.445 \\
$\operatorname{Med}[Y] / \mathrm{E}[Y]$ & 0.181 & 0.317 & 0.317 & 0.371 \\
$\operatorname{Std}[Y] / \mathrm{E}[Y]$ & 7.055 & 5.789 & 5.795 & 5.357 \\
$\operatorname{Cor}[Y / L, L]$ & 0.186 & -0.100 & -0.102 & -0.084 \\
$\operatorname{Cor}[Y, W L]$ & 0.740 & 1.000 & 1.000 & 1.000 \\
$\mathrm{E}[d Y / Y]$ & 0.071 & 0.061 & 0.061 & 0.059 \\
$\operatorname{Std}[d Y / Y]$ & 1.246 & 0.182 & 0.182 & 0.180 \\
$\operatorname{Cor}[d Y / Y, Y]$ & -0.003 & -0.100 & -0.102 & -0.084
\end{tabular}




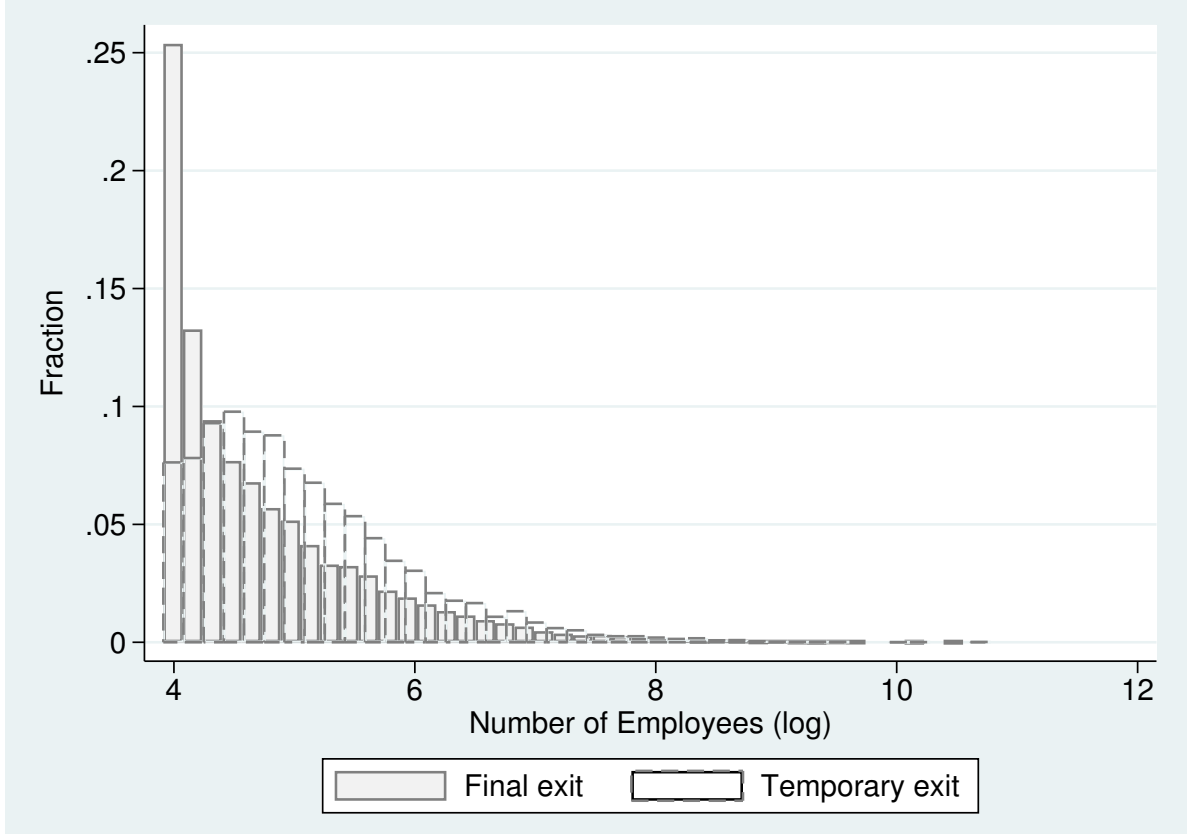

Figure A.1: Employment Distributions for Final Exit and Temporary Exit Firms

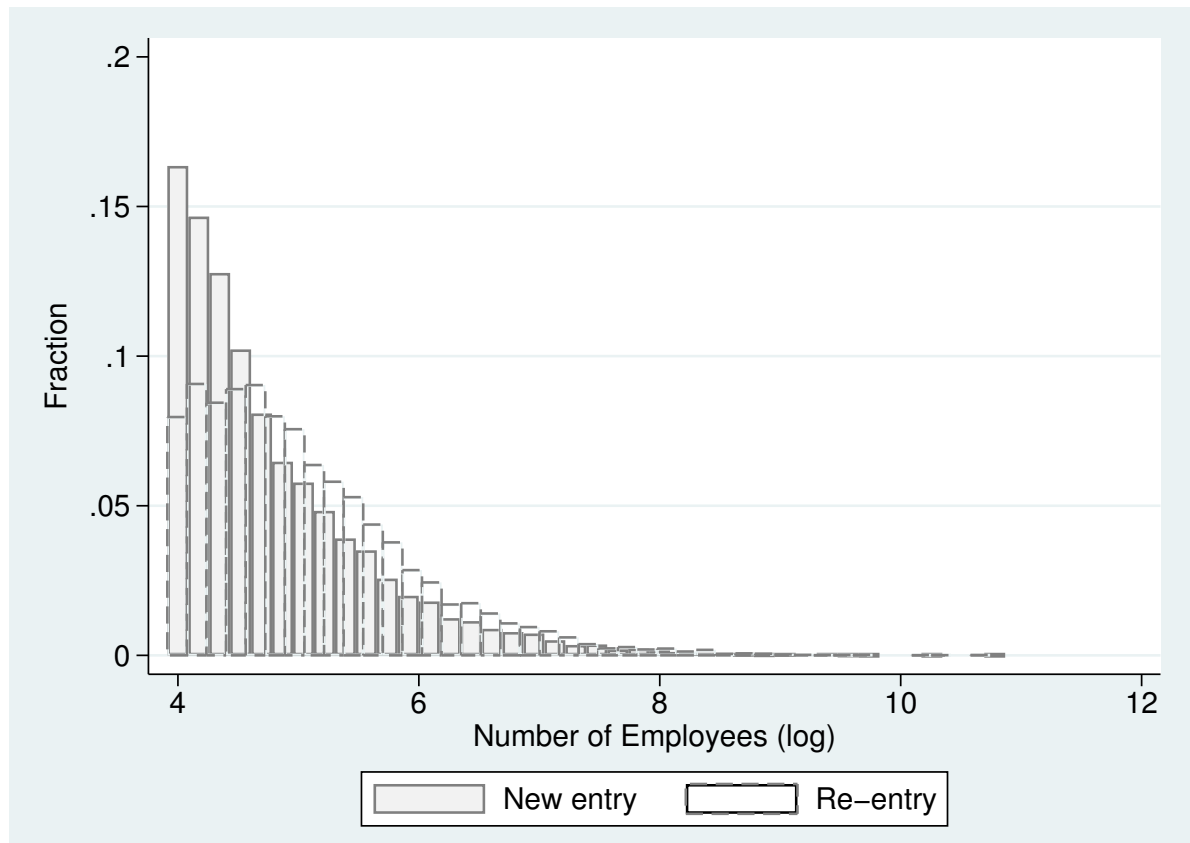

Figure A.2: Employment Distributions for New Entry and Re-entry Firms 

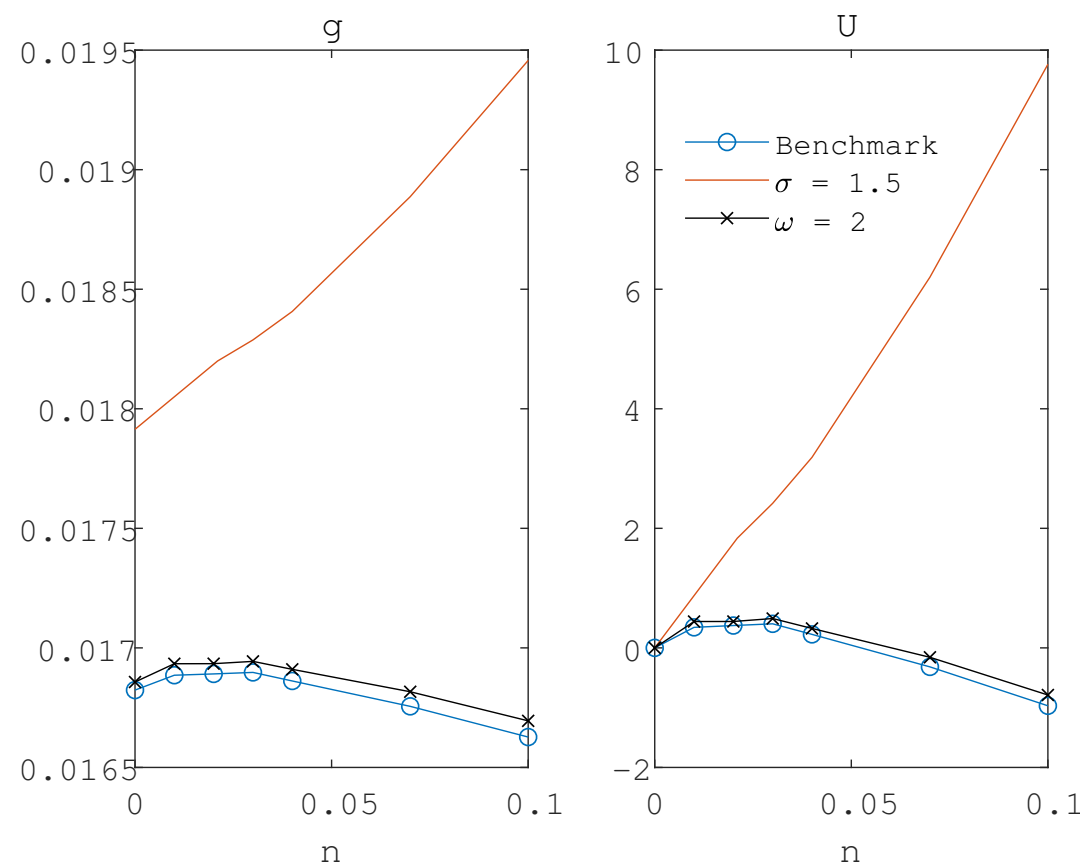

Figure A.3: Effects of Nominal Growth in Modified Models Note: Intertemporal utility $U$ is normalized at zero when $n=0$. 